\title{
CONTRIBUCIÓN A LA FORMACIÓN DE DOCENTES DE LAS TECNOLOGÍAS INFORMÁTICAS
}

Recuperación y registro de estrategias de enseñanza

\author{
Héctor Raúl González
}

Director: Mag. Rodolfo Bertone

Tesis presentada para obtener el grado de Magíster en Tecnología Informática Aplicada en Educación

Facultad de Informática - Universidad Nacional de la Plata Noviembre, 2011 


\section{Resumen}

La presente tesis es un proyecto de desarrollo tecnológico que asume como tema principal las metodologías o estrategias de enseñanza que construyen los docentes de las escuelas media de Neuquén. Las metodologías o estrategias de enseñanza que se toman en cuenta para este proyecto deben incluir herramientas informáticas. En consecuencia se propone una secuencia, una guía, para diseñar una base de casos que memorice las narraciones de las metodologías o estrategias que desarrollan los docentes cuando deben enseñar contenidos utilizando herramientas informáticas, para luego, ser recuperados y re significados por otros docentes para una nueva propuesta de enseñanza, esta propuesta luego de ser puesta en juego en el aula, se vuelve a memorizar para una recuperación posterior.

La secuencia comienza con la recuperación de casos de enseñanza (métodos o estrategias de enseñanza) provistos por los docentes; el paso siguiente es la construcción de una ontología a partir de los casos de enseñanza y de otras fuentes bibliográficas; luego se utiliza algunos principios de la teoría CBR (Cases Based Reasonig) para modelar la interacción de la base de casos con los usuarios, los docentes; por último, para ejemplificar el uso de la secuencia propuesta, se recurre a un software denominado sistema IRS (Information Retrieval System) que soportará el diseño de la base de casos. De la base de casos se recuperan aquellos casos de mayor similitud aun caso dado utilizando como expresión de búsqueda un problema de enseñanza.

La secuencia propuesta potencialmente es útil cuando se necesitan algunas directrices que ayuden a diseñar una base de casos; mejorar la calidad de las búsquedas para casos similares a uno dado en la base de casos; establecer criterios razonables de interacción entre los docentes y la base de casos utilizando los principios del razonamiento basado en casos; ayudar a fijar consenso en el uso de la terminología informática; y, finalmente, como recurso para diseñar estrategias que ayuden a la formación de los docentes que quieren utilizar las tecnologías informáticas en la enseñanza. 


\section{Agradecimientos}

Quiero agradecer al profesor Rodolfo Bertone por haber aceptado dirigir esta tesis.

También agradecer a la profesora Rita De Pascuale por sus necesarias observaciones formales que tuvieron como consecuencia la reorganización de la tesis; a la profesora Mónica Echenique por su minuciosa lectura que hizo que repensara algunos pasajes importantes del trabajo. Ambas profesoras de la Facultad de Ciencias de la Educación de la UNCo.

Quiero además, agradecer a mi mujer Anahi, por su constante aliento cuando mi falta de paciencia y cansancio comenzaban a socavar mis fuerzas. A mi hija Abril, a Julián y Mariano que ocuparon tiempo de mi trabajo en la tesis para no perderme en la obsesión. 
En alguna parte usted dijo que un escritor -delicadamente agregó: todas las personas- debe pensar que cualquier cosa que le suceda es un recurso. (Estaba hablando de su ceguera.)

Por Susan Sontang acerca de J.L. Borges 


\section{Índice:}

\section{PARTE I: FUNDAMENTACIÓN}

1.1. Introducción y objetivos --- 1

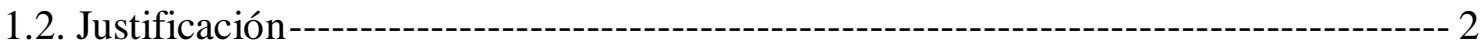

1.2.1. La formación docente --- 2

1.2.2. Las narraciones de los métodos o estrategias de enseñanza desde las perspectivas de la resolución de problemas de enseñanza------------------------ 3

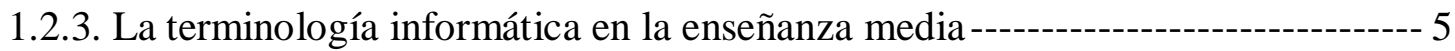

\section{PARTE II: MARCO TEÓRICO}

2.1. Introducción --- 7

2.2. Acerca de la noción de tecnología --- 7

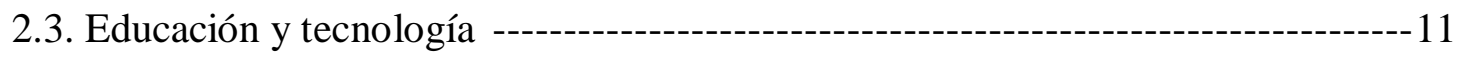

2.4. Apropiación de la informática en la escuela media ---------- 15

2.5. Razonamiento Basado en Casos (CBR) -----o-

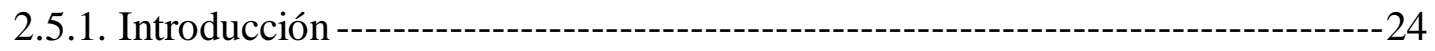

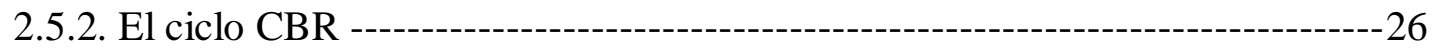

2.5.3. El problema del marco referencial---_-

2.5.3.1. Tipo de contenidos-------29

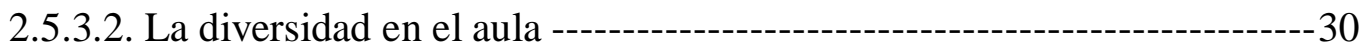

2.5.3.3. Estructura cognitiva y conocimientos previos de los alumnos----------- 30

2.6. Antecedentes en el uso de del CBR----_-

\section{PARTE III: METODOLOGÍA}

3.1. Introducción ---

3.2. Secuencia de la metodología---

3.3. Planilla de registro de casos ---

\section{PARTE IV: ONTOLOGÍA DE CASOS DE ENSEÑANZA}

4.1. Introducción ----

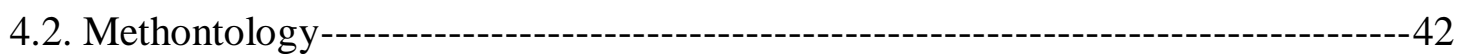

4. 3. Diseño e implementación de la ontología---

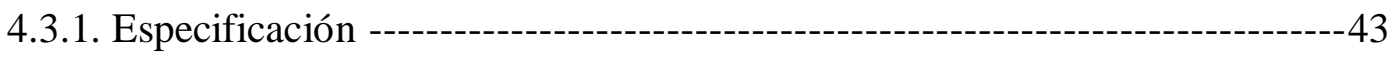

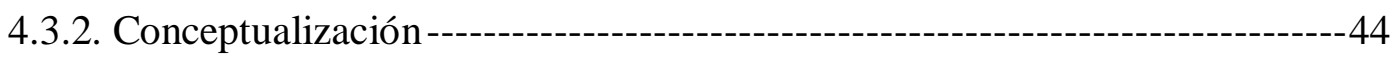

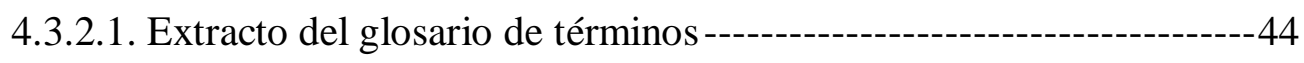




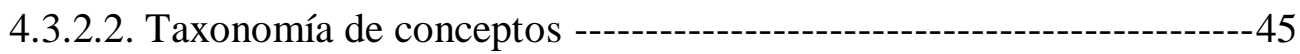

4.3.2.3. Extracto de los diagramas de relaciones binarias -------------------47

4.3.2.4. Diccionario de conceptos -------------------------------------------50

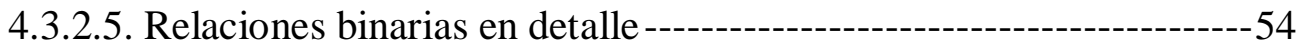

4.3.2.6. Los atributos de las instancias---------------------------------------55

4.3.2.7. Atributos de clase---------------------------------------------------55

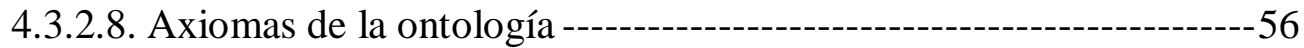

\title{
PARTE V: EL CICLO CBR APLICADO A LA BASE DE CASOS
}

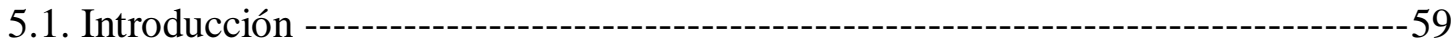

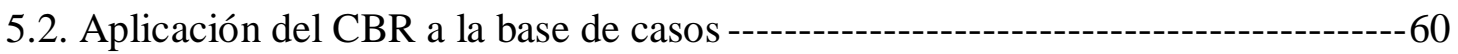

PARTE VI: CONCLUSIÓN Y TRABAJOS FUTUROS -------------------65

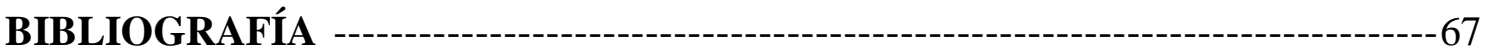

\begin{abstract}
ANEXOS

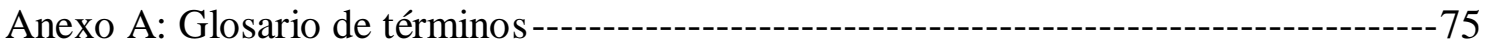

Anexo B: Implementación de la ontología de casos de enseñanza con Protégé-----------83

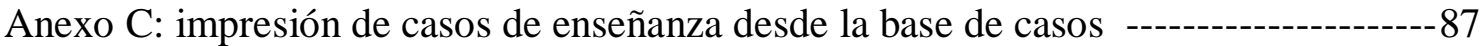




\section{Índice de figuras y tablas}

Tabla $\mathrm{N}^{\mathrm{o}}$ 1: uso de la información en las revoluciones tecnológicas ---------------------12

Figura $\mathrm{N}^{\mathrm{o}}$ 1: mapa conceptual con la noción del paradigma informacionalismo----------13

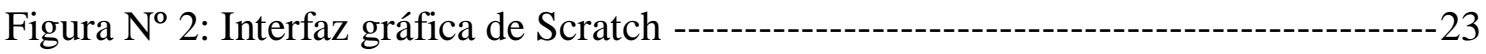

Figura $N^{o}$ 3: Ejemplo de las estructuras de control en Scratch----------------------------23

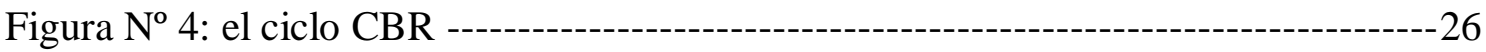

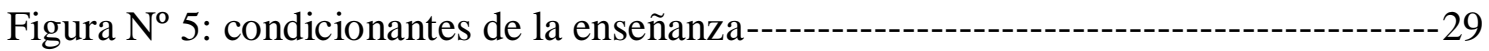

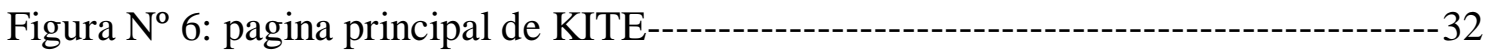

Figura $N^{\mathrm{o}}$ 7: nombre de los campos de la base de casos ------------------------------35

Tabla $N^{\circ}$ 2: campos de la base de caso más detallado-------------------------------------36

Figura $N^{\circ}$ 8: el ciclo CBR adaptado a los casos de enseñanza ----------------------------37

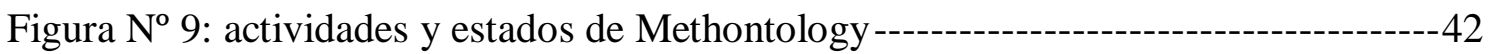

Figura $\mathrm{N}^{\mathrm{o}}$ 10: tareas asociadas a la conceptualización -------------------------------------43

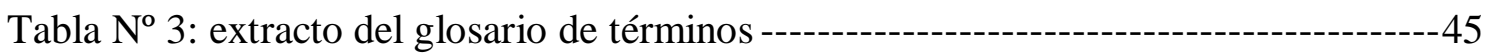

Figura $N^{\circ}$ 11: a) taxonomía de casos de enseñanza-----------------------------------------46

Figura $\mathrm{N}^{\circ}$ 11: b) taxonomía de contenidos informáticos de los casos ---------------------46

Figura $\mathrm{N}^{\mathrm{o}}$ 11: c) taxonomía de conceptos algunas materias de nivel medio --------------46

Figura $\mathrm{N}^{\circ} 12$ : El caso "La informática como material educativo" y la relación binaria

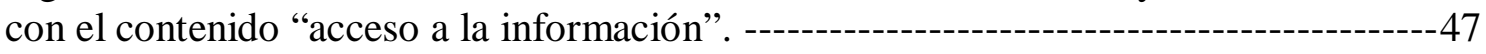

Figura $\mathrm{N}^{\mathrm{o}}$ 13: El caso "videojuego" y la relación binaria con la materia de nivel medio

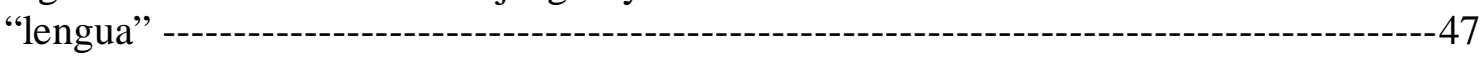

Figura $\mathrm{N}^{\circ}$ 14: El caso "alfabetización informática" y la relación binaria con el contenido

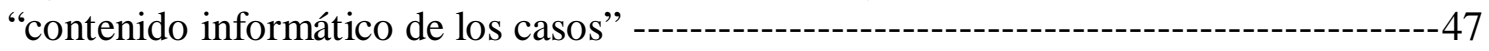

Figura $\mathrm{N}^{\circ}$ 15: El caso "La informática como recurso didáctico" y la relación binaria con el contenido "creación, instructivo, comunicación" ------------------48

Figura No 16: El caso "videojuego" y la relación binaria con el contenido "desarrollo de

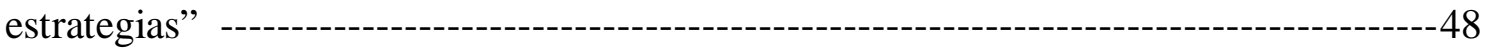

Figura $N^{\circ}$ 17: El caso "Informática como material educativo" y la relación binaria con la

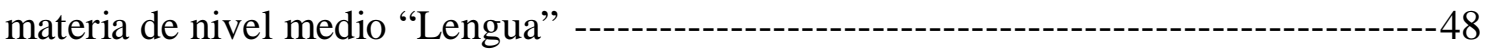

Figura $\mathrm{N}^{\mathrm{o}}$ 18: El caso "alfabetización informática" y la relación binaria con la materia

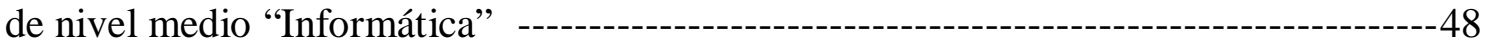

Figura $\mathrm{N}^{\circ}$ 19: El caso "La informática como material educativo" y la relación binaria con la materia de nivel medio "Lengua. -----------------------------------------------49

Figura $N^{\circ}$ 20: El caso "La informática como recurso didáctico" y la relación binaria con la materia de nivel medio "Matemática". ---------------------------------------------49

Figura $N^{\circ}$ 21: El caso "La informática como recurso didáctico" y la relación binaria con

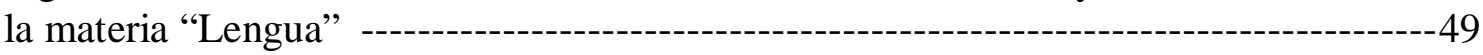

Figura No 22: El caso “videojuego" y la relación binaria con la materia "Matemática” 50 
Tabla No 4: diccionario de conceptos ------------------------------------------------------54

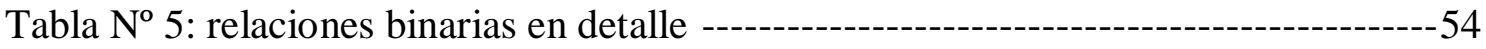

Tabla No 6: atributos de las instancias ----------------------------------------------55

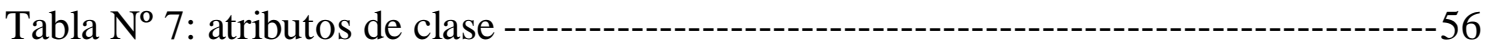

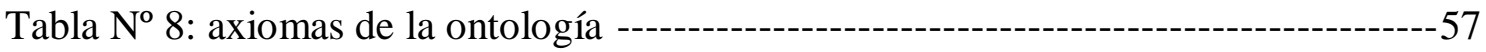

Tabla N ${ }^{\circ}$ 9: resultado de la intersección "Contenidos informáticos" y "materia de nivel medio" y el tipo de caso que le corresponde ------------------------------------58

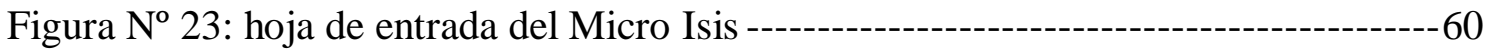

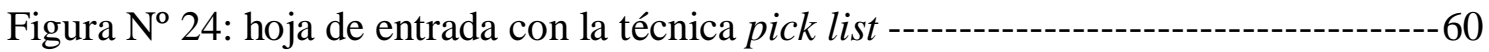

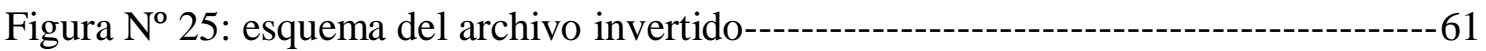

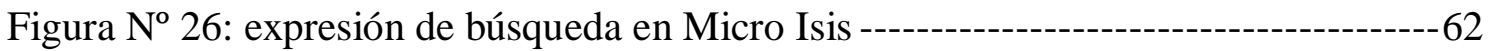

Figura $N^{\circ}$ 27: resultado de ejecutar la expresión de búsqueda, caso 1 --------------------63

Figura $\mathrm{N}^{\mathrm{o}}$ 28: resultado de ejecutar la expresión de búsqueda, caso 2. -------------------63

Figura $N^{\circ}$ 29: recorte de las propiedades y objetos de la clase "Alfabetización informá-

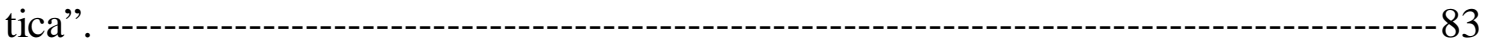

Figura No 30: las clases de la ontología de casos de enseñanza------------------------84

Figura $\mathrm{N}^{\mathrm{o}}$ 31: recorte de dos objetos (individuals) con sus propiedades y valores. -----84

Figura $\mathrm{N}^{\mathrm{o}} 32$ : los atributos de la ontología de los casos de enseñanza -------------------84

Figura $\mathrm{N}^{\mathrm{o}}$ 33: los axiomas de la ontología casos de enseñanza -------------------------85

Figura $\mathrm{N}^{\mathrm{o}}$ 34: ficha Jambalaya con nodos y propiedades de dos casos de enseñanza ---86 


\section{PARTE I: FUNDAMENTACIÓN}

\subsection{Introducción}

Existe un creciente interés en los docentes que usan las computadoras en el aula en recuperar metodologías o estrategias de enseñanza que les faciliten formalizar actividades con sus alumnos. Desde otra perspectiva, desde los estudios sobre la implementación de la computadora en la educación, existen "muchas incertidumbres acerca de la tecnología informática. No conocemos muy claramente lo que es un "buen-uso" o "uso de calidad" o el impacto real sobre los alumnos" (Gallego Arrufat, 1998). Las nuevas tecnologías ingresaron a las escuelas sobre una narrativa de eficiencia y de mejora, en particular, en la relación formado por la triada docente, alumno y contenido, pero los resultados positivos obtenidos en la enseñanza utilizando computadoras no se obtienen de la máquina per se sino de la metodología o estrategia utilizada (Bartolomé y Aiello, 2006). Davini (2008:73) entiende que los "métodos constituyen estructuras generales, con secuencia básica, siguiendo intenciones educativas y facilitando determinados procesos de aprendizaje. Los métodos brindan, así, un criterio o marco general de actuación que puede analizarse con independencia de contextos y actores concretos." ${ }^{1}$ Leliwa (2008:81) prefiere, en vez de metodología, hablar de estrategias, "La idea de estrategia permite ver que la enseñanza más que una técnica de aplicación- es un arte complejo no exento de decisiones políticas respecto del cómo, el por qué y el para qué enseñar. Para los docentes, las estrategias se constituyen en un protocolo de trabajo y pueden expresarse en un escrito breve que sirva de guía, de orientación. En él se apuntan los pasos a seguir, colaborando, ayudando a tomar decisiones acerca de cómo enseñar”.

La presente tesis es un proyecto de desarrollo tecnológico que asume como tema principal las metodologías o estrategias de enseñanza que construyen los docentes de las escuelas media de Neuquén. Las metodologías o estrategias de enseñanza que se toman en cuenta para este proyecto deben incluir herramientas informáticas ${ }^{2}$. En consecuencia se propone una secuencia, una guía, para diseñar una base de casos que memorice las narraciones de las metodologías o estrategias que desarrollan los docentes cuando deben enseñar contenidos utilizando herramientas informáticas, para luego, ser recuperados y re significados por otros docentes para una nueva propuesta de enseñanza, esta propuesta luego de ser puesta en juego en el aula, se vuelve a memorizar para una recuperación posterior.

Objetivo general:

Diseño de una base de casos que permita registrar casos de enseñanza.

Objetivos específicos:

a) recuperar casos de enseñanza, que incluyan tecnología informática, a partir de entrevistas a los docentes;

b) construir una ontología a partir de los casos de enseñanza y de la utilización de otras fuentes bibliográficas;

\footnotetext{
${ }^{1}$ Para Davini (2008:73) no "hay contradicción alguna entre métodos y estrategias de enseñanza".

${ }^{2}$ El diccionario en línea Merriam-Webster define al término herramienta (tool) como un dispositivo de mano que ayuda a realizar una tarea. También dice que es algo (un instrumento o aparato) que se utiliza en la realización de una operación; o que es necesario en el ejercicio de una profesión o vocación. Por ejemplo: los libros escolares son las herramientas de un alumno o docente; un elemento de un programa de computadora (como una aplicación de gráficos) que activa y controla una función particular (una herramienta de dibujo). En consecuencia en esta tesis cuando se hace referencia al uso de las tecnologías informática como herramienta se quiere decir que ayudan a realizar una tarea de tipo didáctica; se emplean para ayudar a enseñar algo a alguien; se emplean para enseñar cómo se usan.
} 
c) utilizar algunos principios de la teoría CBR (Cases Based Reasonig) para modelar la interacción de la base de casos con los usuarios, los docentes.

d) utilizar el software Winisis, de la familia de los sistemas denominados IRS (Information Retrieval System), para ejemplificar el uso de la secuencia propuesta.

La estructura de la tesis inicia en la parte I, con la fundamentación. Se introducen los objetivos y se continua con la justificación: en el apartado 1.2.1, se pone de manifiesto la necesidad de la formación docente; luego se sigue con las narraciones en las perspectivas de la resolución de problemas de enseñanza, es decir que se asume en esta tesis las metodologías de enseñanza como problemas que pueden ser abordados a partir de la recuperación de métodos similares, apartado 1.2.2 y, finalmente, se muestran algunas señales de la problemática de la terminología Informática en la enseñanza media, apartado 1.2.3. En la parte II se muestra el marco teórico; se describe algunas nociones de tecnología que ponen de manifiesto dos aspecto de la disciplina, por un lado el diseño de objetos tecnológicos (O.T.), y por otro, la peculiaridad del conocimiento tecnológico con algunas consecuencias para la enseñanza, apartado 2.2; en el apartado 2.3 se desarrolla la relación de las tecnologías y su introducción en la educación; luego en el apartado 2.4 se analiza sucintamente la relación de las computadoras, desde los años '80, con la escuela media en la Argentina, considerando las diversas tendencias metodológicas en el uso de la tecnología informática; en el apartado 2.5 se continúa con el método CBR (Razonamiento Basado en Casos) y su relación con la educación. En la parte III se explicita la metodología desarrollada en la tesis tomando en consideración la noción de caso para luego mostrar la secuencia que se llevó adelante para la formalización del proyecto tecnológico. En la parte IV se muestra el diseño y construcción de la ontología de casos de enseñanza. En la parte V se muestra la base de casos construida con el software Win Isis y la aplicación del método de resolución de problemas denominado CBR (Razonamiento Basado en Casos). En la parte VI, la última, se explicitan las conclusiones y trabajos futuros.

\subsection{Justificación}

\subsubsection{La formación docente}

Levis (2007:19), destaca que los documentos oficiales relacionados a incorporar la Informática en la escuela "relegan a un segundo plano o tercer plano, cuando no ignorando, la imprescindible formación docente y la fijación de objetivos pedagógicos que trascienda la enseñanza-aprendizaje del uso instrumental de máquinas y programas".

Aprea (2006:251), sintetiza que "Son varios los factores que se suelen relacionar con este fracaso (la integración de los maestros en proyectos que incluyen el uso de las TIC): el proceso de empobrecimiento y disgregación social que vive la Argentina, fallas técnicas en la implementación de los planes, la redefinición del rol docente y las escuelas en el marco de las transformaciones que vive el sistema escolar público a partir de la aplicación de la Ley federal de Educación, la crisis de la escuela en su conjunto."

La Informática o el uso de recursos y herramientas informáticas, integrada en el campo de la Educación Tecnológica y en la Tecnología Educativa, es una disciplina reciente, si se lo compara con Matemática, Física o Química, donde aun "no presenta todavía planteos didácticos suficientemente consensuados" (Mandón, 1999) o como escribe Leliwa (2008:21) tiene una "corta historia en los currículos escolares, tanto a nivel internacional como nacional". En este contexto los docentes en la búsqueda de mejorar su práctica adoptan métodos didácticos probados en otras disciplinas. Recorriendo la Web se encuentra pocos registros de los métodos didácticos usados por nuestros docentes en las prácticas cotidianas; los ejemplo encontrados, paradójicamente, pertenecen a docentes de 
habla hispano, no argentinos, utilizan ABP (aprendizaje basado en problemas) (Lacuesta, 2004), la enseñanza basado en casos (Capella, 2002), la Webquest, el método analógico; otros reproducen metodologías de enseñanza de los docentes que le tocaron en suerte en su formación profesional.

La implementación de estas metodologías en el trabajo cotidiano en el aula pueden ser medianamente exitosas o pueden ser un fracaso debido a diversos factores que intervienen en el proceso de la enseñanza: conocimientos previos y capital cultural de los alumnos, posibilidades didácticas del docente, tiempos y metodologías de enseñanza, tipo de contenidos, tecnologías utilizadas, etc.

Nada de la experiencia de nuestros docentes queda registrado para: a) su posterior utilización en el momento de enseñar los mismos contenidos o similares por el mismo profesor o por otros; b) establecer un análisis crítico de los métodos de enseñaza para su posterior rectificación; c) analizar que estructura subyace a un cuerpo de conocimiento para determinar los problemas que se debe afrontar al momento de su enseñanza (Botia,1993); d) analizar comparativamente los resultados de los métodos de enseñanza usado en otras disciplinas afines con los resultados obtenidos en la informática.

En definitiva no le queda a la comunidad de docentes que usan las tecnologías informáticas una memoria donde pueda mirar críticamente los rastros dejados por sus pares y que se pueda utilizar como recurso en forma significativa para la formación docente.

\subsubsection{Las narraciones de los métodos o estrategias de enseñanza desde las perspectivas de la resolución de problemas de enseñanza}

En este apartado se exponen dos líneas de trabajo en relación a los casos o narraciones para la resolución de problemas. Por un lado desde la perspectiva pedagógica se sostiene que modelos contemporáneos de instrucción comparten, desde el punto de vista de la enseñanza, una característica principal: la resolución de problemas ayuda al aprendizaje de los alumnos. La configuración o el soporte que sostiene la resolución de problemas son las narraciones; las narraciones son el medio natural para describir experiencias de conocimiento que se deben recuperar para resolver problemas (Jonassen, 2002). Las narraciones permiten trabajar con problemas mal estructurados, que no tiene una única solución, los finales son abiertos y están compuestos de varios sub problemas; frecuentemente tienen varios caminos posibles de solución y no poseen claridad al comienzo y al final de la narración. Las narraciones permiten trabajar con problemas sacados del mundo real a fin de ayudar a los alumnos a construir habilidades útiles para el contexto de trabajo. Los estudiantes podrán reflexionar acerca de las similitudes y diferencias entre el nuevo problema y las narraciones de problemas pasados. Las historias bien construidas constan de cinco elementos: un actor, una acción, una meta, un escenario y un instrumento, a los que hay que sumar un problema. El problema consiste en la existencia de un desequilibrio entre cualquiera de los cinco elementos anteriores (Bruner, 1997).

Por otro lado, desde los fundamentos cognitivos, el proceso de resolución de problemas implica la resolución de problemas por analogía ${ }^{3}$ haciendo uso de casos anteriores o hipotéticos. La aplicación de las experiencias anteriores en la solución de problemas es algo que la gente parece hacer en ámbitos tan diversos como en la matemática, la física, la medicina y en los ámbitos judiciales; es una parte importante de la

\footnotetext{
3 (Felipe, Gallarreta y Merino, 2006): "En términos generales, una analogía puede definirse como la comparación entre dos dominios, uno más familiar (denominado "fuente" o "análogo") y otro menos conocido (denominado "concepto", "blanco" o "target"), que comparten información de tipo relacional. Así Ruhl (2003) señala que "una analogía es una comparación de una cosa familiar con otra no familiar con el objetivo de interpretar o aclarar una característica compartida". El establecimiento de conexiones entre la analogía y el concepto, constituyen el mapeo o transferencia."
} 
realización de predicciones en la comprensión. Una experiencia previa puede desempeñar varias funciones:

- proponer una solución a un problema nuevo o un medio de interpretar la situación,

- advertir de un problema que surgirá, o

- permitir reconocer los efectos potenciales de una propuesta de solución que se predijo.

Estos son las clases de inferencia necesarios para abordar los tipos de problemas mal definido o complejos que surgen en nuestro transitar diario en el lugar de trabajo, en la escuela y en casa (Kolodner, B).

Las historias recuperadas se focalizan en el conocimiento de algo que genera experiencias y opciones. La gente que aprende nuevas habilidades naturalmente usa aquello que se ha aprendido en problemas previos y aplicados a nuevos problemas.

Jonassen (2000) sugiere cómo el docente puede usar la recuperación de casos previos en la instrucción:

1) El docente debe guiar al estudiante en el análisis de innumerables historias sacadas del contexto del mundo real a fin de ayudar a desarrollar habilidades genéricas en la resolución de problemas.

2) Exponer al alumno a la narración de historias mientras lucha con una situación problema; el estudiante contará con la "reflexión en la acción", esto es, sobre el terreno abre juicios, reestructura y prueba la comprensión intuitiva de la experiencia.

3) Una hipótesis compartida por algunos investigadores es que estas historias pueden funcionar como sustituto de la experiencia directa, cosa que el novato no posee. Apoyar el aprendizaje con historias puede ayudar al estudiante a beneficiarse con la experiencia de otros vicariamente o en forma delegada. Si se recupera alguna historia parecida para contar es probablemente una historia que fue narrada. Ello no representa la experiencia directa. Algunas personas tiene la esperanza de que compartir historia es equivalente a la experiencia como fenómeno en si mismo.

4) El proceso de comprender y resolver problemas usando la librería de casos tiene tres partes: a) recuperar experiencias pasadas; b) interpretar la nueva situación en términos de las partes fundamentales de la vieja experiencia; c) adaptar convenientemente la vieja solución a la nueva situación. Recuperar historias pasadas depende si han sido bien organizadas en un índice; esto es, qué características o atributos de la vieja experiencia fueron archivadas en la memoria. Mientras el índice está más claramente construido las historias son más accesible y usables.

Interpretar un problema es un proceso de hacer un mapa -mapping ${ }^{4}-$, comparar y contrastar, de la experiencia pasada sobre la nueva. Si el caso pasado ofrece un consejo útil o una solución para el caso nuevo, entonces es usada. Si no, el viejo caso es adaptado insertando algo nuevo en una vieja solución, borrando algo o haciendo una sustitución.

Buscar una estrategia o una metodología para la enseñanza de algún contenido curricular es enfrentarse a un problema; el problema se acrecienta si además se quiere utilizar, como parte de la estrategia o de la metodología, herramientas informáticas. Y aquí, el autor se arriesga a pensar, que la didáctica y la tecnología se parecen en un punto: ambas intentan solucionar problemas, la primera, problemas de enseñanza, la segunda problemas

\footnotetext{
${ }^{4}$ Used as a function word to indicate a set each element of which is the image of at least one element of another set <a function mapping the set $S$ onto the set $T>$. Usado como una palabra función que indica que cada elemento del conjunto del cual es imagen uno a uno de los elementos de otro conjunto.
} 
tecnológicos que afectan a contextos sociales. La resolución de problemas de enseñanza son problemas que se comparten entre docentes utilizando como soporte la narración; si los problemas y sus soluciones son registrados, memorizados, en una base de casos, su recuperación posterior a través de un índice permitirá reconstruir el conocimiento para la solución de problemas nuevos.

\subsubsection{La terminología informática}

En este apartado se intenta mostrar, con algunos ejemplos, la problemática respecto del uso de la terminología informática y las disputas acerca de su significado en el campo educativo.

La Informática, según Scolari, (2004), es un campo del saber en construcción, muchos términos usados se han construido a partir de la apropiación de términos de otras disciplinas y usados en forma metafórica ${ }^{5}$, por ejemplo la palabra virus.

Paradójicamente, en Barchini (2004) el término "Informática" tiene una crisis de identidad. "Para algunos Informática es el estudio de la estructura, comportamiento e interacciones de los sistemas computacionales naturales o artificiales (Gutierrez, 1993) (Dahlbom, 2002), para otros la Informática estudia el tratamiento sistemático y automático de la información (Barchini, 1989) (Capurro, 1992). Hay quienes afirman que es una ciencia artificial (Dahlbom, 2002), una disciplina ingenieril (Wendt, 2003) o una tecnología conceptual (Bunge, 1981). Otros sostienen que la Informática es la disciplina que trata sobre los Sistemas de Información (SI) (Matthew, 1997) (Estay et al, 1999) (Khazanchi et al, 1999) (Marcos, 2002)."

En el trabajo de investigación de Brito Peixoto (1995), cuyo objetivo es la construcción de un glosario de términos informáticos para la enseñanza de la disciplina en el idioma portugués, estos autores encontraron en los datos analizados variantes en el vocabulario que ponen de manifiesto la problemática del sentido de los términos que utilizamos en la enseñanza de la disciplina.

Por ejemplo la forma escrita del adjetivo que compone la frase terminológica:

- El software educacional = software educativo,

- Juego educacional = juego educativo;

La utilización de sinónimos, por ejemplo:

Software educativo $=$ programa educativo por computadora.

Se puede sumar a la problemática que estamos tratando ejemplos de conceptos usados habitualmente que tienen significados distintos en función de los autores consultados.

¿Se entiende lo mismo cuando se utiliza el concepto "alfabetización informática"?

En Silvera (2005) se encuentra que, por un lado, hay una acepción muy difundida que habla de alfabetización informática como la adquisición de destrezas, por ejemplo cita a Kanter $^{6}$ : "normalmente implica la habilidad para utilizar una computadora personal" y Oxbrow $^{7}$ : "el desarrollo de destrezas para el uso de las tecnologías". Por otro lado cita a Ferreira y

\footnotetext{
${ }^{5}$ Lopez (2003:167) "Metáfora es una palabra griega que significa translación. Su propio nombre indica, pues, que una palabra se emplea en un sentido que no le corresponde. La metáfora establece una relación de identidad basada en la similitud o analogía entre dos conceptos. Esta analogía puede estar relacionada con la forma, la función o cualquier otra característica de los objetos".

${ }^{6}$ Kanter J. Managing with information. New Jersey: Prentice Hall, 1992.

${ }^{7}$ Oxbrow N. Information literacy: the final key to information society. En: The Electronic Library 1998; 6(6):359-60.
} 
Didziak $^{8}$, "sitúan la alfabetización informática o digital más allá del enfoque puramente basado en destrezas e incluyen una indicación explícita sobre la importancia de las computadoras y de saber utilizarlas en un contexto social... la alfabetización digital implica muchas veces la apropiación de los nuevos conocimientos a partir de aprender a utilizar los componentes del hardware, los aplicativos y programas, los mecanismos de búsqueda y la información disponible en ambientes electrónicos, como finalidad en sí misma... [pero] este tipo de apropiación de conocimientos o alfabetización digital, carece de profundidad desde las perspectivas del análisis de contenido y el pensamiento crítico, porque el foco de la atención se ubica en la adquisición de habilidades y conocimientos prácticamente mecánicos. Por ello, entienden que la capacitación para la ciudadanía -objetivo último de la inclusión digital e informacional- se basa en el alcance de un nivel superior de apropiación, tanto de los medios - herramientas e instrumentos de acceso- como del acceso intelectual efectivo a la información y al conocimiento".

¿Qué se entiende por el concepto "software educativo"?

Gros (2000:61) escribe que son "todos aquellos programas realizados con una finalidad instructiva, formativa".

En cambio Squires (2001:17) rechaza analizar los atributos del programa para enfocarse en las cuestiones pedagógicas. "Proponemos un nuevo paradigma para pensar el software educativo, basado en las interacciones mutuas entre las perspectivas de los principales "actores" en la utilización del software: el profesor y el alumno". Este enfoque pone énfasis en el uso que hacen del software los "actores" independientemente de la finalidad que tuvo el creador del mismo.

Otro ejemplo que se puede analizar es el término "interfaz" a partir del trabajo de Scolari (2004). Escribe que el concepto de interfaz es "un concepto-paraguas susceptible de innumerables interpretaciones"; Scolari reconstruye dicho concepto a partir de su historia preinformática -desde la hidrostática-, siguiendo por los significados de diversos diccionarios, para mostrar su sentido en cuatro interpretaciones metafóricas del mismo.

Con el advenimiento de la Web 2.0 Kuklinski, (2007:137) escribe que "Existe una ley de Moore semántica que trabaja del mismo modo que la aceleración tecnológica; promoviendo una obsolescencia terminológica planificada, abandonando conceptos de poco uso y rediseñando nuevas palabras constantemente, pensando más en el marketing viral que en su necesidad lingüística. Con esta lógica, algunos términos se convierten en potentes memes ${ }^{9}$ y se reproducen ganando visibilidad, como es el caso del concepto Web 2.0".

Los ejemplos citados muestran que los términos que conforma el dominio de la Informática -o mejor con un término mas abarcador, las TIC- requieren, por un lado, de consenso entre los usuarios de la disciplina para ser usados con propiedad, y, por el otro, una herramienta tecnológica que materialice el consenso obtenido entre los usuarios, por ejemplo una ontología ${ }^{10}$.

\footnotetext{
${ }^{8}$ Ferreira SMSP, Dudziak EA . La alfabetización informacional para la ciudadanía en América Latina: el punto de vista del usuario final de programas nacionales de información y de inclusión digital. En: World Library and Information Congress: 70th IFLA General Conference and Council. "Libraries: Tools for Education and Development" [en línea] August 22th - 27th 2004, Buenos Aires, Argentina Disponible en: http://www.ifla.org/IV/ifla70/papers/157s-Pinto.pdf

9 "Un meme es una idea contagiosa que se propaga como un virus replicándose a través de las redes, los mass media y la comunicación interpersonal. Internet contribuye sobremanera a la expansión de dichos conceptos. Un ejemplo de presentación de memes es la sección Wired/Tired / Expired de la revista Wired.” (Kuklinski, 2007:139)

${ }^{10}$ Ver parte IV: ontología de casos de enseñanza, p.41
} 


\section{PARTE II: MARCO TEÓRICO}

\subsection{Introducción}

En este apartado se desarrolla el marco teórico que da significación al dominio sobre el que se erige la ontología de casos (García Peñalvo, 2004) y la noción del CBR que da sustento metodológico a la propuesta. Se comienza desarrollando la noción de tecnología y algunas consecuencias epistemológicas para la enseñanza; luego se intenta mostrar la relación de las tecnologías con la educación; se continua comentando la apropiación de la tecnología informática por parte de la escuela desde la década de los ' 80 y se sigue con una breve explicación de la noción de CBR y su relación con la educación y se muestra finalmente, como antecedente, una base de casos donde se recopilan casos de enseñanza que utilizan tecnología.

\subsection{Acerca de la noción de tecnología}

La informática (Barchini, 2004), como tecnología, se incorpora al mundo real o virtual a partir de aplicaciones prácticas en forma de productos o servicios. La presente tesis propone una secuencia de aspectos, una guía, para el diseño una base de casos para su uso en la educación, en consecuencia, se considera pertinente abordar sucintamente algunas cuestiones referidas a lo que algunos autores dicen sobre la noción de tecnología, dado que una base de casos es un objeto tecnológico.

Acevedo Díaz (2006) desarrolla un enfoque sistémico de tecnología donde se supone que esta "perspectiva es más completa y permite la apertura de la tecnología a la participación pública para su evaluación y control". En este enfoque se articulan tres dimensiones: técnica, organizativa e ideológica-cultural a la que habría que sumar una dimensión afectiva o emotiva -se refiere a los sentimientos derivados de la experiencia personal con la tecnología-. "La dimensión técnica está asociada al significado más restringido de la tecnología, que es la más corriente. La dimensión organizativa incluye los aspectos sociales y políticos de mayor relieve, extendiendo así la noción de tecnología. La dimensión ideológica-cultural también amplía el concepto de tecnología al tomar en consideración los valores e ideología que conforman una perspectiva cultural capaz de influir en la actividad creativa de los diseñadores e inventores tecnológicos." En esta tesis no se abordará este enfoque tan completo, se citará algunos autores con la intención de mostrar por un lado, algunos criterios que permiten vislumbrar los distintos objetos tecnológicos que han intermediado la educación y, por el otro, remarcar que la presente propuesta emerge en el contexto de un nuevo paradigma donde se supone que el conocimiento es una construcción social y las tecnologías de la información son la infraestructura sobre el que se erige ese conocimiento (Castells 1999, 2000, 2002; Lévy 2004).

El lugar habitual para acceder al significado de un término es el diccionario de la Real Academia Española:

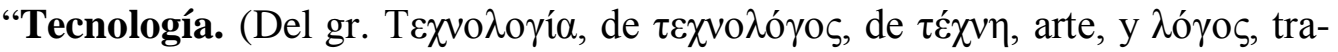
tado). 1. f. Conjunto de teorías y de técnicas que permiten el aprovechamiento práctico del conocimiento científico. 2. f. Tratado de los términos técnicos. 3. f. Lenguaje propio de una ciencia o de un arte. 4. f. Conjunto de los instrumentos y procedimientos industriales de un determinado sector o producto".

Ciapuscio (1994) en el capítulo dos, escribe que la tecnología es reciente, tomo cuerpo en la primera Revolución Industrial, hacia 1875, paradójicamente cuando comenzó la interacción entre los trabajos de los científicos básicos y de los científicos industriales, 
es decir cuando la ciencia ${ }^{11}$ comenzó a influir en el desarrollo tecnológico. Este autor intenta "clarificar la naturaleza y funciones de la ciencia y la tecnología en la sociedades contemporáneas" y para lograr este propósito trabaja distintas nociones de tecnología, argumentando en torno a la controversia de lo que los epistemólogos llaman "la cuestión de la demarcación" entre la tecnología y la ciencia. Comienza escribiendo distintas definiciones de tecnología que varía en función de los autores. Pero quizás donde mejor refleja la noción de qué es tecnología es cuando contrapone la noción de ciencia por los distintos output de cada uno, es decir el producto o resultado de cada uno.

“[...] Si, cuando alguien trabaja, el producto principal de su investigación es conocimiento, algo que tiene que ser publicado abiertamente, ha hecho ciencia. $\mathrm{Si}$, por otro lado, el producto de su labor es primariamente una cosa, un químico, un proceso, algo para ser vendido o comprado, entonces ha hecho tecnología" (Ciapuscio 1994:53).

Más adelante el autor hace una "clarificación didáctica" a partir de una distinción que hace Mc Ginn ${ }^{12}$ de cuatro significados para tecnología, también lo da para la ciencia, pero para los fines que sigue esta narración no se citarán (Ciapuscio 1994:54-55):

“1) Productos materiales de fabricación humana; artefactos o, en términos ingenieriles, hardware, producidos por una persona, grupo o sociedad.

2) "Tecnología" como "una tecnología". Por ejemplo, la frase: "gran progreso se ha hecho en la tecnología de la bicicleta desde la primera guerra mundial". Aquí tecnología se refiere al complejo de conocimientos, métodos, materiales y, si cabe, partes constitutivas (techinics, ellas mismas) usadas en cierta clase de técnicas.

3) "Tecnología" como una forma de actividad cultural humana, una práctica humana, distintiva, como son "arte", "derecho", "religión", practicada por los tecnólogos.

4) "Tecnología" como la empresa de una sociedad ${ }^{13}$. Ejemplo: "El alunizaje del Apolo XI fue un triunfo de la tecnología americana"”."

Todos los significados que hemos citado de Ciapuscio (1994) sumado a la noción que da el diccionario de la RAE, relaciona la noción de tecnología con la producción o diseño de artefactos -en Acevedo Díaz (2006) la encontramos como la dimensión técnica-. La producción de conocimiento lo deja para la ciencia.

Giluliano (2007:30), en el marco de las posturas antagónicas que vinculan la ciencia y la tecnología, adscribe a Joseph Pitt ${ }^{14}$ en la noción de “... que considera que la tecnología y la ciencia son dos formas de conocimiento diferentes”. Según Giuliano (2007) lo que

11 “[...] "ciencia", que puede caracterizarse como conocimiento racional, sistemático, exacto, verificable y por consiguiente falible... [Por racional entiende:] la coherencia con un sistema de ideas aceptado previamente... Además de la racionalidad, exigimos de los enunciados de las ciencias fácticas que sean verificables en la experiencia, sea indirectamente (en el caso de las hipótesis generales), sea directamente (en el caso de las consecuencias singulares de las hipótesis). Únicamente después que haya pasado las pruebas de la verificación empírica podrá considerarse que un enunciado es adecuado a su objeto, o sea que es verdadero, y aún así hasta nueva orden. Por eso es que el conocimiento fáctico verificable se llama a menudo ciencia empírica". Mario Bunge: La ciencia. Su método y su filosofía. En: http://blogs.clarin.com/blogfiles/biblio-lujan-inst-mignone/bunge_ciencia.pdf . Revisado (14-09-10)

${ }^{12}$ Mc Ginn, R. (1991) Science, Technology and Society, Printice Hall, N. Jersey (1983) «Stokowski and Bell Telephone Laboratories», Tecn. And Culture 24, No 1

13 "Como la empresa de una sociedad que destina presupuesto y recursos en investigación, desarrollo, producción y operación de técnicas" (Giuliano, 2007:28).

${ }^{14}$ Pitt, Joseph, 2000, "Thinking About Technology, Foundations of the Philosophy of Technology”, Seven Bridges Press, U.S.A. 
hace Pitt es mostrar a través de estudios históricos que la construcción y utilización de artefactos y complejos sistemas tecnológicos o bien han antecedido a las explicaciones científicas sobre su funcionamiento, o bien no se basan en conocimiento científico alguno. Además rechaza la idea de la ciencia como conocimiento puro en abstracto, sino que siempre persigue un fin práctico, porque está fundada en una compleja actividad comunitaria atravesado por múltiples intereses.

Cupani (2006) intenta mostrar que la tecnología no es ciencia aplicada, intenta mostrar en definitiva, que es más que la aplicación práctica de las teorías científicas; en principio recurre a un conjunto de definiciones acerca de qué es tecnología en relación al conocimiento científico. Se transcriben aquí las definiciones para clarificar de qué habla este autor cuando habla de tecnología.

"conocimiento relativo al proyecto de artefactos y la planificación de su realización, operación, ajuste, manutención y monitorización a la luz del conocimiento científico". (Bunge)

"una forma de conocimiento humano dirigida a producir objetos más y más diversificados, con rasgos cada vez más interesantes, de un modo cada vez más eficiente". (Skolimowki)

"conocimiento de lo que funciona". (Jarvie)

“implementación práctica de la inteligencia”. (Ferre)

"ciencia de lo artificial". (Simon)

Para la tecnología, según Cupani (2006), "resolver problemas constituye la mayor actividad cognoscitiva del profesional de la tecnología" y para eso produce objetos tecnológicos. Luego el autor analiza distintos momentos de la producción de O.T. donde verdaderamente hay conocimiento tecnológico diferente al conocimiento científico, entonces reconoce: conocimientos adaptativos, producto de aplicar resultados de conocimiento básico a la aplicación tecnológica; la especificidad del conocimiento tecnológico para cada tarea; conocimiento inventivo para salvar la brecha entre la ciencia aplicada y la implementación de sus conclusiones; el conocimiento tecnológico es prescriptivo a diferencia del científico que es descriptivo; los datos con que trabaja el tecnólogo es en su mayoría de la experiencia no científica; el conocimiento tecnológico debe satisfacer exigencias técnicas y culturales; la tecnología formula reglas de acción para dar origen a los fenómenos artificiales; utiliza el pensamiento analógico para adaptar recursos de un artefacto existente para la producción de otro nuevo. La conclusión de este autor es que "parece que esta fuera de dudas de que la tecnología es un modo específico de conocimiento y previamente, un modo específico de resolver determinados problemas de conocimiento". Abonando esta idea de producción de conocimiento por parte de la tecnología, Fernández et. Al. (2003:334) escribe que la tecnología construye conocimiento para situaciones específicas reales, complejas, "en las que no es posible dejar a un lado toda una serie de aspectos que en una investigación científica pueden ser obviados como no relevantes, pero que es preciso contemplar en el diseño y manejo de productos tecnológicos que han de funcionar en la vida real".

Herschbach (2007), sugiere que el conocimiento tecnológico "no es un tipo de conocimiento formal similar al de otras disciplinas académicas reconocidas. Tiene características epistemológica diferentes que lo sitúan fuera del conocimiento formal", por ejemplo a la matemática o la física. Y señala que la característica que "define al conocimiento tecnológico es la relación con la actividad". Considera que el conocimiento tecnológico, para usar palabras de Cupani (2006) es un modo específico de conocimiento, 
pero aplicado a situaciones reales, cuya aplicación es interdisciplinaria y específica para actividades particulares. Reconoce tres tipos de conocimiento tecnológico: descriptivo, prescriptivo y tácito. Por descriptivo reconoce aquel conocimiento parecido o cercano al conocimiento formal de una disciplina; "describe las cosas como son, pueden ser en forma de reglas, conceptos abstractos y principios generales, y a menudo desarrolla una estructura generalizable y consistente", por ejemplo propiedades de los materiales a tener en cuenta, información técnica de un dispositivo, características de las herramientas, etc. En informática un conocimiento descriptivo es la información susceptible de analizar en un manual que describe la sintaxis de un lenguaje de programación.

El conocimiento presciptivo "se genera por medio de la experimentación, el ensayoerror y se usan formas específicas de testeo para hacer predicciones 'sobre lo que puede ser identificado como un nivel preteorético'... es un desarrollo de aplicaciones específicas, no es fácilmente codificado en una forma general y de todos modos es menos susceptible de generalizaciones educativas que van más allá de una actividad particular", por ejemplo a través de la experimentación se generan procedimiento u operaciones que con la intensificación de la experiencia pueden sufrir modificaciones. En informática la utilización de un algoritmo puede sufrir variaciones debido a los distintos contextos que se usa dando cuenta de un conjunto de prescripciones: tipo de hardware, características de los datos de prueba, etc.

El conocimiento tácito "es implícito, y es el resultado del juicio individual, la habilidad y la práctica", es el conocimiento que se adquiere trabajando codo a codo con técnicos experimentados o prácticos, se caracteriza por su difícil codificación. Por ejemplo, es el conocimiento que un alumno puede obtener viendo al docente resolver un problema a través de la ejecución de un software o la resolución de un problema usando un software.

Los autores que siguen presentan criterios para la demarcación de los O.T. Buch (1999), en el capítulo dos de su libro, caracteriza el concepto de "Objeto tecnológico". El O.T. es el resultado de las acciones tecnológicas que actúan sobre el objeto. "La preeminencia de la acción se encuentra en dos ámbitos: el de la decisión y el de la creación". Para demarcar los O.T. asume el concepto que denomina "dominio de existencia". Los O.T. pueden pertenecer al dominio de existencia físico o simbólico. Así una computadora o un teclado pertenecen al dominio físico; una teoría de aprendizaje o un método didáctico o una partitura musical al dominio simbólico. Por ejemplo la computadora esta compuesto de hardware, dominio físico, y por software, dominio simbólico.

Benbenaste (1995:272), escribe que la "tecnología computacional representa un cambio en el concepto de tecnología", y establece dos instancias en la demarcación de los O.T.: objetos pre-computacionales y computacionales. Los primeros son puro hard, utilizan la energía eléctrica sólo como fuente de alimentación; los segundos utilizan la energía no sólo como fuente de alimentación, sino que ocupa también el lugar del código y por ende el de la operatividad. "En la computación la energía es modulada por el código binario" (Benbenaste, 1995:273).

Desde la colaboración intelectual que hacen los O.T. Salomón (1992) asume que las tecnologías pueden dividirse aproximadamente en dos grupos, según el uso que se hace de ellas: hay máquinas que trabajan para nosotros y hay herramientas con las que nosotros trabajamos. El motor -no el coche en su totalidad-, el reloj y el piloto automático trabajan para nosotros. El lápiz, el azadón, el microscopio, la cámara fotográfica, el procesador y el paquete estadístico computarizado solicitan que se trabaje con ellos; sin nuestra participación son de poca utilidad. Se puede agregar que las computadoras también se pueden 
comportar como tecnologías del primer tipo, por ejemplo, en los controles de procesos en tiempo real.

Para finalizar este apartado se transcribe una definición de tecnología citado por Burghi Cambón y Bourdieu (2009:19) que es interesante por la conjunción de la dimensión social, de saberes y de Objetos Tecnológicos: “(...) una relación social que se constituye a partir de un sujeto, una máquina y un saber que media entre ellos. Esta concepción de lo tecnológico supone, por un lado, un conjunto de técnicas, saberes y habilidades y, por el otro, objetos materiales (...)".

\subsection{Educación y tecnología}

Brünner (2003) destaca tres momentos históricos relacionado a la base tecnológica de la educación: la primera el nacimiento de las escuelas parroquiales cuyo origen no se remontan más allá del siglo X. "De hecho, la escuela se constituye ella misma como tecnología; es decir, como una organización metódica para la producción de un servicio donde impera la racionalidad de los medios" (Brünner, 2003:25). Eran instituciones privadas, dependientes de la iglesia y dispersas territorialmente. No existía propiamente un sistema escolar, planificado, coordinado y unificado. La formación escolar transcurría esencialmente en un medio de cultura oral, donde el conocimiento se limitaba a lo que las personas eran capaces de recordar; de ahí la importancia de la memoria. El método de enseñanza era la repetición. Por ejemplo Hamesse (1998:159-160), desde la perspectiva de la evolución de la técnica de la lectura, escribe que en la época escolática, siglo XII, "La 'lectura' se convirtió en un ejercicio escolar, regido por su propias leyes. El lugar principal donde se llevó a cabo esa actividad fue la escuela, y luego la universidad... el libro no se abordaba de cualquier manera. Existía la necesidad de comprender el método seguido para abordar la lectura de un texto". Aquí se piensa ya el "método" como una técnica o de acuerdo a Buch (1999) como Objeto Tecnológico.

Entre el Renacimiento y la Revolución Industrial sobreviene la segunda revolución educativa: la creación de sistemas escolares públicos. Por primera vez aparecen componentes de lo que hoy conocemos como un sistema estatal de educación. Es decir, un conjunto de instituciones públicas formal y exclusivamente dedicadas a la enseñanza, con proyección a todo el territorio nacional y cuyo control y supervisión estaban, al menos en parte, en manos de la naciente burocracia gubernamental. Este proceso será acompañado gradualmente por la difusión de la imprenta y consecuentemente el paso de la cultura oral a la cultura del texto.

La Revolución Industrial trae la tercera revolución educativa. La educación masiva equivale efectivamente la alfabetización de todos. La estandarización del proceso educacional se convierte en la base de su progresiva extensión a todos, así como la organización de la producción en las fábricas permite masificar los productos industriales. Ambos fenómenos se basan en los mismos principios de división mecánica del trabajo, especialización y secuencialización de las tareas, disciplinamiento de la actividad humana y jerarquización de las funciones y posiciones ${ }^{15}$.

Aquí, en este punto de la narración se puede establecer qué relación tiene las nociones de tecnología y de O.T. con lo que Brünner (2003) denomina la base tecnológica de la educación. Se puede observar en principio que las tecnologías introducidas en los distintos momentos históricos en la educación fueron de índole físico o simbólica, según la distin-

\footnotetext{
15 Benbenaste (1995:301) define al modelo como "industrialista" “...que consiste en implementar un Programa, frecuentemente anual, que se caracteriza por dos aspectos rectores: la presentación temática por contenidos, y un tiempo uniforme para impartirlos."
} 
ción que hace Buch (1999). Por ejemplo las escuelas parroquiales, el aula, los sistemas organizativos burocráticos, la imprenta, los métodos de enseñanza, etc.

En el presente, la educación "se encuentra en el umbral de una nueva revolución de base tecnológica" (Brünner, 2003:43), la intervención de las prácticas educativas se formaliza en un espacio cultural donde la tecnología tiene una dimensión fundamental y distinta.

A continuación a través de algunos de escritos de Castell se intenta mostrar el contexto sociotecnológico en que se encuentra inmersa la escuela. Castell (1999) sostiene que el impacto de las nuevas tecnologías se caracteriza por su penetración en todos los dominios de la actividad humana, no como una fuente que viene desde afuera, como una fuente exógeno, sino como algo que, utilizando una metáfora, es como el género con que está tejida la actividad humana.

Castells $(1999,2002)$ dice que se está ante un nuevo paradigma tecnológico. Un paradigma tecnológico según este autor "es un modelo conceptual que establece los criterios estándares de interpretación. Integra los descubrimientos en un sistema coherente de relaciones caracterizadas por su sinergia, es decir, por el valor añadido del sistema respecto a sus componentes individuales" (Castells, 2002:167). Este autor utiliza la analogía para explicar la sociedad de la Información. Una analogía (Thagard, 2008) se puede definir como la comparación entre dos dominios, uno más familiar -denominado "fuente" o "análogo"- que representa la situación anterior que puede adaptarse y otro menos conocido -denominado "concepto", "blanco" o "objetivo"- que representa la situación nueva sobre la que se razona, ambos comparten información de tipo relacional. Para su aplicación didáctica o computacional se desechan las disimilitudes y se trabaja con las similitudes.

En nuestra analogía la "fuente" o "análogo" es la revolución Industrial donde el paradigma era el industrialismo que se caracteriza por tener un núcleo tecnológico capaz de generar y distribuir energía -máquina al vapor, electricidad, combustibles fósiles, energía nuclear.

Por otro lado el "blanco" o "objetivo" es la sociedad de la información, cuyo núcleo se caracteriza, por la capacidad del procesamiento de la información, aquí convergen la microelectrónica, computación -máquinas y software- y telecomunicaciones/transmisiones.

Castells (1999) escribe que todas las revoluciones se sostienen en el uso de los nuevos conocimientos e información y que no es privativo del nuevo paradigma tecnológico. En la tabla siguiente se muestra una comparación, siguiendo la analogía, de los modos que se abordo la información en las revoluciones industrial e informacional.

\begin{tabular}{|l|l|}
\hline \multicolumn{1}{|c|}{ Revoluciones } & Uso de la información \\
\hline Primera revolución industrial (Siglo XVIII) & $\begin{array}{l}\text { No tuvo bases científicas, se apoyó en el uso extendido de la } \\
\text { información, aplicando y desarrollando conocimientos } \\
\text { preexistentes. Disponible 100 años antes. }\end{array}$ \\
\hline $\begin{array}{l}\text { Segunda Revolución Industrial (ultimas } \\
\text { décadas del siglo XIX) }\end{array}$ & $\begin{array}{l}\text { Estuvo caracterizada por el rol decisivo de la ciencia en } \\
\text { incentivar la innovación. }\end{array}$ \\
\hline $\begin{array}{l}\text { Revolución informacional (Siglo XX, parti- } \\
\text { cularmente a partir de 1970) }\end{array}$ & $\begin{array}{l}\text { Lo nuevo es la tecnología del procesamiento de la información } \\
\text { y el impacto de esta tecnología en la generación y aplicación } \\
\text { del conocimiento. }\end{array}$ \\
\hline
\end{tabular}

Tabla $\mathrm{N}^{\circ}$ 1: uso de la información en las revoluciones tecnológicas 
Castells (2002) afirma que "La tecnología de la información es para esta revolución [la informacional] lo que las nuevas fuentes de energía fueron para las sucesivas Revoluciones Industriales".

El nuevo paradigma tecnológico ${ }^{16}$, se lo denomina informacionalismo, se constituyó en la década del 1970, organizado alrededor de las nuevas tecnologías de la información y de las comunicaciones ${ }^{17}$.

El informacionalismo es un paradigma tecnológico, proporciona las bases para un determinado tipo de estructura social que Castells $(1999,2002)$ denomina "sociedad red". Una red es un conjunto de nodos interconectado. Los nodos aumentan su importancia para la red absorbiendo más información y procesándola en forma eficiente. La relativa importancia de un nodo no deriva de sus rasgos específicos sino de su capacidad de aportar información valiosa a la red.

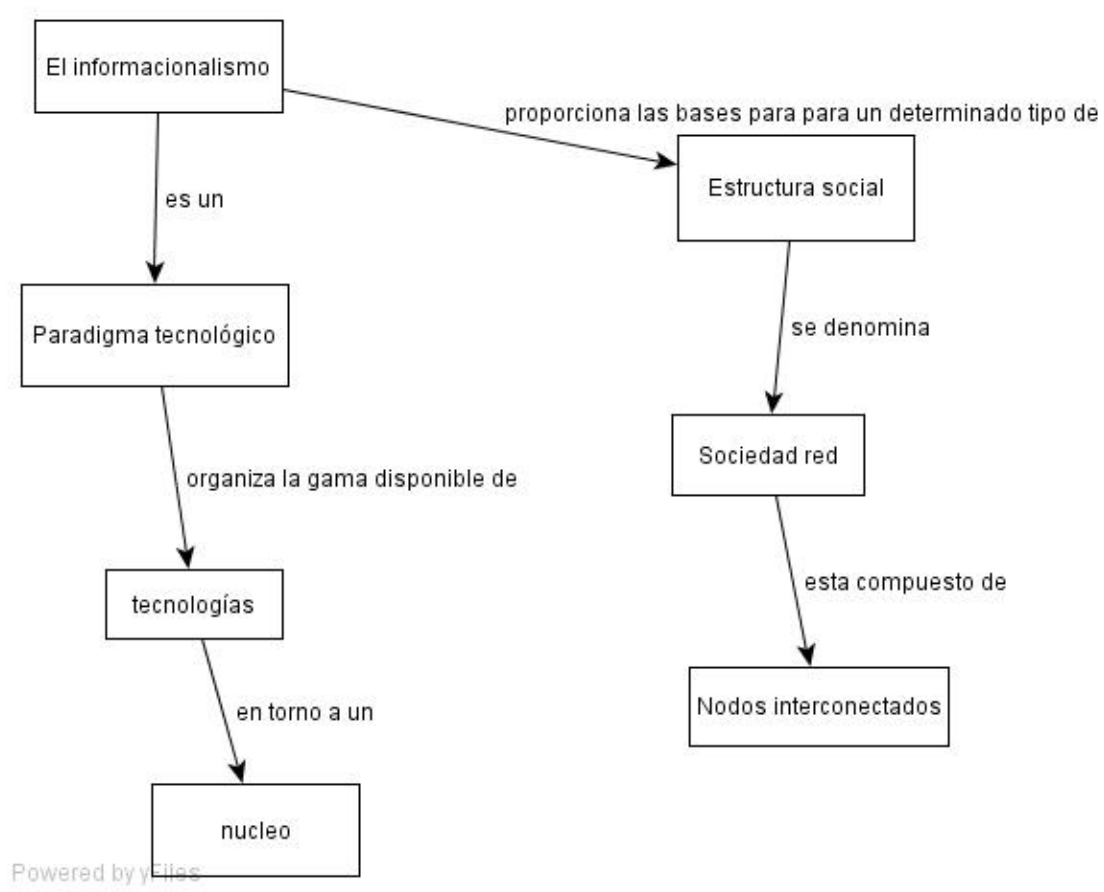

Figura $\mathrm{N}^{\mathrm{0}}$ 1: mapa conceptual con noción de del paradigma informacionalismo

Castells (1999) escribe:

"Lo que caracteriza la revolución tecnológica actual no es la centralidad del conocimiento y la información, sino la aplicación de ese conocimiento e información a la generación de conocimiento y los dispositivos de procesamiento/ comunicación de la información, en un circuito de retroalimentación acumulativa que se da entre la innovación y los usos de la innovación... En otras palabras a diferencia de cualquier revolución, el núcleo de esta transformación que estamos experimentando en la revolución actual refiere a las tecnologías del procesamiento y comunicación de la información".

\footnotetext{
${ }^{16}$ Castells (1999) entiende por tecnología: "el uso de un conocimiento científico para especificar modos de hacer cosas de un modo reproducible".

17 Castells (1999) incluye entre las tecnologías de la información "el conjunto convergente de tecnologías en microelectrónica, computación (máquinas y software), telecomunicaciones/transmisiones, y la optoelectrónica”, incluye también "a la ingeniería genética y su creciente conjunto de descubrimientos y aplicaciones". La optoelectrónica es el nexo de unión entre los sistemas ópticos y los sistemas electrónicos. Los componentes optoelectrónicos son aquellos cuyo funcionamiento está relacionado directamente con la luz. En: http://es.wikipedia.org/wiki/Optoelectr\%C3\%B3nica.
} 
Castells $(1999,2002)$ sostiene que el impacto de este nuevo paradigma en la sociedad será superior a las revoluciones tecnologías que conocemos, como la invención de la imprenta. Lo distintivo de esta revolución tecnológica es:

1. la capacidad de estas tecnologías para ampliar por sí mismas el procesamiento de la información en cuanto volumen, complejidad y velocidad,

2. su capacidad recombinatoria, y

3. su flexibilidad distributiva.

Por ejemplo, con relación al primer punto, en el campo de la microelectrónica, Gordon E. Moore ${ }^{18}$ al ver la tendencia del crecimiento de transistores en una única unidad, en el chip, formula la ley empírica bautizada posteriormente con su nombre, Ley de Moore. Esta ley dice básicamente que, aproximadamente, cada 24 meses la velocidad de los ordenadores se duplicará debido a la creación de transistores cada vez más pequeños, por lo cual se podrán fabricar chips con mayor número de ellos, consecuentemente implicaría reducir drásticamente los costos.

La posibilidad recombinatoria está relacionada a la potencialidad de las nuevas tecnologías, a partir de la digitalización de los distintos formatos con que se expresa la realidad simbólica -por ejemplo texto, imagen, sonidos-, generar múltiples fuentes de información para ser distribuida a través, por ejemplo, de la Web.

La flexibilidad distributiva está relacionada a la potencialidad de estas nuevas tecnologías -notebook, celulares, etc.-, a distribuir la información y su procesamiento en distintos puntos a través de redes de comunicación.

Castells, $(1999,2002)$ sostiene que "Las nuevas tecnologías de la información no son simples herramientas para ser aplicadas, sino que son procesos para ser desarrollados". Esto significa que las NTIC pueden ser apropiadas y redefinidas por sus usuarios. En su uso hay un proceso de retroalimentación en la misma tecnología y en relación directa con los procesos sociales que permite ampliar sus desarrollos. Por ejemplo Internet es un claro ejemplo de una tecnología que se va reconfigurando en función de la apropiación social que tiene por sus propios usuarios a través de la creación y reconversión simbólica de la cultura. Y así en esta dinámica de retroalimentación social y tecnológica se van creando bienes y servicios. Internet, según Serra (1999), es una infraestructura "El reto en las próximas décadas será saber que ponemos sobre esta infraestructura. Que sociedad diseñamos y construimos sobre esta nueva plataforma".

En síntesis, se trazan las etapas de innovación en tres campos tecnológicos principales que, aunque estrechamente interrelacionados, constituyeron la historia de las tecnologías basadas en la electrónica: la microelectrónica, las computadoras, y las telecomunicaciones.

En este escenario "el conocimiento se ha convertido en la mercancía más valiosa de todas, y la educación y la formación en las vías para producirla y adquirirla" Coll (2009:114). La educación adquiere el rol de promoción del desarrollo social y económico y las computadoras, dispositivos y redes digitales se muestran como los instrumentos adecuados para promover el aprendizaje (Coll, 2009).

A modo de conclusión de este apartado la tecnología, de acuerdo a los criterios de demarcación comentados más arriba, ha mediatizado la educación desde el medioevo

18 Gordon E. Moore, nació en California, EEUU, el 3 de junio de 1929. Cofundador de Intel. http://www.computer.org/portal/web/awards/moore-goode. Revisado (01-10-2011) 
hasta en la actualidad donde el nuevo paradigma tecnológico, el informacional, siguiendo a (Esnaola, 2006) socava las estructuras desde donde se erigieron sus certezas "del ecosistema educacional", la organización escolar y la escritura; o siguiendo a (Brünner, 2003:79) las transformaciones en curso se desenvuelven en los sistemas educacionales a partir de tres transformaciones: “1) Expansión de la plataforma de la información y conocimiento; 2) Cambios en el mercado laboral; 3) Crisis en el mundo de la vida"; o como escribe Leliwa (2008:58) "El problema para los docentes es apropiarse de la nueva cultura audiovisual e informática sin dejar de lado el análisis cultural reflexivo y profundo".

\subsection{Apropiación de la informática en la escuela media}

Levis (2007:23) escribe que "la inserción de cualquier tecnología en la vida cotidiana pone en juego tres lógicas interrelacionadas entre sí: técnica, comercial y social; siendo la apropiación social la que confirma, en última instancia, su inserción o su fracaso"... [en la Argentina] "la apropiación social de computadoras y redes en el ámbito educativo no termina de conformarse".

Según Babini (1991) las bases de la informática en la Argentina fueron establecidas por la iniciativa de un grupo de precursores a partir del año 1956 en la Universidad Nacional de Buenos Aires, principalmente, la Universidad Nacional del Sur y la Universidad Nacional de Tucumán. La sistematización de la formación de los "profesionales de la informática" se dio a fines de 1963 con la aprobación de la creación de la carrera de computador científico en el ámbito del Departamento de Matemática de la Universidad Nacional de Buenos Aires, a instancia de Manuel Sadosky. El primer antecedente de la enseñanza de la computación en el ciclo secundario fue en el año 1969 un establecimiento privado, en las Escuelas Ort.

La incorporación de la Informática en la educación media data desde los años $1980^{19}$, durante la dictadura militar (Levis, 2007:36). Esta incorporación se fundo en algunos supuestos (Muraro, 2005:13-17) que en la práctica no ha podido corroborarse en lo que respecta a "los efectos benéficos para la enseñanza y el aprendizaje..." (Levis, 2007:28).

a) Desarrollo de la inteligencia: este supuesto sostiene que la iniciación, por parte de los alumnos, en resolver problemas a través de la utilización de algoritmos ${ }^{20}$ computacionales desarrollaba diferentes estrategias intelectuales sobre el objeto de conocimiento. Con relación a este supuesto Nogera (1992:32-33) cita algunos estudios relacionados a las estrategias intelectuales que emplean estudiantes de informática, expertos en programación, al momento de construir algoritmos:

- "Los diseñadores tienen representaciones mentales abstractas de algoritmos y fragmentos de algoritmos que no están ligadas a un lenguaje de programación en particular.

- Normalmente, los diseñadores eligen, al principio, un esquema básico para el diseño del algoritmo, y el resto del tiempo lo gastan en refinar ese esquema inicial.

- La estratega de control usada en el diseño del algoritmo es una estrategia de refinamiento top-down, en la que se estudia el objetivo que se quiere alcanzar, el estado en el que nos encontramos, y como consecuencia se ponen los medios

\footnotetext{
${ }^{19}$ Muraro (2005:18) "Se toma como fecha de inicio las acciones desarrolladas por el "Centro Nacional para la Enseñanza de la Informática - CENEI", primer proyecto nacional generado y atendido desde el Ministerio de Educación y Cultura"

${ }^{20}$ Busaniche (2007:54) en el contexto de la alfabetización digital en el sistema educativo escribe que "Los rudimentos básicos de la programación son tan esenciales hoy como la matemática misma".
} 
necesarios para alcanzar ese fin (análisis de fines y medios, o means-end analysis).

- Existe una continua ejecución mental del algoritmo parcialmente desarrollado a fin de permitir el análisis means-end.

- El análisis del comportamiento de los programadores demuestra la evidencia de una profundización progresiva, similar a la que se encuentra en el análisis de protocolos de los jugadores de ajedrez.

- Los diseñadores usan la explicación (a otros o a ellos mismos) de cómo funciona el algoritmo para detectar errores.

- El aprendizaje es esencial en todo el proceso del diseño. Los humanos continuamente aprenden. El aprendizaje se usa para facilitar la construcción de programas similares y para adquirir nuevas terminologías y estrategias de diseño".

En el mismo trabajo de Nogera (1992) se encuentra que el tipo de lenguaje de programación incide en el comportamiento de los programadores: los programadores de lenguajes estructurados como por ejemplo el "viejo" Pascal, necesitan esquemas mentales previos; los programadores de lenguajes como el aun "más viejo" Basic, no estructurados, solo algunas pistas del control de flujo del programa.

b) Modifica las propuestas didácticas: se suponía que con el ingreso de los programas educativos mejorarían las propuestas didácticas para enseñar contenidos de otras disciplinas. Al principio la propuesta didáctica era la programación para la resolución de problemas matemáticos -por ejemplo se ponía de manifiesto la lógica algorítmica de las operaciones matemática para relacionarla con la lógica algorítmica computacional- con autonomía de las otras disciplinas curriculares. En algunos casos, en apoyo de la programación, se enseñaba la construcción de algoritmos con diagramas de flujo y lógica de primer grado para justificar la toma de decisiones en el mismo. Posteriormente, se esperaba que el ingreso de software educativo cambiara la dinámica de la enseñanza, pero los resultados no fueron alentadores por diversos motivos, particularmente "porque la escuela mantiene una organización poco adecuada para la integración de la tecnología informática" (Muraro, 2005:14) y por la escasa apropiación "socioeducativa de las TIC y en particular de la informática" por parte de la escuela (Levis, 2007:29).

c) Motiva el aprendizaje de los alumnos: la computadora, consecuencia de la información de diversos medios comunicacionales, se supone motivadora per se. Este supuesto no se verificaba en la práctica, "la investigación ha demostrado que los conceptos de motivación son el resultado directo de las experiencias del aprendizaje" (Boekaerts, 2006:10). La programación es una tarea fatigosa para los alumnos frente a las exigencias lógicas y metodológicas que implicaba esta modalidad de resolución de problemas. Benbenaste (1995:310) desacredita la "motivación" porque busca reemplazar el sentido debido a que es "una noción exógeno al procesos de pensar, con la que se busca inducir al sujeto desde afuera;... La omisión del papel del sentido, sustituido por la motivación, hace que la significación de la experiencia denominada educacional, propenda a organizarse en forma de Poder: el sujeto siente que puede ubicarse, ya en el polo estructurante, ya en el complementario, según aprenda -se adapte- o no."

d) Promueve la enseñanza personalizada: el nacimiento de los tutoriales y los programas multimediales e hipertexto se valoran como una posibilidad de que los alumnos aprendan a su propio ritmo. Investigaciones acerca de cómo aprenden los niños Vosniadou (2006:7) muestran que el aprendizaje en la escuela es posible si se consideran los siguientes principios: "ambientes de aprendizaje que alienten a los estudiantes a aprender activa- 
mente, a colaborar con sus compañeros y a hacer uso de tareas significativas y materiales auténticos". El éxito en la implementación de estos programas requiere la consideración de estos tres principios para crear un ambiente propicio para el aprendizaje. Las nuevas investigaciones relacionadas al aprendizaje de los niños están estrechamente relacionadas a algunos supuestos de la disciplina tecnológica. Vosniadou (2006:13) escribe que "Las personas aprenden mejor cuando participan en actividades que perciben como útiles en la vida cotidiana y que culturalmente son relevantes". Herschbach (2007) escribe que la tecnología es una disciplina vinculada con la actividad, aplicada a situaciones reales.

e) Democratiza el acceso a la información: esta idea se apoya en que cualquier sujeto está en condiciones de acceder a la información soportada en redes globales. Este supuesto no asume que el acceso a la información requiere de una serie de enfoques que están íntimamente relacionados, todos confluyen a la calidad de la búsqueda. La primera cuestión a considerar en el momento de diseñar una búsqueda es la experticia del usuario en el conocimiento del dominio de la disciplina a la cual pertenecen los términos de búsqueda. La segunda cuestión es reconocer los modos de accesibilidad de los distintos servicios que nos presenta las TIC. La tercera cuestión, está relacionado al conocimiento que podemos alcanzar del soporte que contiene la información, esto es: qué lectura podemos hacer, por ejemplo, de la interfaz que nos presenta el recurso y de los elementos que están en el contexto de los contenidos. La cuarta cuestión, tiene que ver con el reconocimiento de algunos criterios de calidad para aplicar a las fuentes de información. Por último, no se asume el concepto de "brecha digital" donde las diferenciaciones económicas-sociales de una sociedad capitalista también se repiten en el acceso a la tecnología (Serrano Santoyo y Martinez, 2003; Buckingham, 2008).

f) Facilita el acceso al conocimiento: este supuesto está basado en que las tecnologías de la comunicación favoreció el almacenamiento y acceso a la información, como consecuencia la información está ahí, solo hay que usarla.

Desde lo metodológico la disciplina informática carece de la madurez de otras disciplinas más antiguas como la física, la matemática o la química. Muraro (2005:18) escribe que "la informática fue integrándose asociada a los contenidos y a la didáctica de otras disciplinas." La informática, que al principio era computación, fue una herramienta para "reconstruir los conceptos matemáticos" a través de la utilización de algoritmos computacionales.

Pentiraro (1986:42) señalaba tres categorías para la utilización del "ordenador personal" en el aula desde un punto de vista didáctico: "aprenderse el ordenador", "aprender a través del ordenador" y "aprender con el ordenador". Estas categorías estaban solapadas o imbricadas en la mayoría de los programas iniciales del uso de la informática en la Argentina con predominio de alguno de ellos en función de la formación del docente y de las posibilidades tecnológicas.

"Aprenderse el ordenador" estaba relacionado al conocimiento del hardware y el software; conocer el funcionamiento de la computadora y la relación entre el hardware y el software ligado particularmente a mejorar la eficiencia en el uso de los lenguajes de programación. "Aprender a través del ordenador" implicaba la experimentación con los lenguajes de programación, particularmente con el BASIC y, posteriormente, Pascal y paralelamente la escritura de algoritmos utilizando para su representación los diagramas de flujo; subyacentemente se ponía énfasis de la posibilidad de la computadora como medio e instrumento para la resolución de problemas (problem solving); surgían algunos programas que contenían materiales de soporte para el profesor. "Aprender con el ordenador" estaba 
relacionado a concebir la computadora como un ambiente de aprendizaje especialmente diseñado para que incidiera en el desarrollo mental de los niños.

En función de lo expuesto y a partir de las categorías propuestas en el libro de Pentiraro (1986) es pertinente recuperar una experiencia personal del autor que ilustra el contexto del estado del arte en la ciudad de Neuquén en la década de los años '80, respecto a la inserción de las computadoras en las escuelas. El estado provincial, había iniciado las primeras experiencias de introducción de la informática en la educación en el nivel medio. Comenzó en el interior de la provincia, primero en Zapala, luego en la Villa del Chocón, en la modalidad de taller y se dictaba a contra turno.

En la Villa del Chocón está el Centro Provincial de Enseñanza Media (C.P.E.M.) $\mathrm{N}^{\mathrm{o}}$ 9 distante a $80 \mathrm{~km}$ de la ciudad del Neuquén. Dicha Institución había recibido por parte de la empresa Hidronor -ahora disuelta- la donación de un conjunto de computadoras TI 99 de Texas Instrument. Estas computadoras tenían incorporado un interprete del lenguaje (BASIC -Beginner's Symbolic Instruction Code) y un conjunto de cartuchos que se podían incorporar a las máquinas, como por ejemplo algunos juegos.

Las primeras experiencias en el uso de las computadoras en el colegio las brindó un ingeniero eléctrico que trabajaba en la empresa y vivía en la Villa del Chocón. Cuando el autor ingresó a trabajar, año 1985, al C.P.E.M No 9 la Dirección del colegio solicitó la presentación del programa de la materia.

$\mathrm{Al}$ momento de pensar y redactar el programa del taller al autor se le ocurrieron tres iniciativas: la primera era conocer las experiencias de otros colegios del nivel medio; la segunda tomar conciencia de la realidad tecnológica con que contaba en el colegio; y la tercera visitar la Facultad de Ciencia de la Educación de la UNCo para que los profesionales de la misma lo aleccionaran sobre algunas posibilidades didácticas para abordar la enseñanza de la informática.

Respecto de la primera inquietud, en la provincia sólo había una experiencia en la ciudad de Zapala, y para ese entonces se había redactado un programa que ponía el eje en las nociones de hardware y software, esto último con el objetivo de la programación de las computadoras. La realidad tecnológica, el segundo punto de las iniciativas, decía que la apropiación didáctica de las computadoras se debía hacer a través de la programación de las computadoras usando el lenguaje $\mathrm{BASIC}^{21}$, único lenguaje incorporado en la máquina. Por último, en la Facultad de Ciencias de la Educación, no había espacios académicos que dieran cuenta de algún abordaje de la relación de las tecnologías informáticas con la educación.

El programa redactado, finalmente, tenía como objetivo general la enseñaza de la programación usando el lenguaje BASIC. Cuatro eran los ejes temáticos de dicho programa: la enseñanza del hardware, lógica de primer grado, la construcción de algoritmos utilizando para su representación los diagramas de flujo y los tipos de datos y sentencias soportados por el BASIC. La resolución de problemas propuestos estaba relacionada a la construcción de algoritmos para resolver ecuaciones matemáticas y el manejo de arreglos para, por ejemplo, cambiar el orden de las letras de palabras ingresadas o generar valores con la función Random() para luego ordenarlas. Para programar la solución de algún problema se debía atender tres cuestiones (Muraro, 2005:19):

- "Los propios conceptos matemáticos involucrados en el problema.

\footnotetext{
${ }^{21}$ Posteriormente el autor, en el año 1994, ingresó al colegio privado Sunrise School S.A. de la ciudad de Cipolletti, Provincia de Río Negro, el aula informática tenía computadoras personales compatibles con IBM, el sistema operativo MS DOS permitía la utilización del compilador Turbo Pascal con lo cual se enseñaba programación estructurada.
} 
- La comprensión de las reglas sintácticas y semántica del lenguaje BASIC.

- El empleo de estrategias metodológicas propias de la informática y específicas de los lenguajes imperativos [de sentencias] o de tipo "paso a paso"”.

Alguna de las conclusiones que se pueden vislumbrar de la experiencia narrada por el autor de su novel trabajo docente son las siguientes: la resolución de un problema matemático usando un lenguaje de programación requería, aun hoy requiere, competencias computacionales que no eran fáciles de adquirir y que se presentaban como un impedimento difícil de sortear por los alumnos y por aquellos docentes que no pertenecían a las disciplinas computacionales ${ }^{22}$; la tecnología condicionaba la apropiación didáctica de la informática; había pocas posibilidades del trabajo interdisciplinario a excepción de matemática e inglés; la motivación inicial que proponían la computadora como tecnología novedosa iba decayendo proporcionalmente con la dificultad que encontraban los alumnos para programarlas; el docente carecía de conocimientos acerca de cómo aprenden los niños y en función de esto cómo elaborar propuestas enriquecedoras; aislamiento por parte de la institución a la actividad del taller por desconocimiento acerca de la disciplina.

Continuando con las categorías propuesta por Pentiraro (1986), la tercera categoría, "Aprender con el ordenador", viene de la mano del lenguaje de programación llamado LOGO, orientado a construir con flexibilidad soluciones de problemas geométricos basados en la construcción poligonal (Muraro, 2005). Pentiraro (1986) auguraba para el LOGO, "un futuro educativo asegurado". Este pronóstico se basaba quizás en el origen académico del LOGO y en la fundamentación epistemológica del mismo: en los trabajos de Jean Piaget. Es el primer ambiente de programación diseñado con el propósito de que lo usen los niños. El mismo se desarrollo en el Massachussets Institute of Technology por el trabajo, principalmente, del matemático y epistemólogo Saymour Papert. La apuesta de los creadores del LOGO fue audaz: convertir a los niños en epistemólogos, que pensaran en su propio pensamiento (Papert, 1984). Suponían que programando computadoras en "ambientes ricos" los pondría a problematizar su propio pensamiento. Suponían que la programación de computadoras en el ambiente LOGO enriquecería el paso del pensamiento "concreto" al pensamiento "formal".

Muraro (2005) en su libro reúne un conjunto de observaciones críticas desde el punto de vista técnico, psicológico, de venta, promoción del lenguaje y curricular, que explicarían el por qué de la declinación del uso de esta propuesta informática para la educación de los niños.

A fines de la década de los '90 la aparición de interfaces gráficas que dieron prioridad al concepto de visualización, la educación, particularmente disciplinas no informáticas, se vieron favorecida con la incorporación de un conjunto de herramientas que tenía incorporado ese concepto. Así surgieron las planillas de cálculo, los procesadores de textos, los administradores de bases de datos y particularmente, en forma paralela, programas que hacían de mediadores del conocimiento.

Los docentes de las escuelas medias, ante la variedad de herramientas que le ofrecía la industria del software, crecientemente se fue apropiando de algunas de ellas para usarlo como recurso de apoyo en alguna de sus actividades didácticas en el aula. Por ejemplo el de mayor aceptación fue el procesador de textos, particularmente en lenguas y disciplinas

\footnotetext{
${ }^{22}$ Esta situación de desarrollar doble habilidades, por un lado conocer cómo enseñar los conceptos propios de la matemática y conocer cómo enseñar programación se lo conoce como doble conceptualización (Kriscautzky Laxague, 2011).
} 
afines; la planilla de cálculo en actividades contables y matemática. La apropiación de estas herramientas se realizaba desde una perspectiva marcadamente operativa.

Para finalizar este resumen de los inicios de la informática en la escuela media, a continuación se cita los distintos significados de la misma dado por Muraro (2005:55-57) para concluir parafraseando a Levis (2007) que en la educación los métodos de enseñanza de esta disciplina están en construcción:

"El enfoque como objeto de estudio, considera la disciplina informática como un espacio curricular propio. Los problemas que tratan, los contenidos que se trabajan y los métodos de producción que se aplican, constituyen su propio objeto de estudio." Este significado está más cerca de la noción de "alfabetización informática". ${ }^{23}$

"El enfoque correspondiente a emplear la informática como recurso didáctico, está ligado a la idea de considerar las herramientas y técnicas informáticas como recursos para tratar los problemas de las diferentes disciplinas". Esto significa que la informática media los contenidos a enseñar colaborando con los alumnos en la producción de actividades propias de la disciplina; así en lenguas se usará el procesador de textos, en contabilidad la planilla de cálculo, en matemáticas programas específicos, en plásticas programas con paletas para dibujo, etc.

"En el enfoque en torno del empleo de materiales educativos la mirada de la informática está puesta en el análisis de las estructuras y formas de empleo de diferentes "recursos didácticos", como otra forma de mediar el conocimiento, que el soporte digital otorga otras formas de mediación". La computadora se circunscribe a ser soporte de los materiales educativos.

A modo de conclusión de este apartado, tomando el espacio temporal entre el libro de Pentiraro (1986) y el de Muraro (2005), más de diecinueve años, los significados de los usos de la computadora desde la década de los ' 80 al presente sufrieron variaciones de sentido debido a los cambios tecnológico y la noción imperante del acceso de la informática desde el punto de vista operativo -por ejemplo, no enseñar los rudimentos básicos de programación por la aparición de programas con interfaz gráfico de uso específico- y al "fracaso" de las diversas propuestas informáticas para la educación -por ejemplo el uso del LOGO.

El significado en el uso de la informática no ha variado para el caso de "aprenderse el ordenador" y de la "alfabetización informática". En ambos casos se introduce al alumno en el conocimiento del hardware y del uso de software "más" usado, por ejemplo los sistemas ofimáticos y sistemas operativos.

En cambio en la comparación de los criterios "aprender a través del ordenador" y de la "informática como recurso didáctico", la significación del aprendizaje estaba mediado por el uso de los lenguajes de programación -Basic, Pascal, SmallTalk, etc.- en el primer caso; en el segundo, cuando el paradigma de la programación por las diversas situaciones explicadas más arriba, desaparece de las aulas, el aprendizaje está mediado por el uso de software específicos, no necesariamente diseñados con fines educativos, que coadyuvan a la resolución de problemas en áreas temáticas delimitadas -procesadores de textos, graficadores, hojas de cálculos, etc.

\footnotetext{
${ }^{23}$ Muraro (2005) sugiere que el concepto de "alfabetización informática” fue tomando diferentes enfoques en función de los diversos desarrollos informáticos. A los inicios, año 1980, significaba saber qué era una computadora y tener nociones de programación; en los años 1990 dejo de tener relevancia las técnicas de programación y la alfabetización se enfocaba en el tratamiento de la información, esto es, ser usuario autónomo de la computadora, saber qué es una computadora y la administración de Sistema operativos y algunos programas ofimáticos; en la actualidad, con la aparición de Internet a lo anterior se suma la navegación, acceder a archivos, usar el correo electrónico, etc.
} 
Con relación a la tercera categoría "Aprender con el ordenador" y "materiales educativos", la idea que subyace en ambos casos es que el alumno participe en ambientes enriquecidos con recursos diseñados con propósitos claramente didácticos. En primer caso, "Aprender con el ordenador", la influencia del LOGO es manifiesta, puesto que el ambiente LOGO era, según sus autores, un "micromundo" donde "la gran máquina poderosa [la computadora] se utiliza como un medio para construir mundos sencillos y limitados. En ellos, el aprendizaje puede producirse sin que se vea dificultado por las complejidades del mundo real" (Papert, 1997). En el segundo caso, "materiales educativos", se "mira a la informática como un conjunto de materiales educativos mediadores del conocimiento o mediadores de las prácticas docentes" (Muraro, 2005:56).

Antes de terminar este apartado se hará una introducción a la zona del software que el autor denomina "videojuegos y su potencialidad educativa" (Esnaola, 2006), que, por "sus atributos propios y diferenciados de otros tipos de programas" (Gros, 2000) requiere una mirada distinta a los significados de la informática vistos más arriba. Luego se muestra el proyecto del Lifelong Kindergarten del MIT Media Lab donde se conjuga la utilización de los medios con propósitos motivadores, siguiendo la idea que subyace en estos productos de que jugar motiva, con la posibilidad de que los niños puedan programar, desde un paradigma distinto a los que hemos visto en los párrafos precedentes, sus propios juegos.

Dos cuestiones ponen a los videojuegos en la consideración de algunos docentes para la enseñanza de contenidos: por un lado, la recuperación de la noción de juego como espacio fundamental de aprendizaje y de interacción social de los/as alumnos/as y que, potencialmente, las tecnologías de los videosjuegos lo reflejarían; y por el otro, la creciente producción de juegos por la industria del software y la aceptación acrítica de los niños y adolescentes de esta nueva propuesta de ocio (Buckingham, 2008). Concomitantemente a estas dos cuestiones, aparece un espacio académico con numerosos trabajos con distintas líneas de investigación sobre la relación videojuegos y educación Méndiz (2001).

En los párrafos que siguen se analizará los videojuegos y su relación con la educación en el marco de la noción juego en general.

Una concepción de juego implica: "una acción o actividad voluntaria asumida dentro de ciertos límites de tiempo y espacio, realizada de acuerdo con reglas estrictas... [se] define al juego como un espacio-tiempo simbólico y mágico; en el se produce un recorte del espacio ordinario que da lugar a la creación del campo de juego" (Cambón, 2009:13).

Según Bruner (1983), las funciones fundamentales del juego en las actividades de los niños/as son:

- $\quad$ El juego reduce la gravedad de las consecuencias de los errores y los fracasos.

- Los niños/as no se preocupan demasiado por los resultados de los juegos sino que modifican lo que están haciendo dejando libre paso a su fantasía.

- A pesar de su variedad, el juego rara vez es aleatorio o casual, sino más bien, por el contrario parece como obedecer a un plan.

- $\quad$ Se dice que el juego es una proyección de la vida interior hacia el mundo, en contraste con el aprendizaje, mediante el cual interiorizamos el mundo externo y lo hacemos parte de nosotros mismos.

- $\quad$ El juego divierte y divierte mucho. 
A continuación se analiza algunas posibles relaciones que tienen cada uno de estas funciones para la actividad de la enseñanza $\mathrm{y}$, consecuentemente, permite a los investigadores conjeturar el uso de los videojuegos en la educación:

- El juego es una actividad seria para los/as niños/as que no conlleva consecuencias frustrantes, contrariamente a las actividades escolares que tienen una carga importante de frustración cuando las actividades realizada por los niños fracasan.

- Los niños/as tienen que preocuparse por comenzar y finalizar las actividades solicitados por los docentes ya que estos deben verificar el aprendizaje; contrariamente en los juegos los/as niños/as no se preocupan por los resultados finales, sino que en el medio del juego pueden cambiar de opinión dejando libre su fantasía buscando nuevos cambios o combinaciones.

- Las actividades propuestas por los docentes están organizadas de manera similar a las actividades que viven los/as chicos/as en la cotidianeidad, el plan está secuenciado por un conjunto de pasos que deben seguir los/as niños/as para finalizar la actividad; la mayoría de los juegos de los/as chicos/as parece que también obedecen a una organización o a un plan, pero a una organización idealizada, que deja de lado lo ordinario, la secuencia que siguen los niños es con el fin de mantener el juego, esto implica que la secuencia del juego puede tener bifurcaciones.

- En el juego el/la niño/a transforma el mundo en función de sus deseos, en el aprendizaje el/la niño/a es transformado para conformarse a la estructura del mundo.

- En general las actividades que proponen los docentes no son divertidas suponen una carga importante de atención ligada a la autoridad del docente; el juego es divertido aun con los obstáculos que supone un juego, sin obstáculos el/la niño/a se aburre.

En cuanto a la eficacia de lo videojuegos como medio para el aprendizaje los datos disponibles de las investigaciones son limitados; sugieren que hay cierta base para la motivación de algunos alumnos, pero no hay elementos suficientes para afirmar de que hay también aprendizaje (Buckingham, 2008:156).

A partir de (Buckingham, 2008:152) se presenta en forma resumida algunos problemas en el uso de videojuegos comerciales en el aula:

- Requiere mucho tiempo y práctica sostenida para dominar los juegos en un nivel de competencia básico.

- Falta de capacitación docente en el uso del juego y su transposición didáctica.

- Dificultad en la capacidad de identificar un juego de buena calidad.

- Imposibilidad de uso de los videojuegos por falta de hardware adecuado en las escuelas.

- La problemática del interés por parte de los alumnos/as en los juegos en función del género.

- El uso del video juego en la escuela se ve afectado por los pre conceptos que tienen los padres sobre los mismos. 
- Dificultad de los alumnos en inmiscuirse profundamente en la enseñanza que se quiere alcanzar con el juego y "perderse" en el juego mismo.

Para finalizar este apartado se describe brevemente el proyecto $\mathrm{Scratch}^{24}$. De acuerdo a (Resnick, 2008), del grupo del Lifelong Kindergarten del MIT Media Lab, es un nuevo lenguaje de programación que permite crear historias interactivas, juegos y animaciones y compartir las creaciones con otros en la Web. La programación con Scratch implica encajar bloques gráficos, en consecuencia carece de los obstáculos de sintaxis y puntuación de los lenguajes de programación tradicionales. De esta manera, la programación, según sus creadores, se hace accesible a una población mucho más amplia y a una edad más temprana.

Los proyectos Scratch están compuestos de un escenario donde los objetos (sprite) "cobran vida", interactuando uno con otros formando parte de una de una narración o de un juego.

Construir un programa (scripts) con Scratch implica en el "Área de programa" encajar bloques desde la "Paleta de bloques" en las estructuras de control haciendo una pila.

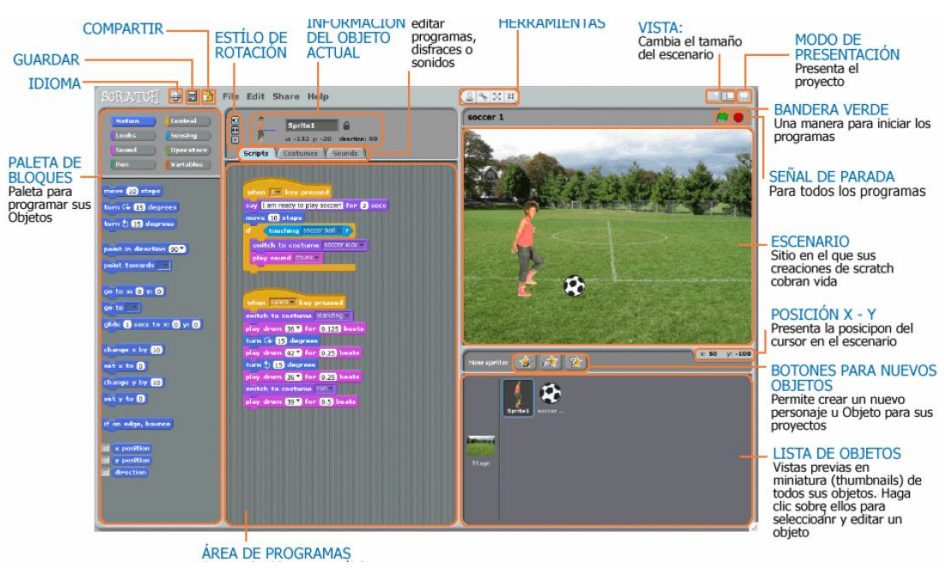

Figura $N^{\circ}$ 2: Interfaz gráfica de Scratch

Los bloques que se encajan dentro de las estructuras de control son de movimientos, apariencia, sonidos que se aplican a los sprite. Además cuenta con censores para la interacción del programa; con operadores lógicos y administradores de variables.

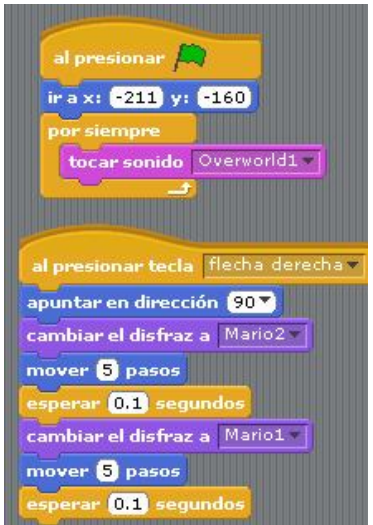

Figura $\mathrm{N}^{\mathrm{o}}$ 3: Ejemplo de las estructuras de control en Scratch

\footnotetext{
24 El nombre de Scratch viene de la técnica "Scratching" usada por los disc jockeys de hip-hop, quienes giran discos de vinilo hacia delante y atrás con sus manos para mezclar la música con video clips de una manera creativa.
} 
Aquí en el ejemplo se ve la estructura de control "por siempre" en el primer conjunto de bloques y la estructura secuencial en el segundo conjunto de bloques.

Los estudiantes que crean proyectos con Scratch pueden compartirlos en el sitio Web de $\mathrm{Scratch}^{25}$ de la misma forma en que comparten sus videos en YouTube ${ }^{26}$.

Los creadores de este proyecto afirman que "Programar en Scratch es mucho más fácil que la programación tradicional de lenguajes: para crear un script, simplemente pones uno al lado de los otros bloques gráficos parecidos a fichas LEGO o a un rompecabezas".

Las manifestación optimista de los proyectos que relacionan los juegos con el aprendizaje, trae a colación, por un lado a las alabanzas del LOGO en la década de los '80; por el otro, algunas nociones de lo que se conoce del aprendizaje y su relación con las interfaces desde la ingeniería cognoscitiva (Raskin, 2001): si lo conciente nace a partir de un estímulo a la información inconsciente, ya almacenada, entonces todo conocimiento que se transforma en habito tiene que pasar por un procesos de aprendizaje. Esto significa que cuando se enfrenta un usuario a una interfaz y puede interactuar con ella es porque es una interfaz familiarizada o habitual: no hay interfaz intuitiva o natural. La posibilidad de formar hábitos con las interfaces permite "olvidarnos" de la computadora y centrar la atención en el aprendizaje o la resolución de problemas nuevos.

\subsection{El Razonamiento Basado en Casos (CBR)}

\subsubsection{Introducción}

El modelo denominado CBR (Case-Based-Reasoning) es una metodología de resolución de problemas, se origina dentro de las ciencias cognitivas en las investigaciones de Roger Schank y de sus discípulos de la Universidad de Yale. Lo relevante de las investigaciones de Schank era entender cómo la gente recuerda información y a su vez trae a la memoria esa información y, consecuentemente, cómo la gente resuelve problemas recordando el modo de resolver problemas similares en el pasado.

Este modelo se caracteriza porque es capaz de utilizar conocimiento específico de experiencias previas, es decir, situaciones de un problema concreto -casos- para resolver problemas. Ante un problema dado, nuevo, se buscan experiencias pasadas y se adaptan para encontrar una solución acorde al planteamiento del problema. De esta adaptación se obtienen experiencias exitosas o no exitosas que se registran para el aprendizaje.

A partir de la concepción de la naturaleza del mundo, emergen dos supuestos fundamentales que sostienen el CBR (Díaz, 2002):

- Su regularidad. De situaciones similares se extraen conclusiones y se aprenden lecciones similares.

- Recurrencia de las experiencias. Es altamente probable que las situaciones futuras sean variantes de las actuales.

En Watson (2000) se encuentra que los sistemas CBR atraen la atención porque:

- no requiere un modelo de dominio de manera explícita y la tarea de sacar o poner casos la convierte en una tarea de recopilación de historias de casos;

- la implementación se reduce a la identificación de las características importantes que describen un caso, una tarea más fácil que la creación de un modelo explícito;

\footnotetext{
${ }^{25}$ http://scratch.mit.edu

26 http://www.youtube.com/
} 
- mediante la aplicación de técnicas de base de datos en gran medida los volúmenes de información pueden ser gestionados;

- puede aprender mediante la adquisición de nuevos conocimientos, casos, por lo tanto hace el mantenimiento más fácil.

Sumamos desde Díaz (2002) que "para la adquisición del conocimiento... resuelve problemas profundos que se plantean cuando no existen los principios aceptados por todos los expertos a partir del cual construir el modelo [de formalización del conocimiento], es decir no existe un modelo, ni siquiera en la mente de los expertos, ya ni siquiera ellos comprenden las implicancias de su actividad diaria".

Lo distintivo del CBR es que saca provecho de las similitudes entre descripciones de casos previamente almacenados y descripciones del caso nuevo. En definitiva, las descripciones de donde se extraen las similitudes son las características relevantes que serán reconocidas como índices al momento de recuperar un caso. El caso más similar debe ser el punto de partida para construir la solución al nuevo problema. La similitud es un concepto central en la resolución de problemas con el CBR. Siempre se recupera el caso más similar, por lo tanto los sistemas CBR además de contar con la información almacenada se debe contar también con un método que reconozca la similitud entre los casos (Díaz, 2002).

En la terminología CBR, podemos definir un caso como una situación de un problema (Carrillo, 2007). En Bergmann (2005) se define al caso como: “...un fragmento contextualizado de conocimiento que representa una experiencia y que enseña una lección importante para conseguir los objetivos del razonador",27. En Peinado Gil (2008) los casos se clasifican en tres categorías: proverbiales ${ }^{28}$, son plantillas genéricas que resultan ser útiles para comenzar a resolver muchos problemas distintos, pero que carecen de información específica para precisar con exactitud la solución exacta a un problema particular; paradigmáticos ${ }^{29}$, muy específicos y con un gran nivel de detalle tanto en la descripción del problema concreto como en su solución, pero difíciles de reutilizar en problemas similares; por último las denominadas historias, proporcionan suficiente detalle sobre el problema y su solución, como los casos paradigmáticos, pero también resumiendo información más general sobre la resolución de un tipo de problemas, como los casos proverbiales. Esto permite su reutilización en múltiples situaciones distintas.

Bergmann (2000) en la presentación introductoria del CBR hace conocer varias definiciones acerca de qué es el Razonamiento Basado en Casos:

Case-based reasoning is [...] reasoning by remembering. Leake, 1996

A case-based reasoner solves new problems by adapting solutions that were used to solve old problems. Riesbeck \& Schank, 1989

Case-based reasoning is a recent approach to problem solving and learning [...] Aamodt \& Plaza, 1994

Case-based reasoning is both [...] the ways people use cases to solve problems and the ways we can make machines use them. Kolodner, 1993

\footnotetext{
${ }^{27}$ Un caso es una "contextualized piece of knowledge representing an experience that teaches a lesson fundamental to achieving the goals of the reasoner"

${ }^{28}$ Según el diccionario en línea de la RAE significa, entre otros, "Muy notorio, conocido de siempre, consabido de todos".

${ }^{29}$ Según el diccionario en línea de la RAE significa, entre otros, "Ejemplo o ejemplar".
} 
Una definición clásica de la metodología CBR es: "Un razonador ${ }^{30}$-quien razonabasado en casos resuelve problemas usando o adaptando soluciones de viejos problemas",31. Watson (1999) hace notar que esta definición nos dice "lo que hace" un razonador basado en casos y no "cómo hace lo que hace". Watson, en el artículo citado, analiza cuatro aplicaciones -denominadas por los autores de las aplicaciones como CBR-donde verifica que cada una emplea distintas tecnologías en la implementación de los sistemas CBR, esta verificación le permite concluir que el paradigma CBR es una metodología y no una tecnología, consecuentemente el CBR no adscribe a ninguna tecnología específica.

\subsubsection{El ciclo CBR}

El ciclo CBR se entiende a partir de poner en consideración un nuevo problema que se compara con los casos en la base de casos, uno o más casos similares son recuperados. Una solución sugerida por los casos comparados es entonces reutilizada y luego repasada para verificar su éxito. La reutilización se comprende como un proceso de readecuar la solución obtenida de la base de casos a la solución del nuevo problema. La solución tendrá que ser revisado para producir un nuevo caso para luego ser retenido.

El CBR es descrito por el llamado "ciclo CBR"; este ciclo comprende cuatro actividades (las cuatro Res):

1: Recuperar (Retrieve) casos similares al problema descrito;

2: Volver a usar $\left(\right.$ Reuse $\left.^{32}\right)$ la solución sugerida por un caso similar;

3: Repasar (Revise) o adaptar la mejor solución ajustándolo al nuevo problema;

4: Conservar (Retain) la nueva solución una vez que ha sido confirmada o validado.

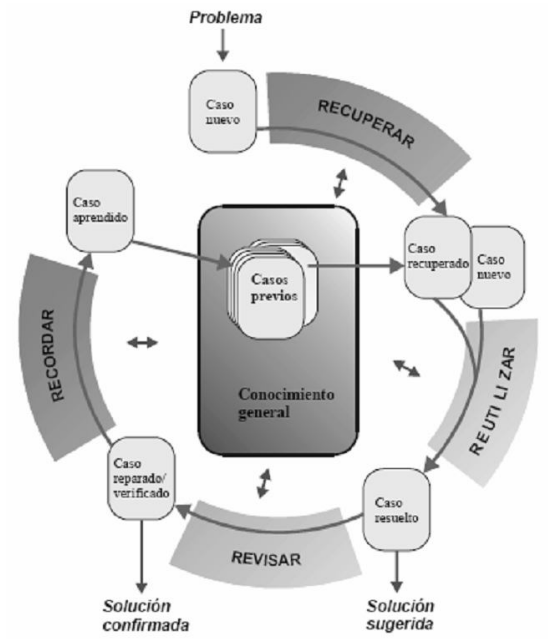

Figura $\mathrm{N}^{\mathrm{o}}$ 4: el ciclo $\mathrm{CBR}^{33}$

\footnotetext{
${ }^{30}$ Reasoner, sustantivo. 1. One who reasons. En: http://en.wiktionary.org/wiki/reasoner (Revisado 31/03/09).

31 "A case-based reasoner solves problems by using or adapting solution to old problems."

${ }^{32}$ La noción de la palabra "reuse" en inglés está relacionada a utilizar de nuevo sobre todo en una manera diferente; o utilizarlo después de reprocesamiento. En: http://www.merriam-webster.com/netdict.htm

${ }^{33}$ Esquema extraído de Carrillo (2007).
} 
Estas cuatro actividades se consideran, desde la perspectiva de Watson (1999) como una metodología porque son un "Un conjunto organizado de principios que guían la acción para tratar de "manejar" (en el sentido amplio) situaciones problemáticas del mundo real".

En la etapa de recuperación se debe considerar la existencia previa de una representación de los casos que normalmente comprende (Watson, 2000): el problema que describe el estado del mundo cuando ocurrió el caso, la solución la cual se manifiesta como la solución derivada de ese problema, y/o los resultados que describen el estado del mundo después de que el caso ocurrió. Para la representación de los casos se puede utilizar una variedad de formalismos de representación, sin embargo para decidir lo que debe ser representado en los casos se debe tomar en cuenta según Watson (2000) citando a Kolodner: la funcionalidad y la facilidad de adquisición de la información representada en el caso.

La indexación de los casos consiste en asignar índices a los casos para facilitar su recuperación. Se debe utilizar un índice de casos o una función de similitud o una combinación de ambos. Se pueden agrupar los casos con problemas similares entre sí, para evitar tener que realizar en esta etapa una búsqueda lineal exhaustiva sobre todos los casos de la base de casos. Las funciones de similitud sirven para comparar dos problemas y obtener un valor numérico que refleje lo similares que son, lo que permite escoger el caso o los casos más adecuados para resolver un problema dado. También es posible anidar varias etapas de recuperación, una tras otra, para refinar la búsqueda, usando índices de casos o funciones de similitud más precisas en cada iteración.

La etapa de adaptación debe realizarse cuando los casos recuperados no son aplicables directamente para la solución del problema. Dado el problema a resolver y uno o más casos recuperados, se debe generar una solución candidata que resuelva dicho problema. A menudo muchos sistemas realizan una adaptación trivial, que consiste en reutilizar directamente la solución de uno de los casos recuperados, dejando el éxito del proceso en función de los resultados de la etapa de evaluación. Otra opción es realizar una adaptación manual, dejando que sea el usuario el que genere la nueva solución usando para ello las soluciones recuperadas. En Díaz (2002) se lee que la etapa de "adaptación se obvia en muchos sistemas, o se deja en manos de los usuarios debido a que requiere modelos del dominio más elaborados, y en cierto modo va en contra del espíritu del CBR que aboga por aliviar los procesos de adquisición del conocimiento".

La etapa de evaluación consiste en verificar si la solución candidata es una solución válida para el problema a resolver. Normalmente el mecanismo de evaluación debe ser ajeno al sistema CBR, pudiendo actuar como evaluador un ser humano experto o un sistema informático externo.

Finalmente la etapa de aprendizaje consiste en decidir si el problema resuelto y su solución merecen figurar en la base de casos, si así es se añade como un nuevo caso. Por norma general aumentar automáticamente la base de casos mejorará el rendimiento del sistema, pero es importante asegurarse de que estos casos son correctos y suficientemente distintos a los ya existentes, teniendo en cuenta el volumen y la organización actual de la base de casos. Se pueden usar técnicas complementarias a este aprendizaje, como el "olvido" de casos que ya no tengan la relevancia que tenían en la base de casos inicial. De nuevo esta etapa puede dejarse en manos del usuario, si no es posible dar con heurísticas adecuadas que permitan enriquecer adecuadamente la base de casos.

En este ciclo, en la actualidad, rara vez se produce sin la intervención humana. Por ejemplo, muchas herramientas CBR actúan principalmente en la recuperación de casos y los sistemas de reutilización. La revisión del caso (es decir, la adaptación) a menudo llevan 
a cabo por los administradores de la base de caso. Sin embargo, no debe ser visto como una debilidad del CBR que fomenta la colaboración humana en apoyo a la decisión (Watson, 2000).

\subsubsection{El problema del marco referencial}

El proceso de resolución de problemas desde la perspectiva del $\mathrm{CBR}$, supone que un agente -usuario-, a partir de problemas conocidos, semejantes a un problema actual, puede readecuar las soluciones previas para solucionar el nuevo problema. Por ejemplo, un docente que tiene como problema abordar la enseñanza del tema los "números binarios" para inferir una solución adecuada debe: a) acceder a una biblioteca de casos; b) el sistema debe buscar y encontrar, de acuerdo a los términos de búsqueda, uno o varios casos que tratan como problema didáctico la enseñanza de números binarios; c) los casos encontrados deben ser readecuados por el docente para inferir una solución a su problema actual. La pregunta es ¿cómo, el docente, a partir de escenarios distintos y pasados puede inferir una nueva solución didáctica para un escenario actual?

Los supuestos sobre la naturaleza del mundo que sostienen el CBR son la regularidad y las recurrencias del mundo. Bajo estas premisas la solución de problemas actuales consiste en readecuar problemas pasados, que es lo mismo decir que el CBR da cuenta de la evolución de escenarios pasados a escenarios actuales. Entonces, nuevamente, cómo se explica desde el CBR que se pueda predecir una solución a partir de un estado de cosas la evolución de ese estados de cosas (Gutierrez, 2005). Este problema se conoce como el problema del marco. Según Silenzi (2007) "[...] el problema de marco intenta describir todas las precondiciones (o supuestos) necesarios, como así también todas las posibles consecuencias, que anteceden y se derivan, respectivamente, de la acción del agente”.

El escenario en un proceso de enseñanza es una triada donde:

"Hay una persona, $\mathrm{P}$, que posee cierto contenido, $\mathrm{C}, \mathrm{y}$ trata de transmitirlo o impartirlo a una persona, $\mathrm{R}$, que inicialmente carece de $\mathrm{C}$, de modo que $\mathrm{P}$ y $\mathrm{R}$ se comprometen en una relación a fin de que R adquiera C." Fenstermacher (1989:151)

La actividad principal de la enseñanza es el perfeccionamiento de la actividad de estudiar, esto es, "la tarea del enseñante incluyen instruir acerca de los procedimientos y exigencias del rol del estudiante..." (Fenstermacher, 1989:155). En esta triada los lugares que ocupan los docentes y los alumnos están delimitados por las funciones específicas de cada uno. A partir de la resignificación de sus saberes previos el alumno construye sus conocimientos y sus estrategias de aprendizaje, el docente construye y reconstruye las condiciones de aprendizaje de los alumnos (Boggino, 2004). La enseñanza debe transmitir conocimientos. Pero el conocimiento, de acuerdo a Chevallard (1991), sufre lo que él llama "transposición didáctica", o conversión didáctica, este proceso para que sea de utilidad debe tener la vigilancia epistemológica por parte de los expertos de la disciplina.

El Conocimiento Didáctico del Contenido, CDC, (Botia, 1993), que refiere aquellos aspectos del contenido, cuyo conocimiento es relevante para la enseñanza, se construye con y sobre el conocimiento del contenido, es decir que los profesores deben desarrollar un conocimiento específico: como enseñar su materia específica. La forma del CDC integra "1. Conocimiento de la comprensión de los alumnos: modo cómo los alumnos aprenden un tópico disciplinar, sus posibles malos entendidos y grados de dificultad; 2) Conocimiento de los materiales curriculares y medios de enseñanza en relación con el contenido y alumnos; 3) Estrategias didácticas y procesos instructivos: representación para la enseñanza de tópicos particulares y posibles actividades/tareas; 4) Conocimiento de los propósitos o 
fines de la enseñanza de la materia: concepción de lo que significa la enseñanza de un determinado tema (ideas relevantes, prerrequisitos, justificación, etc.)".

En el marco de referencia el docente debe considerar condicionantes variables que inciden en la inferencia de una nueva solución a partir de soluciones pasadas. En la figura de $\mathrm{N}^{\mathrm{o}} 5$ se señalan algunos:

La enseñanza $\left\{\begin{array}{l}\text { Está condicionada por } \\ \end{array} \begin{cases}\checkmark & \text { Tipos de contenidos } \\ \checkmark & \text { La diversidad en el aula } \\ \checkmark & \text { Estructura cognitiva y } \\ \text { conocimientos previos de los } \\ \text { alumnos }\end{cases}\right.$

Figura $\mathrm{N}^{\mathrm{o}}$ 5: condicionantes de la enseñanza

\subsubsection{Tipo de contenidos}

Boggino (2004), para comprender qué conocimientos tienen las áreas curriculares, asumiendo los aportes de Piaget, señala tres tipos de conocimientos: el conocimiento físico, el conocimiento lógico-matemático y el conocimiento social.

a) "Los objetos físicos -empíricos-, siguiendo a Boggino (2004:49), tienen entidad propia y son, por lo tanto, independientes de la acción del sujeto. Su fuente es exógeno pero es el sujeto quién construye y reconstruye el conocimiento, aproximándose paulatinamente y reduciendo las distancias con lo real, aunque nunca lo alcance plenamente". En Buch (1999) podemos acceder a una metodología reconocida en la Educación Tecnológica como "Análisis del objeto tecnológico", que nos permite a través del análisis morfológico, análisis funcional, análisis referencial y análisis de la finalidad del objeto tecnológico, acercarnos al conocimiento de la computadora desde la perspectiva del estudio del hardware.

b) El conocimiento lógico-matemático "se estructura, continuando con Boggino (2004:49), con relaciones lógicas y matemáticas inventadas por el sujeto y que sólo existen en su 'mente'. Por lo tanto su fuente es endógena y se trata de un objeto 'puro' que no pertenece al mundo físico". Existe una estrecha relación entre los algoritmos matemáticos y los algoritmos de computación. Denning (2005) cuando examina los criterios para definir si computación es una ciencia dice que "Hoy, computación, ingeniería, matemática, arte y todas sus combinaciones son agrupadas bajo el nombre "ciencia de la computación". Barchini (2004) escribe que los métodos de la Informática, "su núcleo teórico está constituido por una teoría lógico-matemática, la teoría de la Computabilidad y algunas de sus teorías supuestas son del campo de la matemática pura y aplicada y de la lógica...”.

c) El conocimiento social, retomando a Boggino (2004:50), "sólo puede ser comprendido en el marco de una trama de relaciones significativas, a partir de las cuales, las acciones de los alumnos, su lugar social e institucional y sus actitudes, cobran sentido y pueden comprenderse.... No puede comprenderse en forma aislada sino todo lo contrario, conlleva pensar relaciones globales con una fuerte interdependencia". La computadora se convirtió en un objeto tecnológico de posición ubicua en el entramado social, desde esta perspectiva el agente deben tener en cuenta algunos contenidos como: a) Ergonomía; b) Las computadoras y el medo ambiente; c) El uso de la computadora en distintos ámbitos de la industria, en la educación y en la nueva configuración de la cultura infantil (Buckingham, 2008). 


\subsubsection{La diversidad en el aula}

Lograr el conocimiento significativo por parte del alumno implica que el docente debe conocer lo diverso y lo propio de cada alumno y respetar las diferencias individuales. El docente debe romper con la ilusión de que es posible enseñar con un solo disparador para toda una población escolar. Se debe ajustar los objetivos y las estrategias didácticas a las reales posibilidades de aprender de cada alumno (Boggino, 2004).

Desde la psicología cognitiva, se habla de estilos cognitivos; las investigaciones en esta disciplina ha indicado que las personas exhiben importantes diferencias individuales en los estilos de procesamiento cognitivo que adoptan al momento de resolver problemas o en otras actividades similares de toma de decisiones (Liu, 1999).

\subsubsection{Estructura cognitiva y conocimientos previos de los alumnos}

Novak (1982:24) escribe que el término estructura cognitiva para Ausubel ${ }^{34}$ significa "el $^{-}$ almacenamiento de información en el cerebro altamente organizado, con conexiones formada entre elementos antiguos y nuevos que dan lugar a una jerarquía conceptual en la que los elementos de conocimiento menos importantes están unidos a (incluidos en) conceptos más amplios generales e inclusivos. De esta forma, la estructura cognitiva representa un sistema de conceptos organizados jerárquicamente, que son representaciones que el individuo se hace de la experiencia sensorial." Consecuentemente se supone que cualquier elemento de una estructura cognitiva es idiosincrásico, los conceptos de un individuo, sus significado, no son exactamente a la de otro individuo. Esto no implica que un sujeto no pueda comunicarse con otro sujeto. A partir de esta noción de estructura cognitiva, se deriva que para enseñar nuevos conceptos se debe conocer los conceptos que sabe un sujeto. El acople de conceptos viejos con conceptos nuevos supone un aprendizaje significativo.

Según Freiría (1996:334) las hipótesis básicas de la Psicología Genética son también mentalistas ${ }^{35}$, esto supone "la existencia de forma de construcción de conocimiento construidas por estructuras cognoscitivas, sistemas de acciones no observable de acciones mentales".

Las posibilidades de conocimiento de un sujeto están mediatizadas por su estructura cognoscitiva, esto implica que "Sin esquemas y estructuras cognoscitivas previas y sin actividad organizadora de la realidad los hechos no son significativos para los niños" (Boggino, 2004:25). Estas estructuras marcan los límites de lo que un alumno puede aprender o no aprender. Boggino (2004) habla de la distancia cognitiva, un concepto que debe ser tomada en cuenta por el docente al momento de enseñar; significa la tensión entre la complejidad de los contenidos -desarrollado en los párrafos precedentes-, el propio estilo de enseñar del docente y la real posibilidad de aprender del alumno, esto es: que tenga una estructura cognoscitiva que permita su asimilación a sus esquemas y conocimientos previos.

\footnotetext{
34 David Paul Ausubel nació en Brooklyn, New York el 25 de octubre de 1918, hijo de una familia judía emigrante de Europa Central. Estudió medicina y psicología en la Universidad de Pennsylvania y Middlesex.

${ }^{35}$ Freiría (1996:334) dice además que otras de las hipótesis básica de la Psicología Genética es el interaccionismo y el constructivismo.
} 


\subsection{Antecedentes en el uso de del CBR para bases de casos}

La School of Information Science \& Learning Technologies de la University of MissouriColumbia presenta una propuesta de una base de casos relacionados a la integración de tecnología en el aula denominada Knowledge Innovation for Technology in Education $\left(\mathrm{KITE}^{36}\right)$. A partir de (Moore, 2007) y de las FAQ del sitio KITE se describe brevemente las características sobresalientes del repositorio ${ }^{37}$.

En principio KITE define un caso como “... una historia. Se trata de información demográfica sobre el profesor entrevistado y sobre los estudiantes en situación de aprendizaje, la información contextual sobre la experiencia y la información sobre la experiencia de integración de las tecnologías. A los profesores se les pide que compartan la actividad de aprendizaje, la tecnología que utiliza, el papel de los estudiantes en la actividad, el rol del profesor en la actividad, las razones para utilizar la tecnología y otras informaciones sobre el caso".

Es un repositorio de conocimiento con cerca de 1.000 historias o casos que describen las experiencias de la vida real de los docentes en servicio. El repositorio de conocimiento KITE es un sistema CBR que incorpora una biblioteca de casos que hablan sobre la integración de la tecnología en la enseñanza. Cada caso contiene una descripción del problema, además de una solución y/o el resultado. El proceso de conocimiento y razonamiento utilizado por un profesor para resolver el problema no se registra, pero está implícito en la solución.

$\mathrm{Al}$ intentar resolver un problema actual, el usuario busca en KITE casos similares en la base de casos. Los casos que son recuperados se utilizan para sugerir una solución, que será reutilizado y probado para la resolución del problema actual. Si es necesario, la solución será revisada. Por último, el problema actual y la solución final se conservan como parte de un nuevo caso.

En el marco de un nuevo problema, los usuarios cuando reutilizan un caso recuperado, deben ser capaces de centrarse en identificar las diferencias entre el caso recuperado y el problema actual; deben identificar las partes del caso reutilizado que se pueda transferir al problema actual. Por lo general, la mayoría de los usuarios de bases de datos prueba utilizar una solución directamente de los casos recuperados. Sin embargo, la revisión de las soluciones para adaptarse a la problemática actual es un importante componente de la solución de problemas. Además, la revisión de los casos que reflejan los resultados de éxito proporciona una oportunidad para que los usuarios aprendan del fracaso.

El proceso en el CBR no será eficaz sin la retención o memorización de la nueva solución. Para conservar un nuevo caso, el usuario debe determinar la información a recordar y el formato; cómo indexar el caso para su futura recuperación; y almacenar el caso en la biblioteca de casos. Este proceso permite al usuario recuperar todos los casos existentes y nuevos que se pueden comparar y sintetizada para uso futuro.

Los casos KITE son historias recogidas de los maestros en actividad. Los profesores provienen de diversas ubicaciones en los EE.UU. Un "explorador de conocimiento" o el entrevistador se reúnen con el profesor y analiza la experiencia de integración de la tecno-

\footnotetext{
${ }^{36} \mathrm{http}: / /$ kite.missouri.edu/

${ }^{37}$ Las bases de casos nombradas en los diversos artículos citados en esta tesis no se ofrecen como antecedente por dos razones: a) no se pueden visitar para analizar sus características, por ejemplo, su interfaz de búsquedas, modo de almacenamiento de los casos, etc., b) sus temáticas no son similares a la temática de la tesis presentada. En Watson y Marir, F. (2000) se puede ver un resumen de bases de casos bajo la metodología CBR.
} 
logía. La entrevista se transcribe y se organiza, se indexada para su colocación en el repositorio de conocimiento.

Lo importante es que los docentes, según (Moore, 2007), utilicen KITE como un recurso, y también lo usen para el último paso en el proceso de CBR, que es la creación de nuevas soluciones que se pueden recuperar. El proceso CBR estimula la reflexión en la acción haciendo que el alumno examine las diferencias y similitudes de un caso para una solución particular. Esta estrategia mejora las habilidades en la resolución de problemas, lo cual es importante para adaptar las tecnologías a situaciones que los profesores encontrarán en el aula.

Desde el punto de vista pedagógico KITE está basado en la creencia de que el aprendizaje es eficaz cuando se sitúa en escenarios reales, donde el alumno realiza sus actividades. Esta pedagogía puede ser descrita como Escenarios Basados en Objetivos que es esencialmente una simulación de un evento. Durante la simulación de un evento el objetivo del alumno es llevar a cabo una misión o una tarea asociada con su rol en un escenario realista donde se encuentra inmerso el alumno.

Para lograr este objetivo, el alumno necesita adquirir habilidades particulares y conocimientos, que es cuando y donde el aprendizaje se lleva a cabo. Un EBO sirve tanto para motivar a los alumnos como para darles la oportunidad de "aprender haciendo".

El repositorio KITE se utiliza como un eje para integrar actividades de enseñanza en el medio ambiente. Algunas de las actividades son las siguientes:

- Demostrar cómo varios estándares de tecnología se pueden manifestar.

- Analizar los múltiples casos dados en una situación de instrucción.

- Sintetizar las mejores prácticas y lecciones aprendidas dado un contexto de instrucción.

- Seleccionar los medios de comunicación para dar a conocer los resultados del aprendizaje previstos.

- Desarrollar planes de estudio basados en la misma línea de los casos.

- Planificar una unidad de aprendizaje para una situación dada.

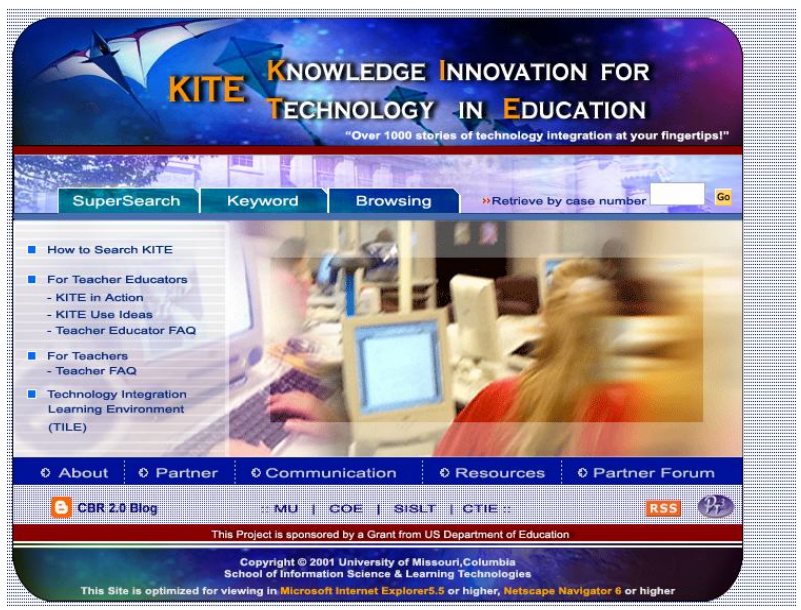

Figura $\mathrm{N}^{\mathrm{o}}$ 6: pagina principal de KITE 


\section{PARTE III: METODOLOGÍA}

\subsection{Introducción}

En este apartado se define la noción de caso y se muestra la secuencia metodológica para diseñar la base de casos. La secuencia comienza con las entrevistas semiestructuradas, continúa con el diseño de la ontología, la construcción de un instrumento para las entrevistas estructuradas, la construcción de la base de casos y, finaliza, con el uso de algunos principios de la metodología CBR donde se establece la relación de la base de casos con los usuarios.

El diccionario en línea de la Real Academia Española dice que un caso es un "Suceso, acontecimiento" o un "Relato popular de una situación, real o ficticia, que se ofrece como ejemplo". Desde la utilización de los casos como método de enseñanza Wassermann (2006:19) escribe que "Los casos son instrumentos educativos complejos que revisten la forma de narrativa... por naturaleza son interdisciplinarios". Los casos son relatos escritos, se caracterizan por tener una "gran idea", tienen personajes y deben tener un dilema. Además se le pide que sea verosímil, provocador, conciso, cercano y ambiguo (Wassermann, 2006).

Para poder aplicar el método CBR se necesita una base de casos (Díaz, 2002). Por lo general es mejor disponer de una base de casos muy poblada que poco poblada, aunque los casos deben ser escogidos con cautela, ya que demasiados casos similares y mal organizados sólo servirán para hacer más costosa la búsqueda de los pocos que sean necesarios para el razonamiento (Peinado Gil, 2008).

El tipo de sistema CBR que se propone en esta tesis se sustenta en casos de tipo textual; estos sistemas se caracterizan por el nivel de intervención humana y porque las experiencias son almacenadas a semejanza de texto (Watson, 2000). "Los textos pueden ser utilizados directamente como casos si se consigue extraer la información contenida en el lenguaje natural y estructurarla adecuadamente" (Guzmán Luna, 2010). Según Carrillo (2007), de los sistemas CBR textuales "Su conocimiento se extrae de una colección de documentos de texto realizados por expertos que solucionaron problemas previos. Su misión posterior es la de soporte, siendo un subconjunto de los primeros con problemática propia de extracción de conocimiento de documentos de texto sin formato ni estructura". En este proyecto tecnológico los expertos que proveen los casos de enseñanza para la base de casos son docentes que utilizan las herramientas y recursos informáticos en las escuelas medias y técnicas de Neuquén para la enseñanza de temas curriculares.

\subsection{Secuencia de la metodología}

a) Entrevistas iniciales semiestructuradas.

El primer aspecto de la metodología son las entrevistas que el autor realizó en el Centro Provincial de Enseñanza Media del Neuquén $\mathrm{N}^{\circ} 44$ a dos docentes que dictan el taller de Informática en los cursos iniciales -desde primero a tercer año-. Las preguntas realizadas sirvieron de guía para que los docentes narraran las metodologías que ponían en juego en el taller para enseñar temas curriculares utilizando tecnología informática. Al iniciar las entrevistas se les informó las características y el objetivo general de las mismas. Luego se les sugirió que eligieran aquellos casos de enseñanza donde percibieran que estaban empleando una estrategia o método medianamente exitoso y, como docentes, se sintieran cómodos para su narración. Al finalizar la narración de cada caso se les solicitó que sugirieran un conjunto de términos para el diseño de la ontología de casos y como palabras claves para el diccionario de la base de casos. Los docentes narraron tres casos de enseñanza cada uno. 
b) Diseño y construcción de la ontología de casos de enseñanza: análisis de los casos recuperados.

El segundo aspecto, fundamental para esta tesis, es el análisis de los casos recuperados en las primeras entrevistas semiestructuradas con el propósito de comenzar el diseño y construcción de la ontología de casos. La ontología se desarrollo con la metodología Methontology -ver la construcción de la ontología en el apartado $\mathrm{N}^{\circ} 4-$, posteriormente se implementó con lenguaje ontológico usando el editor Protégé -ver anexo B.

c) Construcción de la planilla de entrevista usando la ontología de casos de enseñanza.

El tercer aspecto, importante desde una perspectiva operativa, es el diseño de un instrumento para las entrevistas futuras. A partir de la ontología de casos de enseñanza se diseño una planilla -ver el desarrollo de la planilla en el apartado 3.3- que tiene como función la de soportar las entrevistas a los docentes.

d) Entrevistas estructuradas

La planilla se utilizó para realizar nuevas entrevista con el propósito de añadir, cambiar y eliminar términos en la versión actual de la ontología y de sumar casos al conjunto de casos ya obtenidos. También, con los nuevos casos, se mejoraron detalles de la planilla de entrevistas, por ejemplo se mejoraron la redacción de las preguntas, se eliminaron ítems, se agregaron nuevos ítems, etc. Con este instrumento se realizaron tres entrevistas donde los docentes narraron dos casos de enseñanza cada uno. Se pueden ver las entrevistas en el Anexo C; lo que se muestra es una impresión de la base de casos.

e) Elección del software para diseñar e implementación de la base de casos.

Para la elección del software se tuvo en cuenta las siguientes características: a) facilidad para administrar bases de datos documentales, textos; b) longitud variable de los campos; c) creación de un índice donde figure cualquier campo e incluso por partes de campos; d) que contenga un lenguaje de consulta pensado exclusivamente para satisfacer las necesidades de recuperación de la información utilizando los conectores lógicos similar a los utilizados en las interfaces de los buscadores Web; e) que las interfaz sea en idioma castellano; f) que el software sea de distribución gratuita; g) que potencialmente puede emigra sus bases de datos a la tecnología Web. El software seleccionado fue el Winisis de la familia de los sistemas denominados IRS (Information Retrieval System).

f) Diseño de la estructura de los registros de la base de casos usando el conocimiento obtenido en la ontología de casos de enseñanza.

Una vez elegido el software se definieron los atributos que deben tener los registros de la base de casos. Un caso se puede estructurar de varias maneras. Frecuentemente sólo se subdivide en un problema y una descripción de la solución, pero el conocimiento adicional podría ser necesario dependiendo del tipo de reutilización previsto (Bergmann, 2005). Bergmann (2005) propone, por ejemplo, una estructura consistente para los casos, citando a Kolodner, alrededor de las siguientes cinco partes: (i) una situación y su objetivo, (ii) la solución y, a veces, los medios que se derivan de ellos, (iii) el resultado de su realización, (iv) la explicación de los resultados, y (v) lecciones que pueden que aprender de la experiencia. En los enfoques tradicionales se pueden clasificar en tres categorías principales la estructura de un caso: presentaciones vectoriales, representaciones estructuradas y las representaciones textuales. Bergmann (2005) describe cómo se puede representar los casos textuales. Se descompone el texto que forma parte de un caso en entidades de información (IE). Una IE es una palabra o una frase contenida en el texto que es relevante para determinar la reutilización del episodio capturado en el caso (paso dos en el ciclo CBR). 
Dado un vocabulario de palabras o frases pertinentes, los caso pueden ser extraídos a partir de las Entidades de Información, lo que permite la adquisición de los casos ser automatizados.

En este proyecto tecnológico se utilizó como guía para el diseño de los registros el conocimiento obtenido de la ontología. Las entidades de información que se tomo en cuanta para el diseño de la base de casos tienen, por un lado, la finalidad de aproximarse a la "re creación del ambiente" donde el caso se implementó para la resolución de un problema de enseñanza y, por el otro, recuperar los atributos comunes de los casos para alimentar el índice de búsqueda. Para el diseño de los casos se tomo en cuenta: el autor (nombre y correo electrónico), característica temática del caso (tipo de caso, título, problema que resuelve el caso, objetivo didáctico del caso, evaluación del caso, narración del caso, materia curricular del caso, tipo de evaluación utilizada con los alumnos, palabras claves) y ambiente donde se desarrolla el caso (acceso a Internet, organización del tiempo, agrupamiento de los alumnos, espacio físico, institución, material didáctico).

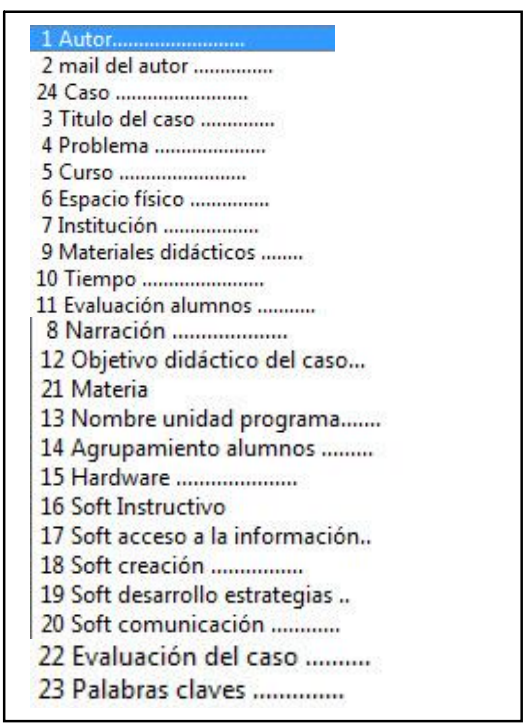

Figura $\mathrm{N}^{\mathbf{0}}$ 7: nombre de los campos de la base de casos

\begin{tabular}{|l|l|l|}
\hline \multicolumn{1}{|c|}{ Nombre del atributo } & Concepto donde es definido & Tipo de valor \\
\hline Autor & Casos de enseñanza & String \\
\hline Evaluación de los alumnos & Casos de enseñanza & String \\
\hline Agrupamiento de alumnos & Casos de enseñanza & String \\
& & \\
\hline Curso & Casos de enseñanza & String \\
\hline Espacio físico & Casos de enseñanza & String \\
\hline Evaluación_del_caso & Casos de enseñanza & String \\
\hline Institución & Casos de enseñanza & String \\
\hline $\begin{array}{l}\text { Instrumento_de_evaluación } \\
\text { alumnos }\end{array}$ & Casos de enseñanza & String \\
\hline Materiales didácticos & Casos de enseñanza & String \\
\hline Objetivos didácticos del caso & Casos de enseñanza & String \\
\hline Tiempo & Casos de enseñanza & String \\
\hline Problema de enseñanza & Casos de enseñanza & String \\
\hline Caso & Casos de enseñanza & String \\
\hline Titulo del caso & Casos de enseñanza & String \\
\hline E-mail del autor & Casos de enseñanza & String \\
\hline Software instructivos & Software & String \\
\hline Software acceso a la información & Software & String \\
\hline Software creación & Software & String \\
\hline Software desarrollo de estrategias & Software & String \\
\hline
\end{tabular}

(Continua en la página siguiente) 


\begin{tabular}{|l|c|l|}
\hline Software comunicación & Software & String \\
\hline Hardware & $\begin{array}{c}\text { Contenido informático de los } \\
\text { casos }\end{array}$ & String \\
\hline Materia & Materia del nivel medio & String \\
\hline Nombre unidad programa & Materia del nivel medio & String \\
\hline Narración del caso & Casos de enseñanza & String \\
\hline Palabras claves & & String \\
\hline
\end{tabular}

Tabla No 2: campos de la base de casos más detallado

g) Construcción de la base de casos usando el software Micro Isis: diseño de la hoja de entrada usando el conocimiento de la ontología de casos para la técnica Pick-List.

Diseñar la base de casos con el software Micro Isis implica una secuencia de cuatro pasos:

1) Definir los campos de los registros usando la Tabla de definición de campos.

2) Definir la hoja de entrada de datos. Aquí se aplica a los datos la técnica pick-lists. Esta técnica consiste en desplegar una lista con distintas opciones de valores/términos para cada campo en particular durante el ingreso de datos. Para definir los valore/términos de cada dato se utiliza el conocimiento obtenido en la ontología. Por ejemplo el campo tipo de caso se define a partir de cuatro términos de entrada: Informática como recurso didáctico, Informática como soporte de materiales, Alfabetización informática y Videojuegos. Cuando se ingresa un caso, el docente, debe optar por uno de los términos del campo tipo de caso. El caso ingresado, en el índice de la base de casos, forma parte del conjunto de casos con el mismo término. Los casos están definidos en cuatro conjuntos de casos.

3) Definir la hoja de impresión, aquí se establece la vista que tienen los casos en la pantalla o en la impresión en papel.

4) Definir los datos que forman parte del índice -archivo invertido- que utiliza el Micro Isis para las búsquedas de los casos; se utiliza la herramienta tabla de selección de campos.

h) Formalización de la metodología CBR para la interacción de los docentes en el uso de la base de casos.

La formalización de la metodología CBR para la interacción de los docentes con la base de casos se muestra en la figura $\mathrm{N}^{\circ} 7$. Se recuerda que el proceso CBR convencional se compone de cuatro etapas: Recuperar (Retrieve) casos similares al problema descrito; Volver a usar (Reuse) la solución sugerida por un caso similar; Repasar (Revise) o adaptar la mejor solución ajustándolo al nuevo problema; Conservar (Retain) la nueva solución una vez que ha sido confirmada o validado. El docente expresa un problema de enseñanza a la interfaz de búsqueda de la base de casos a través de una expresión de búsqueda -ver parte IV-; la base de casos muestra al docente un conjunto de casos similares; el docente hace una adaptación de los casos más similares obteniendo un caso para utilizar en la resolución del problema de enseñanza; el caso obtenido es verificado en el aula con los alumnos; el caso, con los aprendizajes obtenidos, se almacena en la base de casos y se cierra el ciclo CBR. 


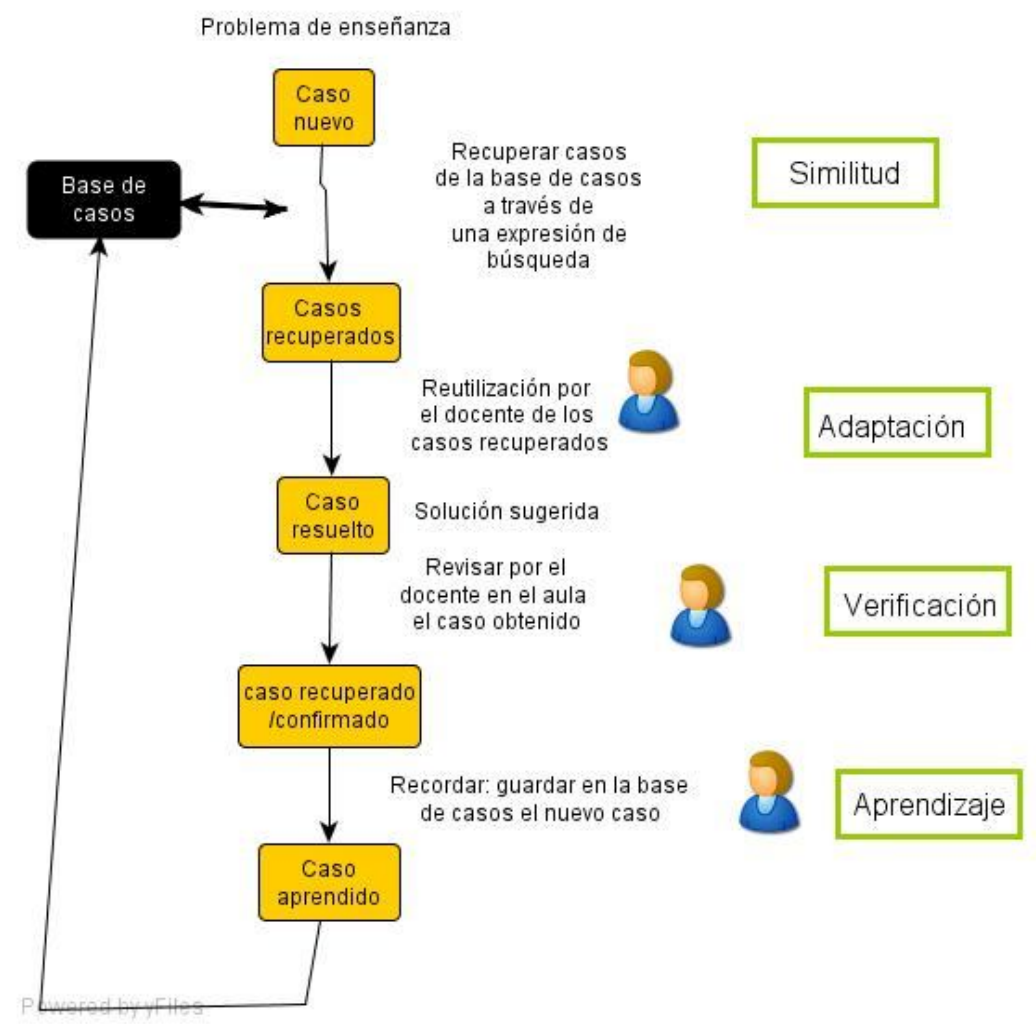

Figura $\mathrm{N}^{\circ}$ 8: el ciclo CBR adaptado a los casos de enseñanza

\subsection{Planilla de registro de casos}

El instrumento de indagación consta de dos partes. En la primera se explica el significado de cada interrogación que se le hace al docente. La segunda parte se presenta el instrumento para ser utilizado en la entrevista.

1. Autor del caso: apellido y nombre del autor del caso.

E-mail del autor:

2. Título del caso: cuando el autor escriba el título del caso, se sugiere resaltar términos relevantes para usarlos en la indexación del caso.

3. Tipo de caso: el autor del caso debe elegir uno de los nombres que caracteriza el tipo de caso.

\subsection{Informática como recurso didáctico:}

Estas narraciones suponen que los docentes harán uso de técnicas y herramientas informáticas para resolver problemas de las diferentes disciplinas y elaborar diferentes productos que surjan de las actividades propias del aula; entre las herramientas incluye el uso de procesadores de texto, editor de representaciones, administrador de bases de datos, editores de páginas Web, planillas de cálculo, lenguaje de programación, browser, programas de comunicación, etc.

3.2 Informática como soporte de materiales:

El contenido de estas narraciones usan los productos informáticos como mediador del conocimiento. Aquí el docente, como responsable de la selección de contenidos y de adecuarlos a la estrategia didáctica, elige distintos materiales digitales para conseguir 
sus objetivos curriculares. Entre los materiales educativos informáticos encontramos: tutoriales, constructores de mapas conceptuales, editores de gráficos, de ejercitación práctica, libros electrónicos, enciclopedias temáticas, revistas electrónicas, páginas Web, juegos lógicos, de aventura, de simulación, etc.

\subsection{Alfabetización informática:}

Las narraciones pueden contener, por un lado, como objeto de estudio a la computadora -objeto físico-. Los temas de estas narraciones pueden ser la organización física y lógica de la computadora; incluye el análisis de los componentes y de los materiales implicados; sus resultados en el nivel morfológico y de perfomance. La característica principal de estos casos es que están vinculados a la materia o taller de nivel medio "Taller de informática" o "Informática" o "Computación".

\subsection{Videojuegos y su potencialidad educativa:}

Las narraciones contienen el video juego como soporte de la enseñanza de contenidos.

4. Objetivo del caso didáctico:

Aluden a los aprendizajes que se esperan de los alumnos con la enseñanza de los contenidos. Los objetivos se interpretan como una guía que orienta el camino, y no como estados a los que hay que llegar imperiosamente (Leliwa, 2008).

5. Curso: nivel escolar de los alumnos: $1^{\circ}, 2^{\circ}, 3^{\circ}, 4^{\circ}, 5^{\circ}$ (escuela media) y $6^{\circ}$ año (escuela técnica).

6. Contenido del caso: se debe señalar el o los conceptos que refiere al contenido temático del caso. Luego narrar alguna particularidad de los mismos. Aquí se define el tipo de software utilizado.

7. Problema que aborda el caso:

Narración de la descripción del problema didáctico que el autor del caso intenta resolver dentro del caso en forma sintética.

8. Solución del caso -narración-: la definición de caso propuesta por Kolodner dice: “Un caso es un fragmento contextualizado de conocimiento que representa una experiencia y que enseña una lección importante para conseguir los objetivos del razonador"

Tomando en consideración la definición anterior, en este ítem, se desea que el creador del caso narre el caso utilizando un lenguaje claro, preciso, evitando la redundancia para que sea entendido por los pares. Que ponga en evidencia la problemática y la solución (o soluciones) a dicha problemática, enfatizando los resultados en relación a los objetivos conseguidos. Se sugiere marcar aquellos términos sobresalientes de la narración para que formen parte del índice de los caso.

9. Evaluación de la aplicación del caso:

El docente debe evaluar su desempeño acerca de las decisiones metodológicas o estratégicas asumidas y de cuáles son los resultados obtenidos (Leliwa, 2008).

10. Descripción del ambiente de enseñanza/aprendizaje: Es el lugar donde el docente transmite lo que sabe. Refiere, además, a ámbitos donde las personas encuentran conocimientos, información, así como herramientas para construir el propio aprendizaje. Este ítem se divide en varios sub ítems: acceso a Internet, evaluación, organización del tiempo, agrupamiento de los alumnos, espacio físico, institución, material didáctico. 


\section{Evaluación:}

Remite al aprendizaje de los alumnos. La evaluación opera como un instrumento de control y verificación de los aprendizajes, tanto del proceso como del momento de la acreditación (Leliwa, 2008).

12. Materia de nivel medio: se debe escribir el nombre de la unidad del programa; el tema principal que trata la narración y los sub temas que pueda tener.

13. Observaciones: el autor puede narrar algunas experiencias adicionales o secundarias al caso que ayuden a mejora o enriquecer la transferencia de la experiencia del caso. Se sugiere narrar si las expectativas esperadas del caso fueron medianamente exitosas en relación a los objetivos propuestos o fueron medianamente un fracaso. Escribir algunos de los hechos que Ud. cree puede ayudar a entender este último punto.

14: Sugerencias de palabras claves: el docente en este ítem sugiere palabras claves significativas para almacenar en el diccionario de la base de casos.

Planilla:

1. Autor del caso:

\begin{tabular}{|l|l}
\hline Apellido: & Nombre: \\
\hline
\end{tabular}

E-mail:

2. Título del caso $^{38}$ :

3. Tipo de $\operatorname{caso}^{39}$ (marque con una $\mathrm{X}$ la descripción elegida):

\begin{tabular}{|l|l|l|l|l|l|}
\hline $\begin{array}{l}\text { Alfabetización in- } \\
\text { formática }\end{array}$ & $\begin{array}{l}\text { Informática como recurso } \\
\text { didáctico }\end{array}$ & $\begin{array}{l}\text { Informática como } \\
\text { soporte de materiales }\end{array}$ & $\begin{array}{l}\text { Videojuegos y } \\
\text { su poten- } \\
\text { cialidad } \\
\text { educativa }\end{array}$ \\
\hline
\end{tabular}

4. Objetivo didáctico del caso:

5. Curso (marque con una $\mathrm{X}$ la descripción elegida):

\begin{tabular}{|l|l|}
\hline $1^{\circ}$ & \\
\hline $2^{\circ}$ & \\
\hline $3^{\circ}$ & \\
\hline $4^{\circ}$ & \\
\hline $5^{\circ}$ & \\
\hline $6^{\circ}$ & \\
\hline
\end{tabular}

6. Contenido informático del caso:

a) Tema principal:

b) Software:

\begin{tabular}{|l|l|l|}
\hline Tipo de software & & Nombre \\
\hline Instructivos & & \\
\hline Acceso a la información & & \\
\hline Creación & & \\
\hline Desarrollo de estrategias & & \\
\hline Comunicación & & \\
\hline
\end{tabular}

\footnotetext{
${ }^{38}$ Resaltar los términos relevantes para usarlos como palabras claves en la biblioteca de términos.

${ }^{39}$ Los tipos de casos son mutuamente excluyentes. Es decir que un caso no puede pertenecer a otro "Tipo de caso".
} 
7. Problema que aborda el caso:

8. Solución del caso:

9. Evaluación de la aplicación del caso:

10. Descripción del ambiente de enseñanza/aprendizaje:

10.1 Acceso a la Internet:

\begin{tabular}{|l|l|l|l|}
\hline \multicolumn{1}{|c|}{ Servicio } & $\begin{array}{c}\text { Descripción del } \\
\text { servicio }\end{array}$ & Dirección & Dirección \\
\hline Sitio Web & & & \\
\hline FTP & & & \\
\hline Mail & & & \\
\hline Otro & & & \\
\hline
\end{tabular}

10.2 Agrupamiento de los alumnos:

10.2.1 Aula frontal:

10.2.2 Pequeños grupos:

10.2.3 Foro:

10.2.4 Grupo en

10.2.4. Individuales:

10.3 Espacio físico:

10.3.1 Laboratorio/Aula informática:

10.3.2 Aula:

10.3.3 Otro:

10.5 Institución

10.5.1 Escuela media:

10.5.2 Colegio técnico:

10.6 Material didáctico:

10.7 Organización del tiempo

11. Instrumento de evaluación de los alumnos:

12. Materia de nivel medio:

a) Nombre de la unidad del programa:

b) Tema principal:

c) Subtema:

13. Observaciones:

14. Palabras claves: 


\section{PARTE IV: ONTOLOGÍA DE CASOS DE ENSEÑANZA}

\subsection{Introducción}

Según el diccionario de la Real Academia Española, en su versión en línea, dice que una ontología es "Parte de la metafísica que trata del ser en general y de sus propiedades trascendentales". Desde la perspectiva de la inteligencia artificial significa compartir y reutilizar conocimiento; desde la ingeniería Web significa la inclusión de descripciones semánticas explícitas de recursos -contenidos y servicios-. Una ontología se materializa en un documento o un fichero que define formalmente las relaciones entre términos (García Peñalvo, 2004). Una ontología tiene como sinónimo la palabra conceptualización y promete "una compresión común y compartida de algún dominio que puede ser comunicado entre personas y computadoras" (Martín, 2004).

En el contexto de las ciencias de la computación y de la información, a una ontología se la define como un conjunto de primitivas representativas para modelar un dominio de conocimiento o de discurso. Las primitivas representativas suelen ser clases -o conjuntos-, atributos -o propiedades- y relaciones -o relaciones entre los miembros de la clase-. En las definiciones de las primitivas se establece información sobre su significado y sus restricciones en su aplicación lógicamente consistente. En el contexto de los sistemas de bases de datos, la ontología puede verse como un nivel de abstracción de los modelos de datos, análogo a los modelos jerárquicos y relacionales, pero destinados a modelar el conocimiento sobre los objetos, sus atributos y su relación con otros objetos. Las ontologías normalmente se especifican en lenguajes que permiten la abstracción lejos de las estructuras de datos y de sus estrategias de aplicación, en la práctica, los lenguajes de las ontologías están más cerca, por su poder expresivo, a la lógica de primer grado que a los lenguajes que se utilizan para modelar las bases de datos. Por esta razón, las ontologías se dice que están al nivel de la "semántica", mientras que los esquemas de las base de datos son modelos de datos a nivel "lógico" o "físico". Debido a su independencia de los niveles inferior de los modelos de base de datos, las ontologías se utilizan para la integración de bases de datos heterogéneas, lo que permite la interoperabilidad entre diferentes sistemas, y la especificación de interfaces de servicios independientes, basadas en el conocimiento. En las ciencias de la computación y la información, la ontología es un término técnico que indica a un artefacto que ha sido diseñado con un propósito, que es permitir un modelo de conocimiento sobre un dominio, real o imaginario (Gruber, 2007).

Las ontologías, según Abad (2004), serían útiles para:

- Compartir conocimiento común sobre la estructura de la información, entre personas o agentes de software.

- Reutilizar el conocimiento de un dominio.

- Separar el conocimiento operacional del conocimiento sobre el dominio.

- Hacer explícitas las suposiciones sobre el dominio.

- Analizar el conocimiento del dominio.

- Preservar el conocimiento perecedero de los expertos en cualquier área de aplicación.

- Usar un formato de intercambio de conocimiento.

Según Ramos (2007B), las ontologías pueden "ser utilizadas con diferentes propósitos tales como búsqueda, representación y navegación del conocimiento de un dominio...”. 


\subsection{Methontology}

En general, las metodologías dan un conjunto de directrices de cómo se debe llevar a cabo las actividades identificadas en el proceso de desarrollo de la ontología. En este apartado se escribe una breve descripción de Methontology que se presenta como un método estructurado para la construcción de ontologías a nivel de conocimiento, propone un ciclo de vida basado en la evolución de prototipos que permite añadir, cambiar y eliminar términos en cada nueva versión -prototipo- de la ontología.

El ciclo de vida de la ontología en este método se mueve hacia adelante a través de los siguientes estados: especificación, conceptualización, formalización, integración, aplicación y mantenimiento. Las actividades como adquisición del conocimiento, evaluación de ontologías y la documentación son tareas que se llevan a cabo durante todo el ciclo de vida de la ontología como muestra la figura $N^{\circ} 9$ (Fernández, 1997).

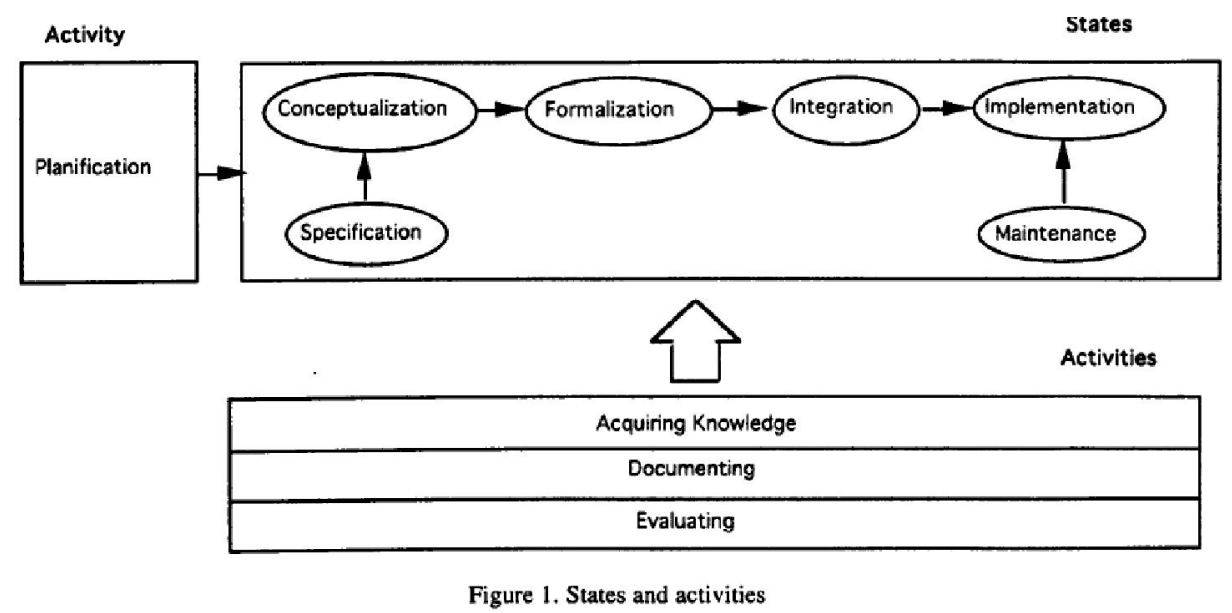

Figura $\mathrm{N}^{\mathrm{o}}$ 9: actividades y estados de Methontology

El objetivo de la fase de especificación es producir en un informe escrito de la ontología, debe contener: el propósito de la ontología, incluida su intención de uso, los escenarios de uso, los usuarios finales; ámbito de aplicación, que incluye el conjunto de términos representado, sus características y granularidad; nivel de formalidad de la ontología implementada, en función de la formalidad que se utiliza para codificar los términos y su significado.

En la actividad denominada conceptualización se estructurara el conocimiento del dominio en un modelo conceptual que describe el problema y la solución en términos de identificar el vocabulario de dominio especificado en las actividades de especificación de la ontología. En la Figura $\mathrm{N}^{\mathrm{o}} 10$ se especifica el conjunto de tareas asociadas a esta actividad. 


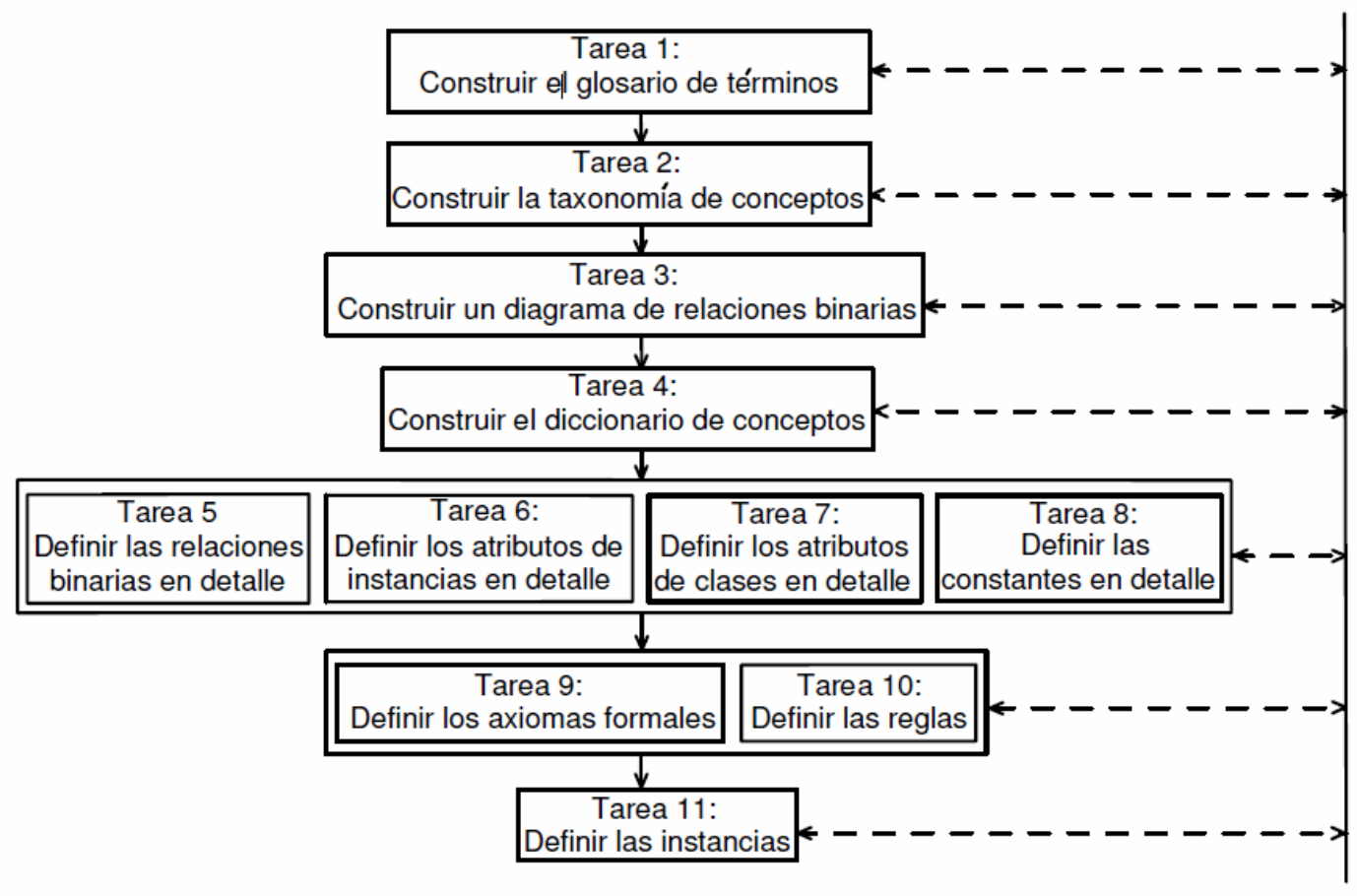

Figura $\mathrm{N}^{\mathrm{o}} 10$ : tareas asociadas a la conceptualización ${ }^{40}$

La actividad de formalización implica realizar la transformación del modelo conceptual en un modelo formal o semi-computable.

Con el objetivo de acelerar la construcción de la ontología, se puede considerar la reutilización de las definiciones ya construido en otras ontologías en lugar de empezar desde cero, esta actividad se la denomina integración.

La implementación implica realizar la codificación de la ontología utilizando un lenguaje formal (Ontolingua, XOL, OIL, DAML, OWL, entre otros).

La actividad de mantenimiento implica la actualización y corrección de la ontología.

Las actividades de apoyo como adquisición de conocimiento, es una actividad independiente en los procesos de desarrollo de la ontología. Se pueden emplear distintas técnicas para recuperar conocimiento: intercambio de ideas y entrevistas con expertos, análisis formales e informales de textos; revisada de libros, manuales, figuras, tablas e incluso otras ontologías afines.

\subsection{Diseño e implementación de la ontología de casos de enseñanza}

\subsubsection{Especificación}

La ontología propuesta se diseña sobre el dominio de los conceptos, términos y relaciones que forman parte de los métodos o estrategias de enseñanza que los docentes construyen para enseñar contenidos utilizando herramientas y recursos de la disciplina Informática. La ontología se aplicara en un escenario donde los docentes buscaran casos de enseñanza en una fuente particular (base de datos, páginas Web, documentos, etc.), cuyo beneficio principal será el acceso más eficiente a los casos similares y una reutilización y uso efectivo de las fuentes de conocimiento (García Peñalvo, 2004).

\footnotetext{
${ }^{40}$ Esquema extraído de Ramos (2007B)
} 
Tres son los propósitos que sobresalen de la presente ontología:

a) Construir consenso sobre el sentido semántico de la terminología informática para posibilitar que las búsquedas de casos similares en la base de casos sean eficiente.

b) La ontología al definir los conceptos que forman parte de los casos de enseñanza permite reconocer directrices para el diseño y construcción de una estructura de datos que priorice la recuperación de aquellos casos de mayor similitud a un caso dado.

c) El conocimiento obtenido de la ontología potencialmente se podrá reutilizar en otros dominios educativos (por ejemplo en la incipiente didáctica de la tecnología) con presencia de herramientas y recursos de la disciplina Informática.

Fuentes:

-Narraciones de estrategias o métodos de enseñanza usados por docentes de las escuelas medias y técnicas de la ciudad del Neuquén. Las metodologías o estrategias de enseñanza que se toman en cuenta para esta ontología deben incluir herramientas informáticas.

- The 1998 ACM Computing Classification System. En: http://www.acm.org/about/class/ccs98-html

\subsubsection{Conceptualización}

\subsubsection{Extracto del glosario de términos:}

Se identifican todos los términos que forman parte de las narraciones de los casos y que son significativos para la actividad de búsquedas de casos -conceptos, instancias, atributos, relaciones entre conceptos, etcétera-. El glosario construido tiene más de 100 términos. Ver anexo A.

\begin{tabular}{|c|c|c|c|c|}
\hline Nombre & Sinónimo & Acrónimo & Descripción & Tipo \\
\hline nido_material_educativo ${ }^{\text {conte- }}$ & & & $\begin{array}{l}\text { Relación binaria que establece nexo } \\
\text { entre un caso informática como } \\
\text { material educativo y contenido } \\
\text { informático. }\end{array}$ & Relación \\
\hline . contenido_recurso_didáctico & & & $\begin{array}{l}\text { Relación binaria que establece nexo } \\
\text { entre un caso informática como } \\
\text { recurso didáctico y contenido in- } \\
\text { formático. }\end{array}$ & Relación \\
\hline $\begin{array}{l}\text { contenido-alfabetiza- } \\
\text { ción_informática }\end{array}$ & & & $\begin{array}{l}\text { Relación binaria que establece nexo } \\
\text { entre un caso alfabetización } \\
\text { informática y contenido informático. }\end{array}$ & Relación \\
\hline .contenido_videojuego & & & $\begin{array}{l}\text { Relación binaria que establece nexo } \\
\text { entre un caso videojuego y conte- } \\
\text { nido informático. }\end{array}$ & Relación \\
\hline Access de Microsoft & & & $\begin{array}{l}\text { Software administrador de bases de } \\
\text { datos. }\end{array}$ & Instancia \\
\hline Agrupamiento de alumnos & & & $\begin{array}{l}\text { Organización de los grupos de } \\
\text { alumnos }\end{array}$ & Atributo \\
\hline Alfabetización informática & & & $\begin{array}{l}\text { Las narraciones que contiene como } \\
\text { objeto de estudio a la computadora } \\
\text { (objeto físico). Los temas de estas } \\
\text { narraciones pueden contener la } \\
\text { organización física y lógica de la } \\
\text { computadora; incluye el análisis de } \\
\text { los componentes y de los materiales } \\
\text { implicados; sus resultados en el } \\
\text { nivel morfológico y de perfomance. } \\
\text { Las narraciones contienen como }\end{array}$ & Concepto \\
\hline
\end{tabular}




\begin{tabular}{|c|c|c|}
\hline & $\begin{array}{l}\text { objeto de estudio a los programas } \\
\text { (objeto simbólico). Los temas de } \\
\text { estas narraciones pueden contener } \\
\text { los distintos tipos de software } \\
\text { implicados en el funcionamiento de } \\
\text { la computadora; el nivel de jerar- } \\
\text { quía y relación con el usuario; los } \\
\text { distintos enfoques y técnicas impli- } \\
\text { cada en su estudio y aplicación; el } \\
\text { proceso de construcción de progra- } \\
\text { mas. Incluye, además, el análisis } \\
\text { referencial, esto es: antecedentes del } \\
\text { origen e historia de la informática } \\
\text { en el mundo y en la Argentina. }\end{array}$ & \\
\hline Analogía & $\begin{array}{l}\text { "En términos generales, una ana- } \\
\text { logía puede definirse como la } \\
\text { comparación entre dos dominios, } \\
\text { uno más familiar (denominado } \\
\text { "fuente" o "análogo") y otro menos } \\
\text { conocido (denominado "concepto", } \\
\text { "blanco" o "target"), que compar- } \\
\text { ten información de tipo relacional. } \\
\text { Así Ruhl (2003) señala que "una } \\
\text { analogía es una comparación de una } \\
\text { cosa familiar con otra no familiar } \\
\text { con el objetivo de interpretar o } \\
\text { aclarar una característica compar- } \\
\text { tida" }\end{array}$ & Instancia \\
\hline Aula & $\begin{array}{l}\text { Espacio físico donde se reúnen } \\
\text { docentes, alumnos y tecnología con } \\
\text { la finalidad de enseñar y aprender. }\end{array}$ & Instancia \\
\hline
\end{tabular}

Tabla No 3: extracto del glosario de términos

\subsubsection{Taxonomía de conceptos:}

La taxonomía define la jerarquía de los conceptos del dominio. Las clases principales son:

a) casos: donde se definen los tipos de casos que narran los docentes. Para esta clase se definen cuatro tipos de casos: alfabetización informática, la informática como material educativo, la informática como recurso didáctico y el videojuego.

b) contenido informático de los casos: para esta clase los contenidos definidos son: ergonomía, Internet, software, hardware, representación del almacenamiento de los datos, origen e historia de la informática. Las subcategorías se pueden ver en la figura $\mathrm{N}^{\mathrm{o}}$ 11 b). En particular para la subclase "software" se usa la distinción que propone Gros Salvat (2000:79) que toma en consideración la aplicación o finalidad de su uso del mismo en la enseñanza. Esta autora propone cinco distinciones: instructivos, acceso a la información, creación, desarrollo de estrategias y comunicación. Los "instructivos" son los programas de aritmética, programas de simulación de física, enseñaza de idiomas, etc. Los de "acceso a la información" son los que permiten acceder a bases de datos, programas de navegación en Internet, etc. Los de "creación" son los programas que no tienen un contenido específico, por ejemplo creación de programas informáticos (lenguaje de autor), producción de textos escritos, etc. Los de "desarrollo de estrategias" son los de juego de aventuras, estrategias, resolución de problemas, etc. Los de "comunicación" son los programas para el uso de redes de comunicación, por ejemplo acceso a foros, correo electrónico, etc.

c) materia de nivel medio: se definen los conceptos que establecen los espacios de la práctica con tecnologías informáticas de cada uno de los casos de enseñanza. Por espacio de la práctica el autor entiende el lugar donde se materializa la reflexión y la 
práctica de los casos de enseñanza de una disciplina utilizando las tecnologías informáticas.

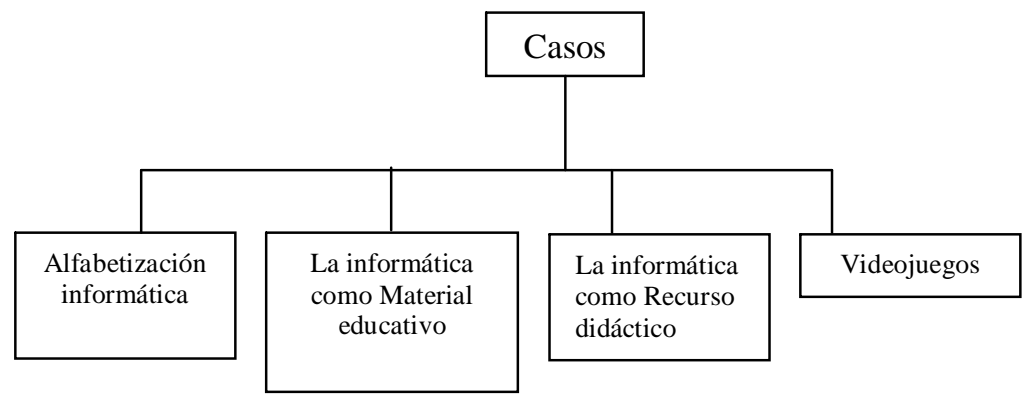

Figura $\mathrm{N}^{\mathrm{o}}$ 11: a) taxonomía de casos de enseñanza

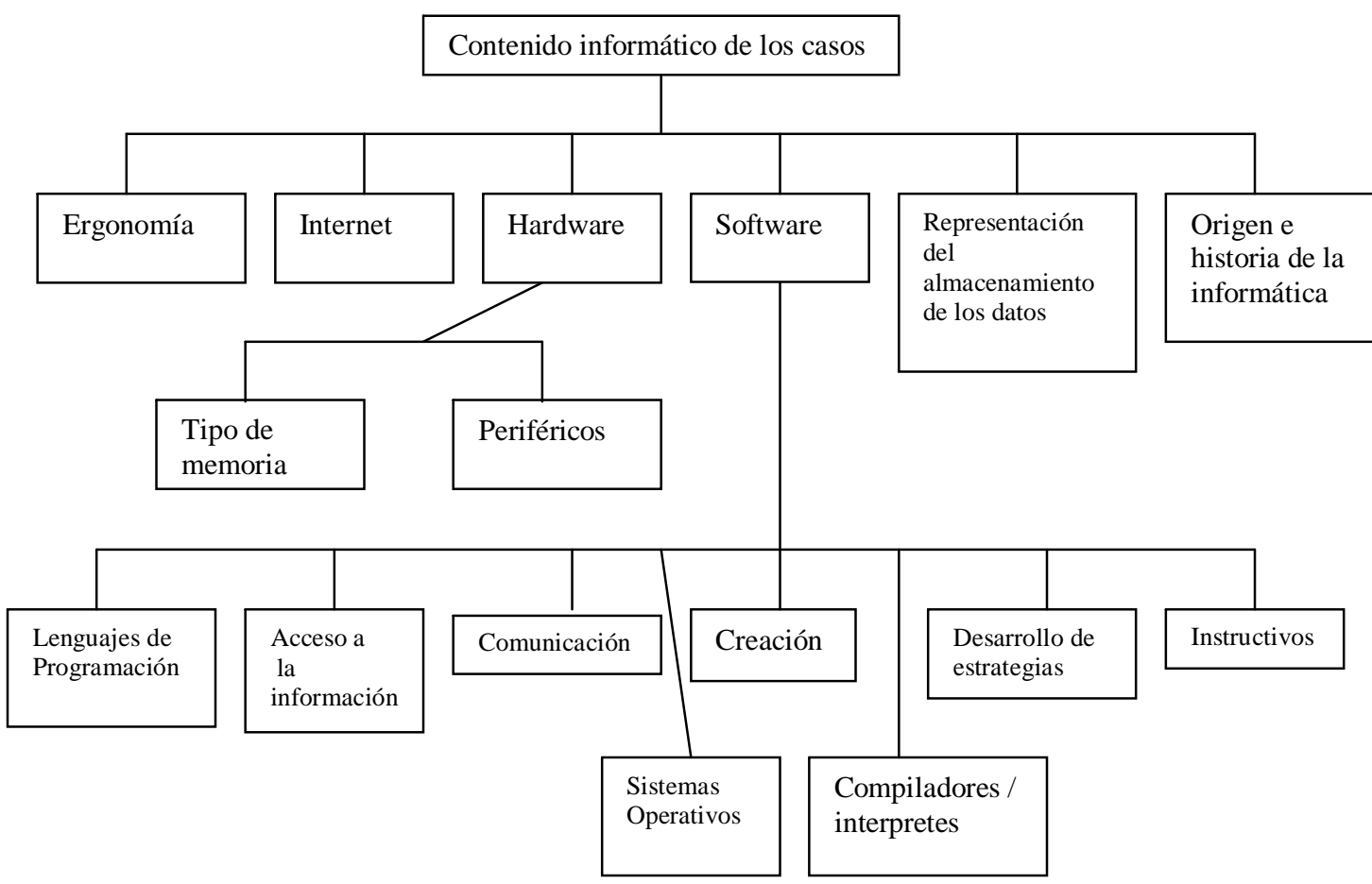

Figura $\mathrm{N}^{\mathrm{o}}$ 11: b) taxonomía de contenidos informáticos de los casos

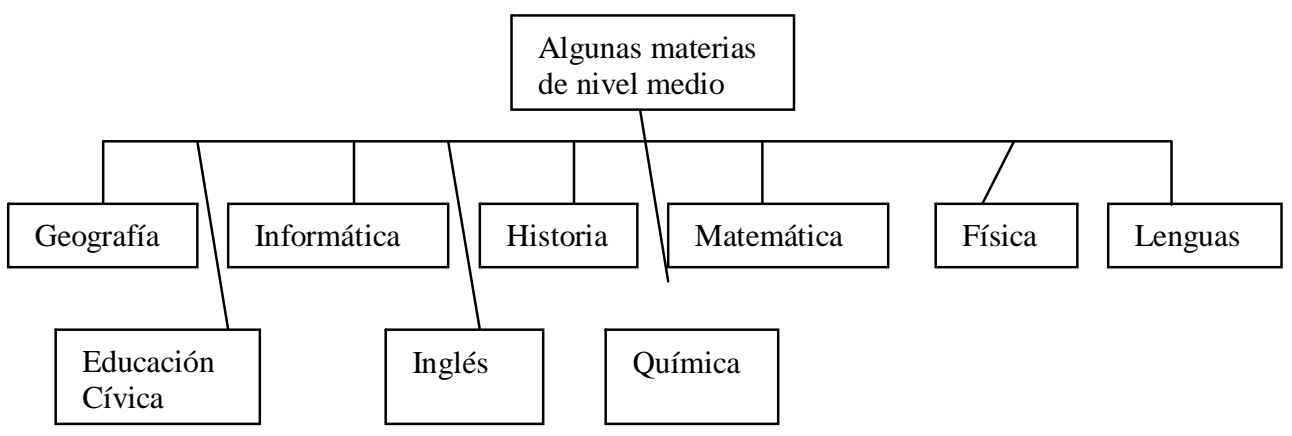

Figura $\mathrm{N}^{\mathrm{o}} 11$ : c) taxonomía de conceptos algunas materias de nivel medio 


\subsubsection{Extracto de los diagrama de relaciones binarias:}

Las relaciones binarias se establecen entre los "casos de enseñanza" y los "contenidos informáticos" y "los casos de enseñanza" y las "materias de nivel medio". Las relaciones binarias establecen que los "casos de enseñanza" están caracterizados por un tipo de contenido informático y por contenidos de una materia de nivel medio. A continuación se describe algunas de las relaciones binarias con el propósito de acercar luz al significado de dichas relaciones para la ontología.

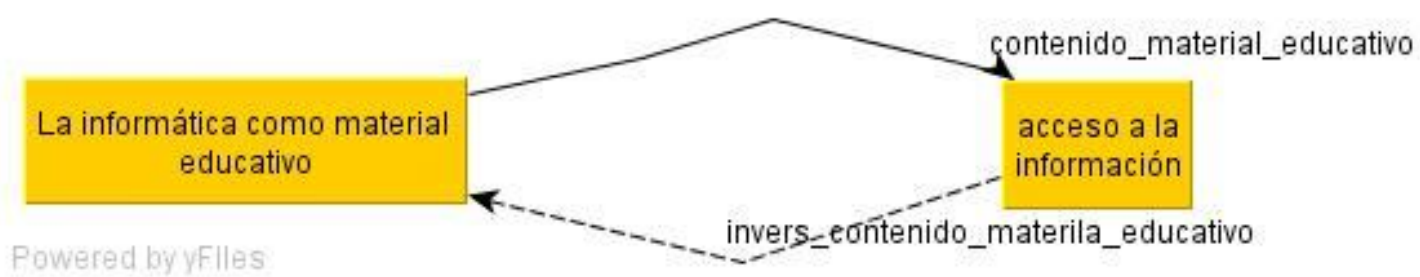

Figura $N^{\circ}$ 12: El caso "La informática como material educativo" y la relación binaria con el contenido "acceso a la información".

En la figura $\mathrm{N}^{\mathrm{o}} 12$ los casos "La informática como material educativo" están relacionados con el contenido operativo y conceptual de los software "Acceso a la información" a través de la relación "contenido_material_educativo" y con su relación inversa "inversa contenido_material_eduactivo". Recordemos ejemplos de la clase de software "Acceso a la información": bases de datos, sitios Web educativos of line o on line, enciclopedias digitales, etc.

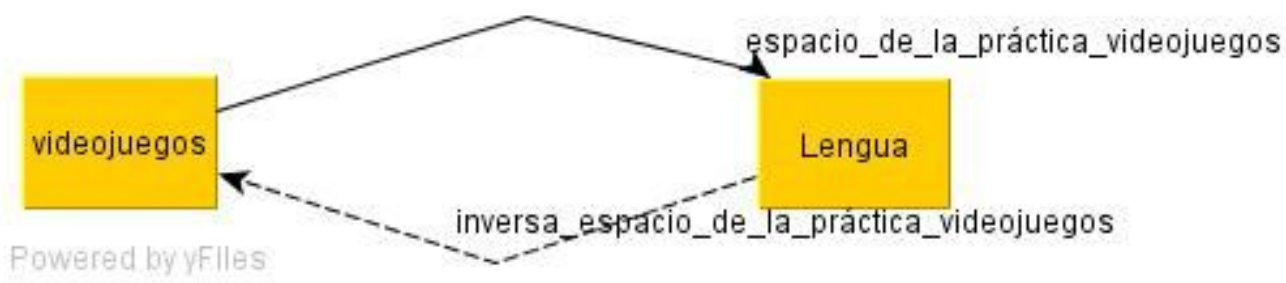

Figura $\mathrm{N}^{\mathrm{o}}$ 13: El caso "videojuego" y la relación binaria con la materia de nivel medio "lengua"

En la figura $N^{\circ} 13$ los casos "Videojuego" están relacionados con la materia de nivel medio "Lengua" a través de la relación "espacio_de_la_práctica" y con su relación inversa “inversa_espacio_de_la_práctica_videojuegos".

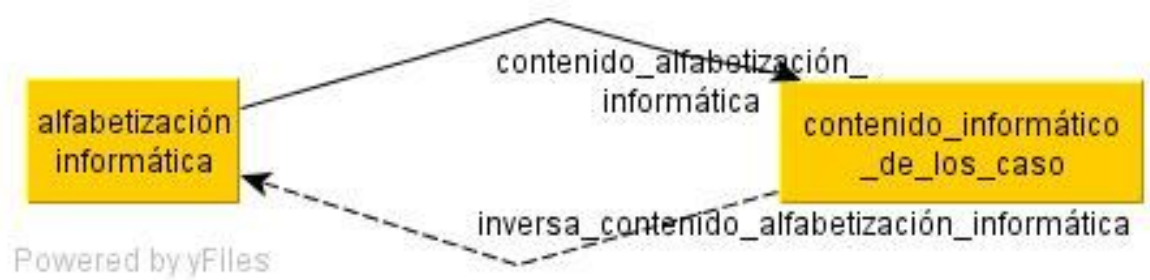

Figura $\mathrm{N}^{\mathrm{0}}$ 14: El caso "alfabetización informática" y la relación binaria con el contenido "contenido informático de los casos"

En la figura $\mathrm{N}^{\circ} 14$ los casos "Alfabetización informática" están relacionados con los contenidos "Contenidos informático de los casos" a través de la relación "contenido_alfabetización_informática" y con su relación inversa "inversa_contenido_alfabetización_informática". En esta relación binaria se pone de manifiesto que en los casos del uso de la Informática como alfabetización informática, están involucrado todos los contenidos de la disciplina Informática. 


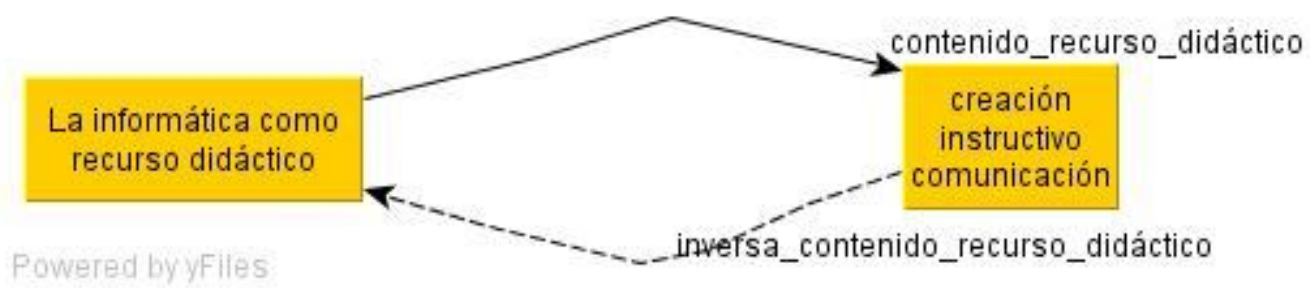

Figura $\mathrm{N}^{\mathrm{0}}$ 15: El caso "La informática como recurso didáctico" y la relación binaria con el contenido "creación, instructivo, comunicación"

En la figura $\mathrm{N}^{\circ} 15$ los casos "La informática como recurso didáctico" están relacionados a través de la relación "contenido_recursos_didáctico" con los contenidos uso de los software de "creación", "instructivos" y "comunicación" y con su relación inversa "inversa_contenido_recurso_didáctico".

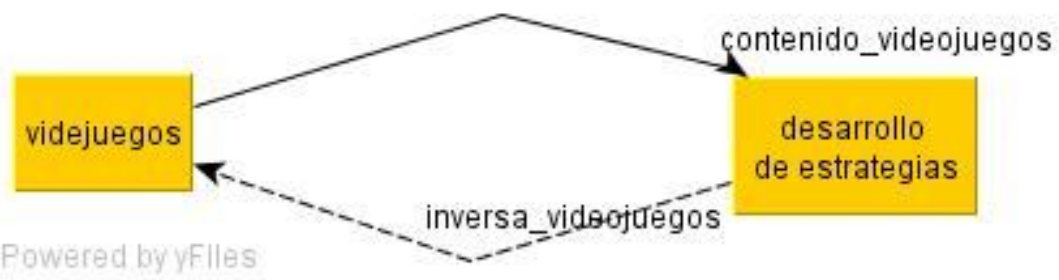

Figura N ${ }^{0} 16$ : El caso "videojuego" y la relación binaria con el contenido "desarrollo de estrategias"

En la figura № 16 los casos "videojuego" están relacionados a través de la relación "contenido_videojuego" con el uso de software "desarrollo de estrategias" y con su relación inversa "inversa_videojuegos".

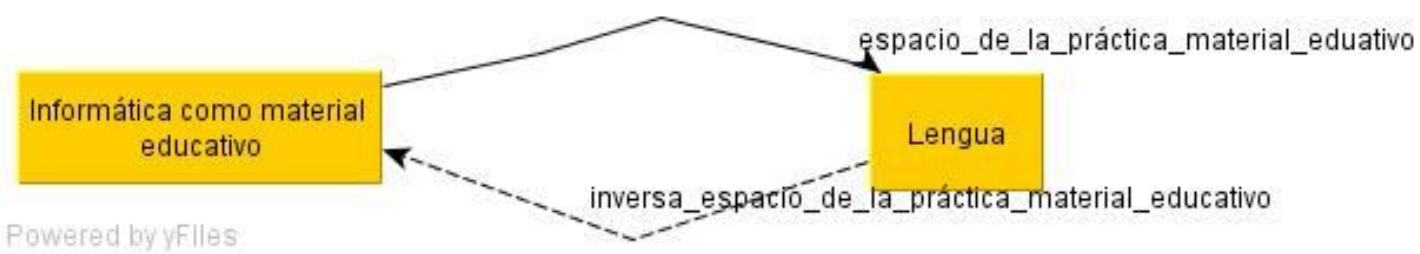

Figura $\mathrm{N}^{\mathrm{0}}$ 17: El caso "Informática como material educativo" y la relación binaria con la materia de nivel medio "Lengua"

En la figura $\mathrm{N}^{\mathrm{o}} 17$ los casos "Informática como material educativo" están relacionados con la materia de nivel medio "Lengua" a través de la relación "espacio_de_la_práctica_material_educativo" y su inversa "espacio_de_la_práctica_material_educativo". Los casos "Informática como material educativo" se hace extensiva para todas las materias de nivel medio.

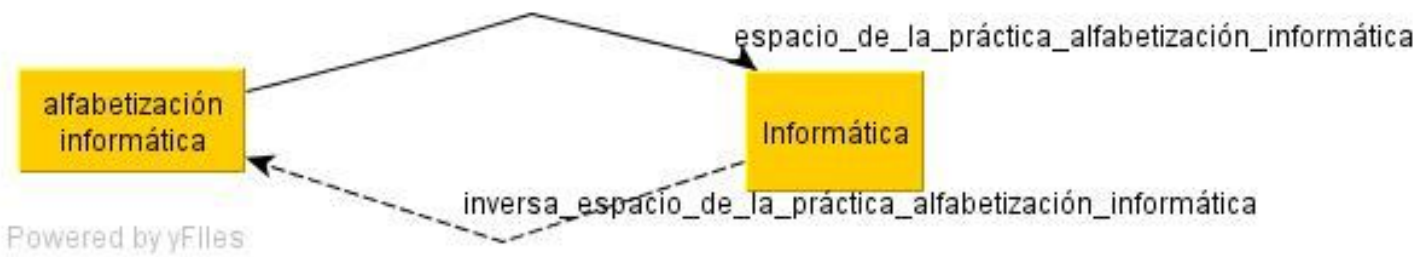

Figura $\mathrm{N}^{\mathrm{0}}$ 18: El caso "alfabetización informática" y la relación binaria con la materia de nivel medio "Informática"

En la figura $\mathrm{N}^{\mathrm{o}} 18$ los casos "Alfabetización informática" están relacionados a la materia "Informática" a través de la relación "espacio_de_la_práctica_alfabetización_informática” y de su inversa “inversa_ espa- 
cio_de_la_práctica_alfabetización_informática". Para los casos "Alfabetización informática" el único espacio de la práctica que tiene definido es la materia o taller Informática.

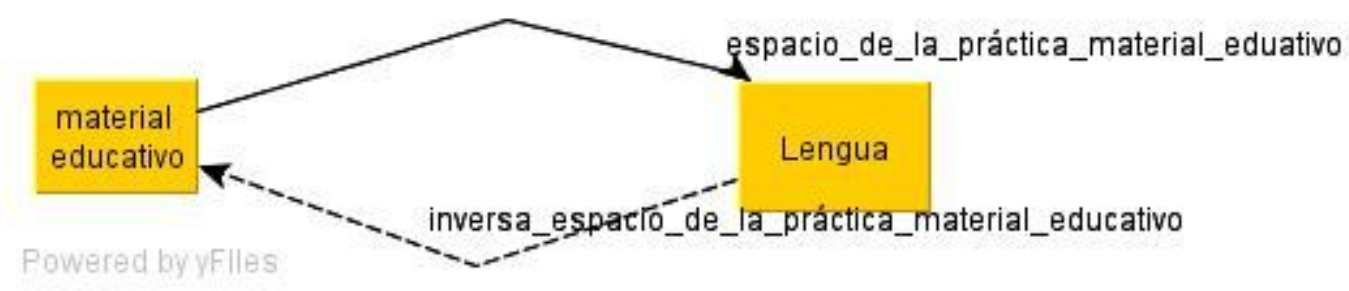

Figura $\mathrm{N}^{\circ}$ 19: El caso "La informática como material educativo" y la relación binaria con la materia de nivel medio "Lengua

En la figura $\mathrm{N}^{\mathrm{o}} 19$ los casos "La informática como material educativo" están relacionados a través de la relación "espacio_de_la_práctica_material_educativo" a la materia de nivel medio "Lengua" y su relación inversa "inversa_espacio_de_la_práctica_material_educativo".

,

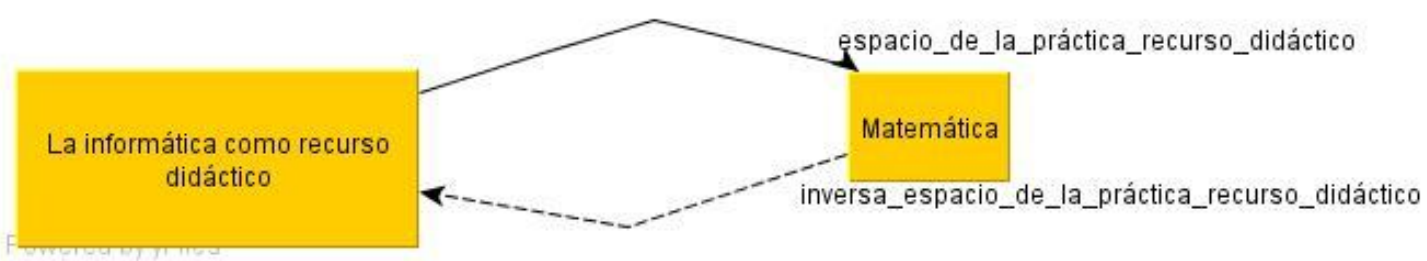

Figura N N 20: El caso "La informática como recurso didáctico" y la relación binaria con la materia de nivel medio "Matemática"

En la figura $\mathrm{N}^{\circ} 20$ los casos "La informática como recurso didáctico" están relacionados a través de la relación "espacio_de_la_práctica_recursos_didáctico" a los contenidos de la materia de nivel medio "Matemática" y con su relación inversa "inversa_ espacio_de_la_práctica_recursos_didáctico". Los casos "La informática como recurso didáctico" se hace extensiva para todas las materias de nivel medio.

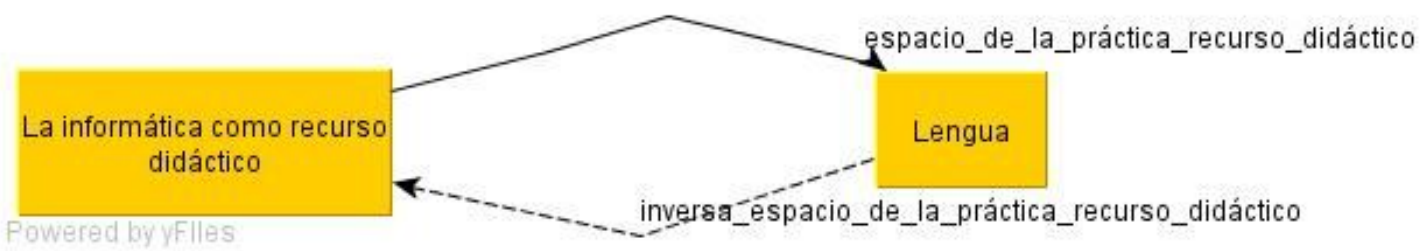

Figura $N^{\circ} 21$ : El caso "La informática como recurso didáctico" y la relación binaria con la materia "Lengua"

En la figura $\mathrm{N}^{\circ} 21$ los casos "La informática como recurso didáctico" están relacionados a través de la relación "espacio_de_la_práctica_recursos_didáctico" a los contenidos de la materia de nivel medio "Lengua" y con su relación inversa "inversa_ espacio_de_la_práctica_recursos_didáctico". Los casos "La informática como recurso didáctico" se hace extensiva para todas las materias de nivel medio. 


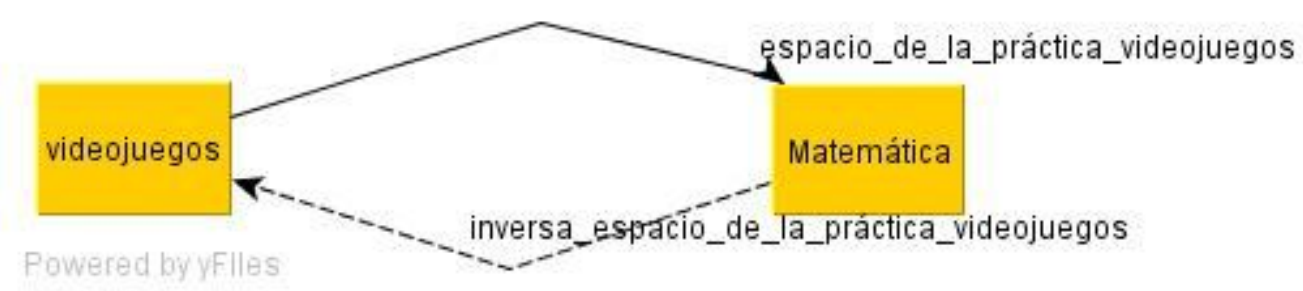

Figura No 22: El caso "videojuego" y la relación binaria con la materia "Matemática"

En la figura $\mathrm{N}^{\circ} 22$ los casos "videojuego" están relacionados a través de la relación "espacio_de_la_práctica_videojuego" con los contenidos de la materia de nivel medio "Matemática" y con su relación inversa "inversa_espacio_de_la_práctica_videojuegos".

\subsubsection{Diccionario de conceptos:}

El diccionario de conceptos contiene los conceptos con sus instancias, sus atributos de clase y de instancias y relaciones que son consideradas relevantes para las búsquedas de casos similares a uno dado.

\begin{tabular}{|c|c|c|c|c|}
\hline $\begin{array}{l}\text { Nombre del } \\
\text { concepto }\end{array}$ & Instancias & $\begin{array}{l}\text { Atributo de la } \\
\text { clase }\end{array}$ & $\begin{array}{l}\text { Atributo de la } \\
\text { instancia }\end{array}$ & Relaciones \\
\hline $\begin{array}{l}\text { Alfabetización } \\
\text { informática }\end{array}$ & $\begin{array}{l}\text { Casos narrados } \\
\text { que cumplan la } \\
\text { condición de } \\
\text { tener contenidos } \\
\text { únicamente in- } \\
\text { formáticos y } \\
\text { espacio de la } \\
\text { práctica la mate- } \\
\text { ria Informática }\end{array}$ & & $\begin{array}{l}\text { Agrupamiento } \\
\text { de alumnos } \\
\text { Autor } \\
\text { Curso } \\
\text { Espacio físico } \\
\text { Evaluación del } \\
\text { caso } \\
\text { Institución } \\
\text { Material didác- } \\
\text { tico } \\
\text { Narración } \\
\text { Objetivo } \\
\text { didáctico del } \\
\text { caso } \\
\text { Problema } \\
\text { Tiempo } \\
\text { Título } \\
\text { E-mail del } \\
\text { autor }\end{array}$ & $\begin{array}{l}\text { Contenido alfabetización informática } \\
\text { Espacio de la práctica alfabetización } \\
\text { informática }\end{array}$ \\
\hline $\begin{array}{l}\text { Caso de ense- } \\
\text { nanza }\end{array}$ & & $\begin{array}{l}\text {-Alfabetización } \\
\text { informática } \\
\text {-Informática } \\
\text { como material } \\
\text { educativo. } \\
\text {-Informática } \\
\text { como recurso } \\
\text { didáctico } \\
\text {-Videojuego }\end{array}$ & & \\
\hline $\begin{array}{l}\text { Contenidos } \\
\text { informático de } \\
\text { los caso }\end{array}$ & $\begin{array}{l}\text { Ergonomía, Inter- } \\
\text { net, software, } \\
\text { hardware, repre- } \\
\text { sentación del } \\
\text { almacenamiento } \\
\text { de los datos, } \\
\text { origen e historia } \\
\text { de la informática. } \\
\text { Para la subclase } \\
\text { "software":ins- } \\
\text { tructivos, acceso } \\
\text { a la información, }\end{array}$ & & $\begin{array}{l}\text { Agrupamiento } \\
\text { de alumnos } \\
\text { Autor } \\
\text { Curso } \\
\text { Espacio físico } \\
\text { Evaluación del } \\
\text { caso } \\
\text { Institución } \\
\text { Material didác- } \\
\text { tico } \\
\text { Narración } \\
\text { Objetivo }\end{array}$ & $\begin{array}{l}\text { Contenido_material_educativo } \\
\text { Espacio- } \\
\text { de_la_práctica_materialEducativo }\end{array}$ \\
\hline
\end{tabular}




\begin{tabular}{|c|c|c|c|c|}
\hline & $\begin{array}{l}\text { creación, desarro- } \\
\text { llo de estrategias } \\
\text { y comunicación }\end{array}$ & & $\begin{array}{ll}\text { didáctico } & \text { del } \\
\text { caso } & \\
\text { Problema } & \\
\text { Tiempo } & \\
\text { Título } & \\
\text { E-mail } & \text { del } \\
\text { autor } & \end{array}$ & \\
\hline $\begin{array}{l}\text { Informática } \\
\text { como recurso } \\
\text { didáctico }\end{array}$ & $\begin{array}{l}\text { Casos narrados } \\
\text { que cumplan la } \\
\text { condición de } \\
\text { tener contenidos } \\
\text { software de "crea- } \\
\text { ción", "comunica- } \\
\text { ción" } \\
\text { e"instructivoa" y } \\
\text { espacio de la } \\
\text { práctica cualquier } \\
\text { materia de nivel } \\
\text { medio y técnico. }\end{array}$ & & $\begin{array}{l}\text { Agrupamiento } \\
\text { de alumnos } \\
\text { Autor } \\
\text { Curso } \\
\text { Espacio físico } \\
\text { Evaluación del } \\
\text { caso } \\
\text { Institución } \\
\text { Material didác- } \\
\text { tico } \\
\text { Narración } \\
\text { Objetivo } \\
\text { didáctico del } \\
\text { caso } \\
\text { Problema } \\
\text { Tiempo } \\
\text { Título } \\
\text { E-mail del } \\
\text { autor }\end{array}$ & $\begin{array}{l}\text { Contenido_recurso-educativo } \\
\text { Espacio_de_la_práctica_recurso_did } \\
\text { áctico }\end{array}$ \\
\hline Videojuegos & $\begin{array}{lr}\text { Casos narrados } \\
\text { que cumplan la } \\
\text { condición } & \text { de } \\
\text { tener contenidos } \\
\text { únicamente de } \\
\text { software } & \text { de } \\
\text { "desarrollo } & \text { de } \\
\text { estrategia" } & \text { y } \\
\text { espacio de la } \\
\text { práctica cualquier } \\
\text { materia de nivel } \\
\text { medio y técnico. }\end{array}$ & & $\begin{array}{l}\text { Agrupamiento } \\
\text { de alumnos } \\
\text { Autor } \\
\text { Curso } \\
\text { Espacio físico } \\
\text { Evaluación del } \\
\text { caso } \\
\text { Institución } \\
\text { Material didác- } \\
\text { tico } \\
\text { Narración } \\
\text { Objetivo } \\
\text { didáctico del } \\
\text { caso } \\
\text { Problema } \\
\text { Tiempo } \\
\text { Título } \\
\text { E-mail del } \\
\text { autor }\end{array}$ & $\begin{array}{l}\text { Contenidos_videojuegos } \\
\text { Espacio_de_la_práctica_videojuegos }\end{array}$ \\
\hline Hardware & & $\begin{array}{l}\text { Periféricos } \\
\text { Placa madre } \\
\text { UCP } \\
\text { Redes }\end{array}$ & $\begin{array}{l}\text { Tema } \\
\text { Subtema }\end{array}$ & $\begin{array}{l}\text { Inversa contenido alfabetización } \\
\text { informática }\end{array}$ \\
\hline Informática & & & $\begin{array}{l}\text { Nombre de la } \\
\text { unidad del } \\
\text { programa } \\
\text { Tema } \\
\text { Subtema }\end{array}$ & $\begin{array}{l}\text { Inversa contenido alfabetización } \\
\text { informática }\end{array}$ \\
\hline Internet & $\begin{array}{l}\text { Red de redes de } \\
\text { alcance mundial } \\
\text { para compartir } \\
\text { servicios. }\end{array}$ & & $\begin{array}{l}\text { Tema } \\
\text { Subtema }\end{array}$ & $\begin{array}{l}\text { Inversa contenidos alfabetización } \\
\text { informática }\end{array}$ \\
\hline $\begin{array}{l}\text { Organización } \\
\text { de los datos }\end{array}$ & $\begin{array}{l}\text { Composite } \\
\text { structures, } \\
\text { Contiguous } \\
\text { representations, } \\
\text { Hash-table } \\
\text { representations, } \\
\text { Linked } \\
\text { representations, }\end{array}$ & & $\begin{array}{l}\text { Tema } \\
\text { Subtema }\end{array}$ & $\begin{array}{l}\text { Inversa contenidos alfabetización } \\
\text { informática }\end{array}$ \\
\hline
\end{tabular}




\begin{tabular}{|c|c|c|c|c|}
\hline & $\begin{array}{l}\text { Object } \\
\text { representation, } \\
\text { Primitive data } \\
\text { items }\end{array}$ & & & \\
\hline Periféricos & $\begin{array}{l}\text { Un periférico es } \\
\text { un dispositivo } \\
\text { electrónico físico } \\
\text { que se conecta o } \\
\text { acopla a una } \\
\text { computadora, } \\
\text { pero no forma } \\
\text { parte del núcleo } \\
\text { básico (CPU, } \\
\text { memoria, placa } \\
\text { madre, alimenta- } \\
\text { ción eléctrica) de } \\
\text { la misma. Los } \\
\text { periféricos sirven } \\
\text { para comunicar } \\
\text { la computadora } \\
\text { con el exterior } \\
\text { (ratón, monitor, } \\
\text { teclado, etc.) o } \\
\text { como almacena- } \\
\text { miento de } \\
\text { información } \\
\text { (disco duro, } \\
\text { unidad de disco } \\
\text { ótico, etc.). }\end{array}$ & $\begin{array}{l}\text { Comunicación } \\
\text { Memorias } \\
\text { auxiliares }\end{array}$ & $\begin{array}{l}\text { Tema } \\
\text { Subtema }\end{array}$ & $\begin{array}{l}\text { Inversa contenidos alfabetización } \\
\text { informática }\end{array}$ \\
\hline Software & & $\begin{array}{l}\text { Acceso a la } \\
\text { información } \\
\text { Compiladores e } \\
\text { interpretes } \\
\text { Comunicación } \\
\text { Creación } \\
\text { Desarrollo de } \\
\text { estrategias } \\
\text { Instructivos } \\
\text { Lenguaje de } \\
\text { programación } \\
\text { Sistemas opera- } \\
\text { tivos }\end{array}$ & $\begin{array}{l}\text { Nombre de los } \\
\text { programas } \\
\text { Tema } \\
\text { Subtema }\end{array}$ & $\begin{array}{l}\text { Inversa contenidos alfabetización } \\
\text { informática }\end{array}$ \\
\hline $\begin{array}{l}\text { Memorias } \\
\text { auxiliares }\end{array}$ & $\begin{array}{ll}\text { DVD - CD } & - \\
\text { PenDrive } & - \\
\text { Disquetes - } & \end{array}$ & & $\begin{array}{l}\text { Tema } \\
\text { Subtema }\end{array}$ & $\begin{array}{l}\text { Inversa contenidos alfabetización } \\
\text { informática }\end{array}$ \\
\hline Periféricos & & $\begin{array}{l}\text { Memorias } \\
\text { auxiliares } \\
\text { Comunicación }\end{array}$ & $\begin{array}{l}\text { Tema } \\
\text { Subtema }\end{array}$ & $\begin{array}{l}\text { Inversa contenidos alfabetización } \\
\text { informática }\end{array}$ \\
\hline Comunicación & $\begin{array}{l}\text { Monitor - Impre- } \\
\text { soras - Mouse - } \\
\text { Lápiz óptico }\end{array}$ & & $\begin{array}{l}\text { Tema } \\
\text { Subtema }\end{array}$ & $\begin{array}{l}\text { Inversa contenidos alfabetización } \\
\text { informática }\end{array}$ \\
\hline $\begin{array}{l}\text { Materias del } \\
\text { nivel medio }\end{array}$ & $\begin{array}{l}\text { Los contenidos } \\
\text { curriculares de } \\
\text { nivel medio }\end{array}$ & $\begin{array}{l}\text { Geografía } \\
\text { Matemática } \\
\text { Física } \\
\text { Informática } \\
\text { Inglés } \\
\text { Francés } \\
\text { Química } \\
\text { Educación } \\
\text { física } \\
\text { Instrucción } \\
\text { cívica }\end{array}$ & $\begin{array}{l}\text { Nombre de la } \\
\text { unidad del } \\
\text { programa } \\
\text { Tema de la } \\
\text { unidad } \\
\text { Subtema de la } \\
\text { unidad }\end{array}$ & \\
\hline Química & & & $\begin{array}{l}\text { Nombre de la } \\
\text { unidad del } \\
\text { programa } \\
\text { Tema de la }\end{array}$ & $\begin{array}{l}\text { Inversa espacio de la práctica material } \\
\text { educativo } \\
\text { Inversa espacio de la práctica recurso } \\
\text { didáctico }\end{array}$ \\
\hline
\end{tabular}




\begin{tabular}{|c|c|c|c|}
\hline & & $\begin{array}{l}\text { unidad } \\
\text { Subtema de la } \\
\text { unidad }\end{array}$ & Inversa espacio de la práctica juegos \\
\hline Física & & $\begin{array}{l}\text { Nombre de la } \\
\text { unidad del } \\
\text { programa } \\
\text { Tema de la } \\
\text { unidad } \\
\text { Subtema de la } \\
\text { unidad }\end{array}$ & $\begin{array}{l}\text { Inversa espacio de la práctica material } \\
\text { educativo } \\
\text { Inversa espacio de la práctica recurso } \\
\text { didáctico } \\
\text { Inversa espacio de la práctica juegos }\end{array}$ \\
\hline Inglés & & $\begin{array}{l}\text { Nombre de la } \\
\text { unidad del } \\
\text { programa } \\
\text { Tema de la } \\
\text { unidad } \\
\text { Subtema de la } \\
\text { unidad }\end{array}$ & $\begin{array}{l}\text { Inversa espacio de la práctica material } \\
\text { educativo } \\
\text { Inversa espacio de la práctica recurso } \\
\text { didáctico } \\
\text { Inversa espacio de la práctica juegos }\end{array}$ \\
\hline Instructivos & $\begin{array}{l}\text { Programas } \quad \text { de } \\
\text { aritmética, de } \\
\text { simulación de } \\
\text { física, enseñanza } \\
\text { de idiomas, etc. }\end{array}$ & $\begin{array}{l}\text { Nombre de la } \\
\text { unidad del } \\
\text { programa } \\
\text { Tema de la } \\
\text { unidad } \\
\text { Subtema de la } \\
\text { unidad } \\
\end{array}$ & $\begin{array}{l}\text { Inversa contenido recurso didáctico } \\
\text { Inversa contenido alfabetización } \\
\text { informática }\end{array}$ \\
\hline $\begin{array}{l}\text { Desarrollo de } \\
\text { estrategias }\end{array}$ & $\begin{array}{l}\text { Juegos en red. } \\
\text { Ajedrez, etc. }\end{array}$ & $\begin{array}{l}\text { Nombre de la } \\
\text { unidad del } \\
\text { programa } \\
\text { Tema de la } \\
\text { unidad } \\
\begin{array}{l}\text { Subtema de la } \\
\text { unidad }\end{array} \\
\end{array}$ & $\begin{array}{l}\text { Inversa contenido videojuegos } \\
\text { Inversa contenido alfabetización } \\
\text { informática }\end{array}$ \\
\hline Creación & $\begin{array}{lr}\begin{array}{l}\text { Programas } \\
\text { ticos }\end{array} & \text { (Opená- } \\
\text { Office, Office } \\
\text { Microsoft, len- } \\
\text { guajes de } & \text { autor, } \\
\text { etc. } & \end{array}$ & $\begin{array}{l}\text { Nombre de la } \\
\text { unidad del } \\
\text { programa } \\
\text { Tema de la } \\
\text { unidad } \\
\text { Subtema de la } \\
\text { unidad }\end{array}$ & $\begin{array}{l}\text { Inversa contenido recurso didáctico } \\
\text { Inversa contenido alfabetización } \\
\text { informática }\end{array}$ \\
\hline Comunicación & $\begin{array}{l}\text { Programas de } \\
\text { correo electróni- } \\
\text { cos, programas } \\
\text { FTP, etc. }\end{array}$ & $\begin{array}{l}\text { Nombre de la } \\
\text { unidad del } \\
\text { programa } \\
\text { Tema de la } \\
\text { unidad } \\
\begin{array}{l}\text { Subtema de la } \\
\text { unidad }\end{array} \\
\end{array}$ & $\begin{array}{l}\text { Inversa contenido recurso didáctico } \\
\text { Inversa contenido alfabetización } \\
\text { informática }\end{array}$ \\
\hline $\begin{array}{l}\text { Acceso a la } \\
\text { información }\end{array}$ & $\begin{array}{l}\text { Navegadores, } \\
\text { Bibliotecas of } \\
\text { line, bases de } \\
\text { datos, Tutoriales, } \\
\text { manuales on/off } \\
\text { line. }\end{array}$ & $\begin{array}{l}\text { Nombre de la } \\
\text { unidad del } \\
\text { programa } \\
\text { Tema de la } \\
\text { unidad } \\
\begin{array}{l}\text { Subtema de la } \\
\text { unidad }\end{array}\end{array}$ & $\begin{array}{l}\text { Inversa contenido material educativo } \\
\text { Inversa contenido alfabetización } \\
\text { informática }\end{array}$ \\
\hline $\begin{array}{l}\text { La informática } \\
\text { como matearla } \\
\text { educativo }\end{array}$ & $\begin{array}{l}\text { Casos narrados } \\
\text { que cumplan la } \\
\text { condición de } \\
\text { tener contenidos } \\
\text { software "Acceso } \\
\text { a la información" } \\
\text { y espacio de la } \\
\text { práctica cualquier } \\
\text { materia de nivel } \\
\text { medio y técnico. }\end{array}$ & $\begin{array}{l}\text { Agrupamiento } \\
\text { de alumnos } \\
\text { Autor } \\
\text { Curso } \\
\text { Espacio físico } \\
\text { Evaluación del } \\
\text { caso } \\
\text { Institución } \\
\text { Material didác- } \\
\text { tico } \\
\text { Narración } \\
\text { Objetivo } \\
\text { didáctico del } \\
\text { caso } \\
\text { Problema }\end{array}$ & \\
\hline
\end{tabular}




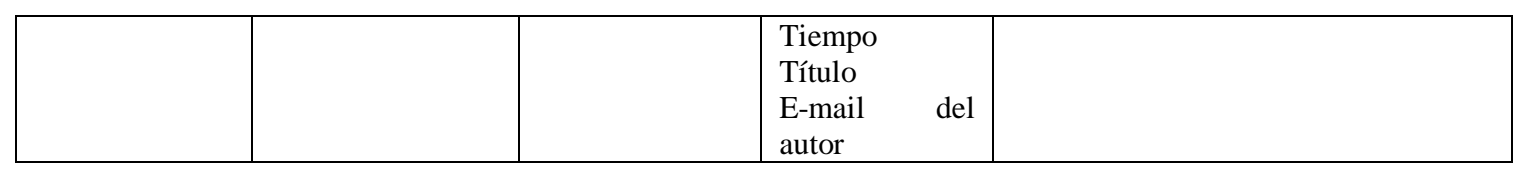

Tabla $\mathrm{N}^{\mathrm{o}}$ 4: diccionario de conceptos

\subsubsection{Relaciones binarias en detalle:}

Aquí se describen detalladamente todas las relaciones binarias incluidas en el diccionario de conceptos. Para cada relación binaria se especifica: nombre de la relación binaria, conceptos origen y destino, cardinalidad y relación inversa.

\begin{tabular}{|c|c|c|c|c|}
\hline Nombre & Concepto origen & $\begin{array}{l}\text { Concepto des- } \\
\text { tino }\end{array}$ & Cardinalidad & Inversa \\
\hline $\begin{array}{l}\text { conte- } \\
\text { nido_material } \\
\text { _educativo }\end{array}$ & $\begin{array}{l}\text { Informática como } \\
\text { Material educativo }\end{array}$ & $\begin{array}{l}\text { Acceso a la } \\
\text { información }\end{array}$ & $1: 1$ & Inversa_contenido_material_educativo \\
\hline $\begin{array}{l}\quad \text { contenido- } \\
\text { alfabetización } \\
\text { _informática }\end{array}$ & $\begin{array}{l}\text { Alfebetización } \\
\text { informática }\end{array}$ & $\begin{array}{l}\text { Contenido in- } \\
\text { formático de los } \\
\text { casos }\end{array}$ & $1: 1$ & $\begin{array}{l}\text { Inversa_contenido_alfabetización_informá } \\
\text { tica }\end{array}$ \\
\hline $\begin{array}{l}\text { conte- } \\
\text { nido_recurso_- } \\
\text { didáctico }\end{array}$ & $\begin{array}{lr}\text { La } & \text { informática } \\
\text { como } & \text { Recurso } \\
\text { didáctico } & \\
\end{array}$ & $\begin{array}{l}\text { Creación } \\
\text { Instructivos } \\
\text { Comunicación }\end{array}$ & $1: 1$ & Inversa_contenido_recurso_didáctico \\
\hline $\begin{array}{l}\text { Contenido_vi- } \\
\text { deo_juego }\end{array}$ & Videojuegos & $\begin{array}{l}\text { Desarrollo de } \\
\text { estrategias }\end{array}$ & $1: 1$ & Inversa_contenido_video_juego \\
\hline $\begin{array}{l}\text { Espacio_de_l } \\
\text { a_práctica_m } \\
\text { aterial_educa- } \\
\text { tivo }\end{array}$ & $\begin{array}{l}\text { Informática como } \\
\text { Material educativo }\end{array}$ & $\begin{array}{l}\text { Química } \\
\text { Física } \\
\text { Matemática } \\
\text { Lengua } \\
\text { Francés } \\
\text { Inglés } \\
\text { Instrucción } \\
\text { cívica } \\
\text { Geografía }\end{array}$ & $1: 1$ & $\begin{array}{l}\text { Inversa_espacio_de_la_practica_material } \\
\text { _educativo }\end{array}$ \\
\hline $\begin{array}{l}\text { Espacio_de_l } \\
\text { a_práctica_alf } \\
\text { abetización_in } \\
\text { formática }\end{array}$ & $\begin{array}{l}\text { Alfabetización } \\
\text { informática }\end{array}$ & Informática & $1: 1$ & $\begin{array}{l}\text { Inversa__ Espa- } \\
\text { cio_de_la_práctica_alfabetización_inform } \\
\text { ática }\end{array}$ \\
\hline $\begin{array}{l}\text { Espacio_de_l } \\
\text { a_práctica_re } \\
\text { curso_didác- } \\
\text { tico }\end{array}$ & $\begin{array}{lr}\text { La } & \text { informática } \\
\text { como } & \text { Recurso } \\
\text { didáctico } & \\
\end{array}$ & $\begin{array}{l}\text { Química } \\
\text { Física } \\
\text { Matemática } \\
\text { Lengua } \\
\text { Francés } \\
\text { Inglés } \\
\text { Instrucción } \\
\text { cívica } \\
\text { Geografía }\end{array}$ & $1: 1$ & $\begin{array}{l}\text { Inversa_Espacio_de_la_práctica_recurso_ } \\
\text { didáctico }\end{array}$ \\
\hline $\begin{array}{l}\text { Espacio_de_l } \\
\text { a_práctica_vi } \\
\text { deojuegos }\end{array}$ & Videojuegos & $\begin{array}{l}\text { Química } \\
\text { Física } \\
\text { Matemática } \\
\text { Lengua } \\
\text { Francés } \\
\text { Inglés } \\
\text { Instrucción } \\
\text { cívica } \\
\text { Geografía }\end{array}$ & $1: 1$ & $\begin{array}{l}\text { Inversa_Espacio_de } \\
\text { la_práctica_videojuegos }\end{array}$ \\
\hline
\end{tabular}

Tabla $\mathrm{N}^{\circ}$ 5: relaciones binarias en detalle 


\subsubsection{Los atributos de las instancias}

La tabla de atributos de instancias describe detalladamente todos los atributos de instancias incluidos en el diccionario de conceptos. Los atributos de instancias son aquellos atributos que describen las instancias de un concepto, y sus valores pueden ser diferentes para cada instancia del concepto.

\begin{tabular}{|c|c|c|c|}
\hline Nombre & Concepto al que pertence & Tipo de valor & Cardinalidad \\
\hline $\begin{array}{l}\text { Agrupamiento de alumnos } \\
\text { Autor } \\
\text { Curso } \\
\text { Espacio físico } \\
\text { Evaluación del caso } \\
\text { Institución } \\
\text { Material didáctico } \\
\text { Narración } \\
\text { Objetivo didáctico del caso } \\
\text { Problema } \\
\text { Tiempo } \\
\text { Título } \\
\text { E-mail del autor }\end{array}$ & Casos de enseñanza & String & 1.1 \\
\hline $\begin{array}{l}\text { Tema } \\
\text { Subtema }\end{array}$ & Contenido informático de los caso & String & $1: 1$ \\
\hline Nombre de los programas & Software & String & $1: 1$ \\
\hline $\begin{array}{l}\text { Nombre de la unidad } \\
\text { Tema de la unidad } \\
\text { Subtema de la unidad }\end{array}$ & Materias de nivel medio & String & $1: 1$ \\
\hline $\begin{array}{l}\text { Nombre de la unidad } \\
\text { Tema de la unidad } \\
\text { Subtema de la unidad } \\
\end{array}$ & Educación física & String & $1: 1$ \\
\hline $\begin{array}{l}\text { Nombre de la unidad } \\
\text { Tema de la unidad } \\
\text { Subtema de la unidad }\end{array}$ & Química & & \\
\hline
\end{tabular}

Tabla $\mathrm{N}^{\mathrm{o}}$ 6: atributos de las instancias

\subsubsection{Atributos de clases:}

La tabla de atributos de clases describe detalladamente todos los atributos de clases incluidos en el diccionario de conceptos.

\begin{tabular}{|l|c|l|l|}
\hline \multicolumn{1}{|c|}{ Nombre } & Concepto donde es definido & Tipo de valor & Cardinalidad \\
\hline Alfabetización informática & Casos de enseñanza & String & 1.1 \\
Material educativo & & & \\
Recurso didáctico & & & \\
Videojuego & & $1: 1$ \\
\hline $\begin{array}{l}\text { Administración de los datos } \\
\text { Ergonomía Hardware } \\
\text { Internet } \\
\text { Origen e historia de la } \\
\text { informática } \\
\text { Software }\end{array} \quad$ String & \\
\hline $\begin{array}{l}\text { Acceso a la información } \\
\text { Compiladores e interpretes } \\
\text { Comunicación } \\
\text { Creación } \\
\text { Desarrollo de estrategias } \\
\text { Instructivos }\end{array}$ & Software & String & \\
Lenguaje de programación & & & \\
Sistemas operativos & & & \\
\hline Química & & & \\
Física & & & \\
Inglés & & String & \\
\hline
\end{tabular}




\begin{tabular}{|l|c|l|l|}
\hline $\begin{array}{l}\text { Francés } \\
\text { Matemática } \\
\text { Informática } \\
\text { Educación cívica }\end{array}$ & & & \\
\hline Periféricos & Hardware & String & \\
\hline Comunicación & Periféricos & String & $1: 1$ \\
\hline Memorias auxiliares & Periféricos & String & $1: 1$ \\
\hline Argentina & Origen e historia de la informática & String & $1: 1$ \\
\hline El mundo & Origen e historia de la informática & String & $1: 1$ \\
\hline Neuquén & Origen e historia de la informática & String & $1: 1$ \\
\hline
\end{tabular}

Tabla $N^{\circ}$ 7: atributos de clase

\subsubsection{Axiomas de la ontología}

A partir de las clases definidas en el glosario de términos y de las propiedades definidas en el apartado anterior se realizaron las siguientes definiciones:

\begin{tabular}{|c|c|c|c|}
\hline $\begin{array}{c}\text { Nombre del } \\
\text { axioma }\end{array}$ & Descripción & Conceptos & Relaciones \\
\hline $\begin{array}{l}\text { Contenidos del } \\
\text { caso alfabetiza- } \\
\text { ción informática }\end{array}$ & $\begin{array}{l}\text { Los caso } \\
\text { alfabetización } \\
\text { informática debe } \\
\text { contener el con- } \\
\text { cepto contenido } \\
\text { Informático }\end{array}$ & $\begin{array}{l}\text { contenido in- } \\
\text { formático de los } \\
\text { casos }\end{array}$ & $\begin{array}{l}\text { Contenido } \\
\text { alfabetización } \\
\text { informática }\end{array}$ \\
\hline $\begin{array}{l}\text { Materia de nivel } \\
\text { medio: Elemen- } \\
\text { tos que contiene } \\
\text { el caso alfabeti- } \\
\text { zación informá- } \\
\text { tica }\end{array}$ & $\begin{array}{l}\text { Los caso } \\
\text { alfabetización } \\
\text { informática debe } \\
\text { contener solo el } \\
\text { concepto materias } \\
\text { de nivel medio } \\
\text { Informática }\end{array}$ & . Informática & $\begin{array}{l}\text { Espacio de la } \\
\text { práctica } \\
\text { alfabetización } \\
\text { informática }\end{array}$ \\
\hline $\begin{array}{l}\text { Contenidos } \\
\text { caso de le la } \\
\text { Informática } \\
\text { como material } \\
\text { educativo }\end{array}$ & $\begin{array}{l}\text { Los casos de in- } \\
\text { formática como } \\
\text { material educativo } \\
\text { debe contener solo } \\
\text { el concepto conte- } \\
\text { nido el software } \\
\text { "Acceso a la } \\
\text { información" }\end{array}$ & $\begin{array}{l}\text { Acceso a la } \\
\text { información }\end{array}$ & $\begin{array}{l}\text { Contenido } \\
\text { material educa- } \\
\text { tivo }\end{array}$ \\
\hline $\begin{array}{l}\text { Materia de nivel } \\
\text { medio: Elemen- } \\
\text { tos que contiene } \\
\text { el caso de la } \\
\text { Informática } \\
\text { como material } \\
\text { educativo }\end{array}$ & $\begin{array}{l}\text { Los caso informá- } \\
\text { tica como material } \\
\text { educativo debe } \\
\text { contener alguno de } \\
\text { los concepto } \\
\text { (Educación_cívica } \\
\text { or Educación_- } \\
\text { física or Física or } \\
\text { Geografía or } \\
\text { francés or Ingles or } \\
\text { Lengua or matemá- } \\
\text { tica or Química) }\end{array}$ & $\begin{array}{l}\text { Educación cívica } \\
\text { Educación Física } \\
\text { Física Geografía } \\
\text { Francés } \\
\text { Inglês } \\
\text { Lengua matemá- } \\
\text { tica } \\
\text { Química }\end{array}$ & $\begin{array}{l}\text { Espacio de la } \\
\text { práctica mate- } \\
\text { rial educativo }\end{array}$ \\
\hline $\begin{array}{l}\text { Contenidos de la } \\
\text { Informática } \\
\text { como recurso } \\
\text { didáctico }\end{array}$ & $\begin{array}{l}\text { Los casos de } \\
\text { informática como } \\
\text { recurso didáctico } \\
\text { debe contener } \\
\text { alguno de los } \\
\text { conceptos } \\
\text { (Instructivos or } \\
\text { creación o comuni- } \\
\text { cación) }\end{array}$ & $\begin{array}{l}\text { Instructivos } \\
\text { Creación } \\
\text { comunicación }\end{array}$ & $\begin{array}{l}\text { Contenido } \\
\text { recurso didác- } \\
\text { tico }\end{array}$ \\
\hline $\begin{array}{l}\text { Materia de nivel } \\
\text { medio: Elemen- } \\
\text { tos que contiene } \\
\text { el caso de } \\
\text { Informática } \\
\text { como recurso } \\
\text { didáctico }\end{array}$ & $\begin{array}{l}\text { Los caso informá- } \\
\text { tica como recurso } \\
\text { didáctico debe } \\
\text { contener alguno de } \\
\text { los conceptos } \\
\text { (Educación_cívica } \\
\text { or Educación_. }\end{array}$ & $\begin{array}{l}\text { Educación cívica } \\
\text { Educación Física } \\
\text { Física Geografía } \\
\text { Francés } \\
\text { Inglés } \\
\text { Lengua matemá- } \\
\text { tica }\end{array}$ & $\begin{array}{l}\text { Espacio de la } \\
\text { práctica recurso } \\
\text { didáctico }\end{array}$ \\
\hline
\end{tabular}




\begin{tabular}{|c|c|c|c|}
\hline & $\begin{array}{l}\text { física or Física or } \\
\text { Geografía or } \\
\text { francés or Ingles or } \\
\text { Lengua or matemá- } \\
\text { tica or Química) }\end{array}$ & Química & \\
\hline $\begin{array}{l}\text { Contenidos del } \\
\text { caso } \\
\text { videojuegos }\end{array}$ & $\begin{array}{l}\text { Los casos de } \\
\text { videojuegos debe } \\
\text { contener solo el } \\
\text { concepto desarrollo } \\
\text { de estrategias }\end{array}$ & $\begin{array}{l}\text { Desarrollo de } \\
\text { estrategias }\end{array}$ & $\begin{array}{l}\text { Contenido } \\
\text { videojuegos }\end{array}$ \\
\hline $\begin{array}{l}\text { Materia de nivel } \\
\text { medio: Elemen- } \\
\text { tos que contiene } \\
\text { el caso } \\
\text { videojuegos }\end{array}$ & $\begin{array}{l}\text { Los caso videojue- } \\
\text { gos debe contener } \\
\text { alguno de los } \\
\text { conceptos (Educa- } \\
\text { ción_cívica or } \\
\text { Educación_física } \\
\text { or Física or Geo- } \\
\text { grafía or francés or } \\
\text { Ingles or Lengua or } \\
\text { matemática or } \\
\text { Química) }\end{array}$ & $\begin{array}{l}\text { Educación cívica } \\
\text { Educación Física } \\
\text { Física Geografía } \\
\text { Francés } \\
\text { Inglés } \\
\text { Lengua matemá- } \\
\text { tica } \\
\text { Química }\end{array}$ & $\begin{array}{l}\text {. Espacio de la } \\
\text { práctica video- } \\
\text { juegos }\end{array}$ \\
\hline
\end{tabular}

Tabla $\mathrm{N}^{\circ}$ 8: axiomas de la ontología

Para esta antología no se consideró definir las constantes en detalle, instancias en detalle y las reglas.

De la ontología propuesta se puede inferir algunas consecuencias analizando las relaciones existentes entre los tipos de casos, el conocimiento informático utilizado y las materias de nivel medio. Por ejemplo, si el conocimiento utilizado en el caso es informático de cualquier tipo (por ejemplo hardware o software) y la materia es Informática entonces el tipo de caso es alfabetización informática. Si el tipo de conocimiento informático utilizado es algún programa de creación (Word, Access, Power Point, Excel, AutoCat, etc.) y el espacio de la práctica es una materia de nivel medio que no es Informática, por ejemplo Química, entonces se puede inferir que el caso es la informática como recurso didáctico. Los casos de enseñaza alfabetización informática los contenidos son necesariamente informáticos; en el otro ejemplo, la informática como recurso didáctico, hay dos o más tipos de contenidos, por un lado el conocimiento informático y por el otro el conocimiento de la materia de nivel medio, en consecuencia podemos afirmar que el docente tiene una intencionalidad de enseñar un conocimiento de una materia de nivel medio usando una herramienta informática. La relación entre los casos videojuegos y los software denominados programas de recreación (juegos de computadoras, juegos en red, etc.) son simétricos. Y el espacio de la práctica de los casos videojuegos puede ser cualquier materia de nivel medio. Los casos de la informática como material educativo -tutoriales, Encarta, Sitios Web de temas específicos, diccionarios, etc.recorren todas las materias de nivel medio.

En la tabla № 9 se especifica la intersección de los conceptos "Materia de nivel medio" y "Contenido informático de los casos" y el caso que le corresponde. Por ejemplo a los casos "Alfabetización informática" y la intersección de la materia "Informática" cubre todos los contenidos informáticos de los casos. 
Identificación de los casos:

1- Alfabetización informática.

2- La Informática como material educativo.

3- La Informática como recurso didáctico.

4- Videojuegos.

\begin{tabular}{|c|c|c|c|c|c|c|c|}
\hline \multicolumn{8}{|c|}{ Algunas materias de nivel medio } \\
\hline \multicolumn{2}{|c|}{ Contenido informático de los casos } & Lengua & Matemática & Informática & Química & Física & Inglés \\
\hline Ergonomía & & & & 1 & & & \\
\hline Internet & & & 3 & 1 & & & \\
\hline \multirow[t]{2}{*}{ Hardware } & Tipo de memoria & & & 1 & & & \\
\hline & Periféricos & & & 1 & & & \\
\hline \multirow[t]{8}{*}{ Software } & $\begin{array}{l}\text { Lenguaje de programa- } \\
\text { ción }\end{array}$ & & & 1 & & & \\
\hline & Acceso a la información & 2 & 2 & 1 & 2 & 2 & 2 \\
\hline & Comunicación & 3 & 3 & 1 & 3 & 3 & \\
\hline & Sistemas operativos & & & 1 & & & \\
\hline & Creación & 3 & 3 & 1 & 3 & 3 & 3 \\
\hline & Compiladores/Interpretes & & & 1 & & & \\
\hline & Desarrollo de estrategias & 4 & 4 & 1 & 4 & 4 & 4 \\
\hline & Instructivos & 3 & 3 & 1 & 3 & 3 & 3 \\
\hline
\end{tabular}

Tabla N ${ }^{\circ}$ 9: resultado de la intersección "Contenidos informáticos" y "materia de nivel medio" y el tipo de caso que le corresponde. 


\section{PARTE V: EL CICLO CBR APLICADO A LA BASE DE CASOS}

\subsection{Introducción}

En este apartado se hará una breve introducción a las características principales del software Micro Isis. Luego se mostrara la metodología CBR aplicado a la base de casos construida bajo dicho programa.

El software Micro Isis -Integrated Set of Information Systems- fue desarrollado en la UNESCO por Giampaolo del Bigio a partir del año 1977. Según el sitio de Web de la $\mathrm{UNESCO}^{41}$ este software se utiliza principalmente para la gestión de datos bibliográficos de bibliotecas, centros de documentación e instituciones sin fines de lucro. El registro oficial de usuario incluye en la actualidad más de 100.000 instituciones y personas que utilizan este software, el número real de beneficiarios, probablemente se puede multiplicar varias veces. Este organismo autoriza su uso gratuitamente. En nuestro país el distribuidor nacional es el Centro de Información CAC, Oficina Isis, de la CNEA ${ }^{42}$.

Las bases documentales de "Micro Isis tienen los campos de longitud variable: se pueden crear índices por cualquier campo e incluso por partes de campos, no requiere una clave primaria, no utiliza varios índices, sino un índice único en donde pueden figurar todos los campos (archivo invertido)". Desde la perspectiva de la recuperación de la información "el MicroISIS tiene un lenguaje de consulta bult in, es decir, un lenguaje construido dentro del programa, que no requiere de conocimientos de la estructura de la base de datos (al menos en una primera aproximación) y que está pensado exclusivamente para satisfacer las necesidades de recuperación de la información. También tiene la posibilidad de recorrer el índice y realizar las consultas a partir de datos positivamente existentes y no dejar sujeta la respuesta de la consulta a la exactitud del tipeo" (Manzanos, 1999).

En síntesis las características más sobresalientes del Micros Isis son ${ }^{43}$ :

- Manejo de un número indefinido de distintas bases de datos, con una información de hasta 500 millones de caracteres, estructurados en registros.

- Puede contener un máximo de 16 millones de registros de hasta 8.000 caracteres desagregables en un máximo de 200 campos diferentes, a su vez, divisibles en subcampos.

- Campos de longitud variable. No es necesario predefinir una longitud del campo, ésta es variable de registro en registro, pudiendo ser nula o extenderse hasta completar la longitud máxima del registro.

- Campos repetibles. Un determinado campo puede repetirse múltiples veces en un mismo registro.

- Potentes recursos de recuperación (búsqueda) de registros seleccionados de acuerdo a su contenido en determinados campos con uso de operadores booleanos y otras expresiones condicionales. Las búsquedas se pueden efectuar por el contenido completo de un campo, por palabras aisladas o secuencia de caracteres.

- Amplias posibilidades de diseño de formularios de ingreso de datos y de formatos de salida impresos, ambos adaptados a información de tipo textual.

\footnotetext{
${ }^{41}$ http://portal.unesco.org/ci/en/ev.php-URL_ID=22423\&URL_DO=DO_TOPIC\&URL_SECTION=201.html (Revisado 29 de octubre de 2011).

${ }^{42} \mathrm{http}: / /$ www.cnea.gov.ar/cac/ci/isis/isidams.htm (revisado 29 de octubre de 2011)

43 http://www.cnea.gov.ar/cac/ci/isis/QUEES.HTM (revisado el 29 de octubre de 2011)
} 
- Salidas en formato ISO 2709 (norma internacional para el intercambio de información documental).

- Operación multilinge: Se puede, en todo momento, durante la operación cambiar el idioma en el que se reciben los mensajes.

- Posibilidad de desarrollar programas para uso específico, utilizando los archivos y funciones del MicroISIS, mediante un lenguaje de programación, subconjunto del PASCAL, denominado ISIS-PASCAL.

\subsection{Aplicación del CBR a la base de casos}

Los casos se almacenan en la base de casos haciendo uso de la hoja de de entrada Figura $\mathrm{N}^{\mathrm{o}} 23$, aquí se aplica la técnica pick list que obliga al usuario ingresar términos seleccionados de la ontología. Figura $\mathrm{N}^{\circ} 24$.

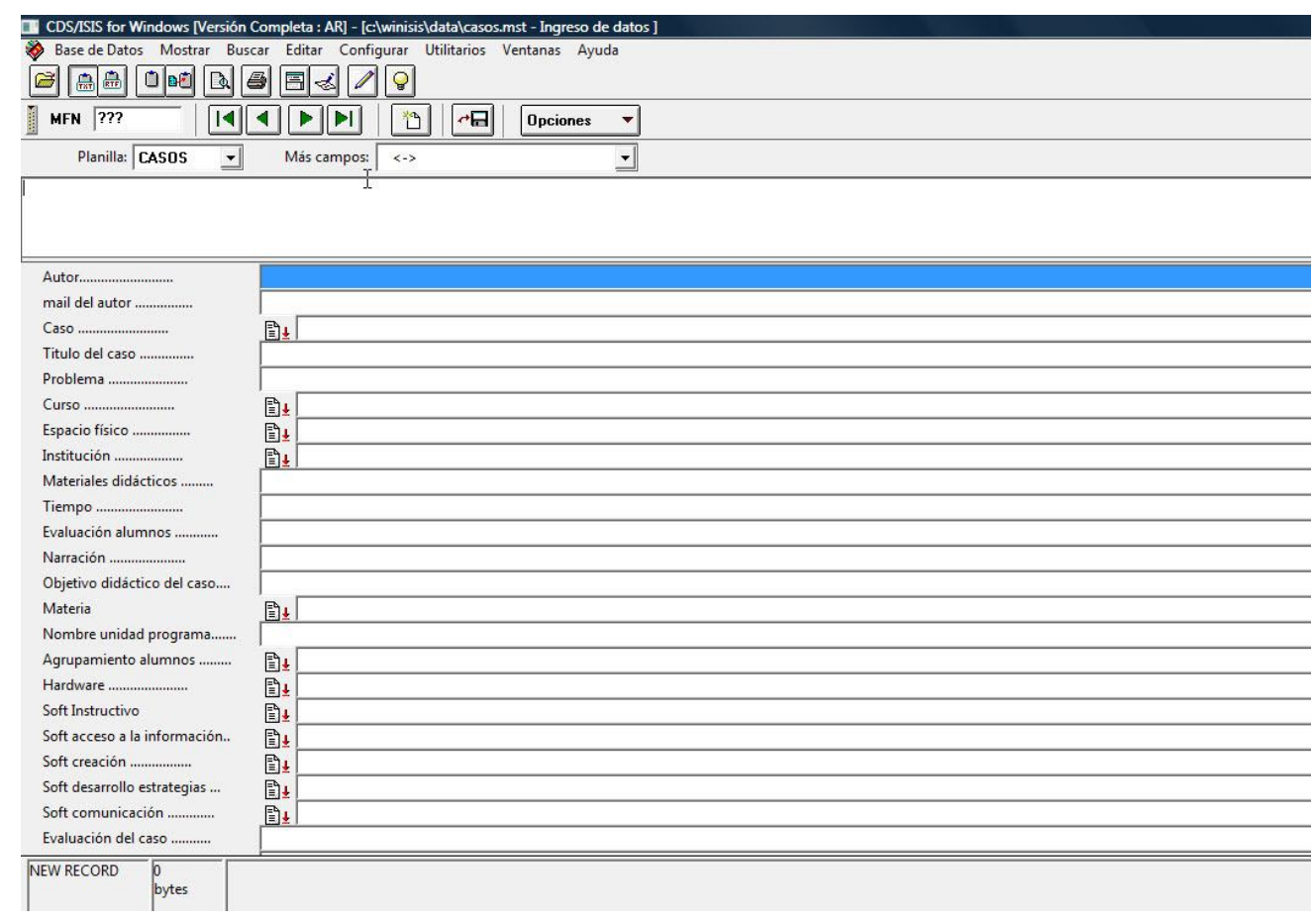

Figura $\mathrm{N}^{\mathrm{o}}$ 23: hoja de entrada del Micro Isis

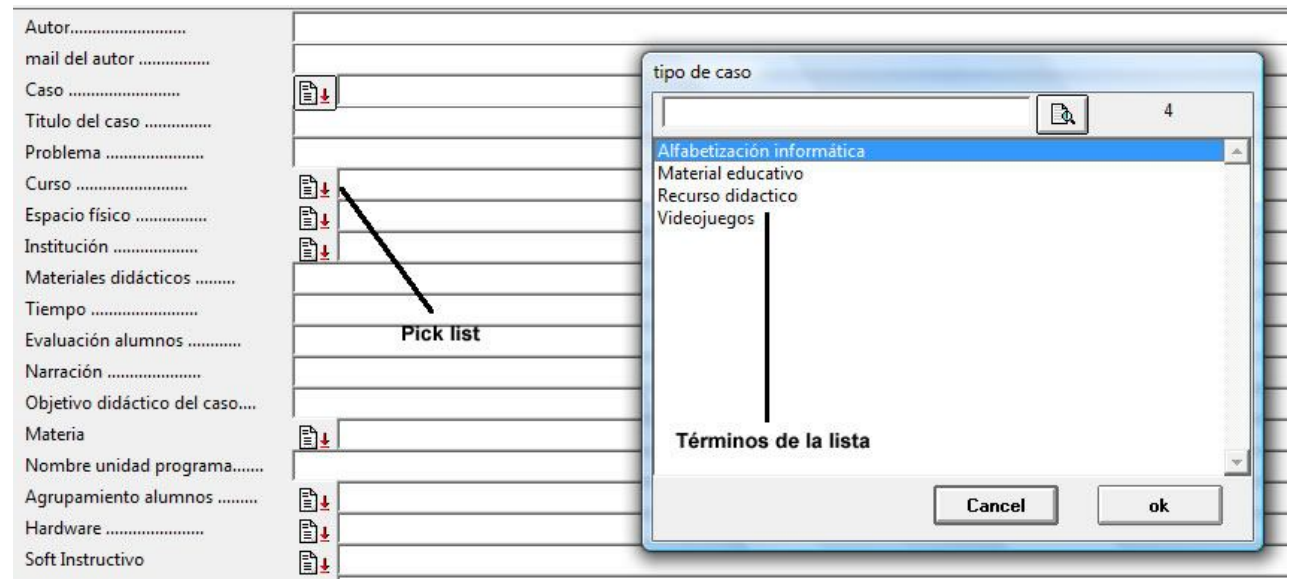

Figura $\mathrm{N}^{\mathrm{0}} 24$ : hoja de entrada con la técnica pick list 
La etapa de recuperación consiste en recuperar uno o más casos similares desde la base de casos utilizando una expresión de búsqueda. La expresión de búsqueda es la formalización del problema nuevo de enseñanza. Esta recuperación, según (Peinado Gil, 2008), se puede hacer utilizando un índice de casos, una función de similitud o una combinación de ambos. Según este autor "Los índices de casos sirven para organizar los casos según una estructura de datos que agrupe los casos con problemas similares entre sí, para evitar tener que realizar en esta etapa una búsqueda lineal exhaustiva sobre todos los casos de la base de casos. Las funciones de similitud sirven para comparar dos problemas y obtener un valor numérico que refleje lo similares que son, lo que permite escoger el caso o los casos más adecuados para resolver un problema dado. También es posible anidar varias etapas de recuperación, una tras otra, para refinar la búsqueda, usando índices de casos o funciones de similitud más precisas en cada iteración”. En esta aplicación, para lograr que los casos similares se agrupen como vecinos, se aprovecha una de las características principales del software propuesto para la implementación de la base de casos. En el Micro Isis las búsquedas se hacen a través de un archivo invertido; esto significa que cada término de búsqueda tiene asociado el conjunto de punteros a los casos que contienen los términos en cuestión. Se propone reconstruir una especie de heurística ${ }^{44}$ para encontrar en una búsqueda de casos aquellos más similares. Se recuerda que los tipos de casos son cuatro: Alfabetización informática, Informática como recurso didáctico y la Informática como material educativo y los videojuegos. Todos los casos de la base de casos deben tener como identificador un tipo de caso ${ }^{45}$-la identificación se define cuando se ingresan los casos utilizando la lista de pick list-. La heurística propuesta aprovecha el archivo invertido y los términos asociados a sus punteros. Por ejemplo -figura 25-, los casos "Alfabetización informática", tiene asociado el término de búsqueda alfabetización informática; cuando se selecciona dicho término desde el diccionario y se hace la ejecución de la búsqueda, el sistema muestra el conjunto de casos asociados al término alfabetización informática punteros 1 y 6-. Colateralmente, la ontología asegura un conjunto de términos mínimos comunes que se almacenan en el diccionario para afinar las búsquedas de casos similares.

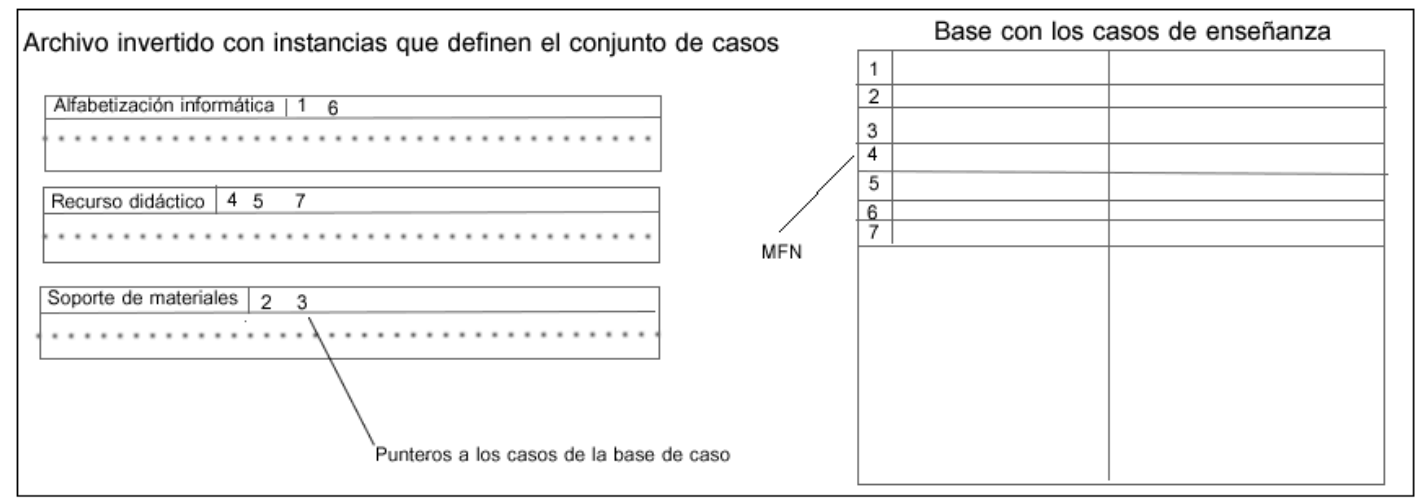

Figura $\mathrm{N}^{\mathrm{o}}$ 25: esquema del archivo invertido

\footnotetext{
44 "Una heurística es cualquier estrategia o truco utilizado para mejorar la eficiencia de un sistema. Las heurísticas presentan un margen de error ya que no representan un análisis exhaustivo del problema, aunque representa una elección aceptable cuando el numero de posibilidades a examinar es muy grande o involucran una función algorítmica muy compleja o desconocida" (Díaz, 2002).

${ }^{45}$ Como se verá en la última etapa del ciclo CBR, en el ingreso a la base del caso nuevo, haciendo uso de los pick list, el sistema obliga al docente a definir el tipo de caso que está ingresando.
} 
La estrategia de búsqueda en el Micro Isis se construye siguiendo los pasos:

1) Se escribe, narra, la expresión de búsqueda con los términos relevantes de un caso dado.

2) De la expresión construida se seleccionan los términos relevantes. Se escriben en la ventana de búsqueda o se eligen del diccionario dichos términos.

3) Existe la posibilidad de utilizar conectores lógicos para reducir o ampliar el número de casos. Los operadores lógicos son: AND, OR Y NOT -se reemplaza por *,,$+ \wedge$ respectivamente-.

4) Se ejecuta la búsqueda.

5) Se muestran los resultados de la búsqueda.

Un problema de enseñanza puede ser el siguiente ejemplo: "qué se debe enseñar para que los alumnos/as adquieran las habilidades necesarias para organizar el disco rígido con el objetivo de mantener ordenado los archivos". La herramienta disponible para trabajar sobre la organización lógica de los archivos es el Explorador de Windows. Los recursos que utilizamos en la organización de un disco son las carpetas.

En este ejemplo los términos relevantes, en principio, pueden ser "Explorador", "Windows", "archivos" y "carpetas". Si el problema de enseñanza se enmarca en otro sistema operativo puedo reemplazar Windows por otro nombre.

Si la consulta implica ampliar la cantidad de casos apuntado por alguno de los dos términos o ambos se debe utilizar el operador lógico OR (+).

Si la consulta intenta reducir la cantidad de punteros a los registros que contienen ambos términos se debe utilizar el operado lógico AND (*).

Si la consulta es para excluir los punteros a un término se debe usar el operador lógico $\operatorname{NOT}\left({ }^{\wedge}\right)$.

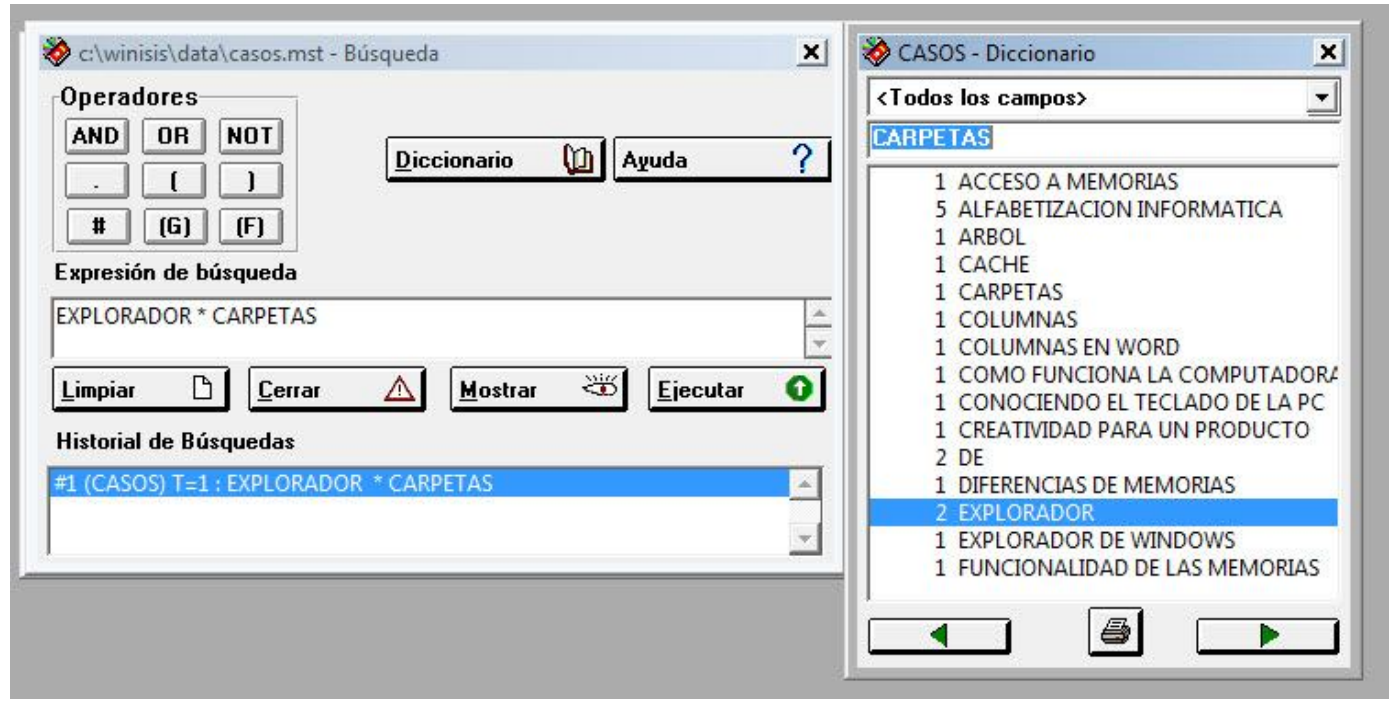

Figura No 26: expresión de búsqueda en Micro Isis

Como regla, si se debe afinar la búsqueda entonces se debe sumar a la expresión otro término, por ejemplo el término alfabetización informática, con el operador lógico AND. En definitiva para afinar las búsquedas se debe sumar más términos de búsqueda a la expresión. 
En las imágenes de abajo se muestra un recorte del resultado de ejecutar la expresión de búsqueda con los dos términos del ejemplo (figura $\mathrm{N}^{\circ} 26$ ). Las palabras pintadas son las palabras que tienen los casos recuperados como términos comunes. En la lista de la izquierda, Figura $\mathrm{N}^{\mathrm{o}} 27$ y 28 , se puede observar que los casos recuperados son casos del tipo "Alfabetización informática".

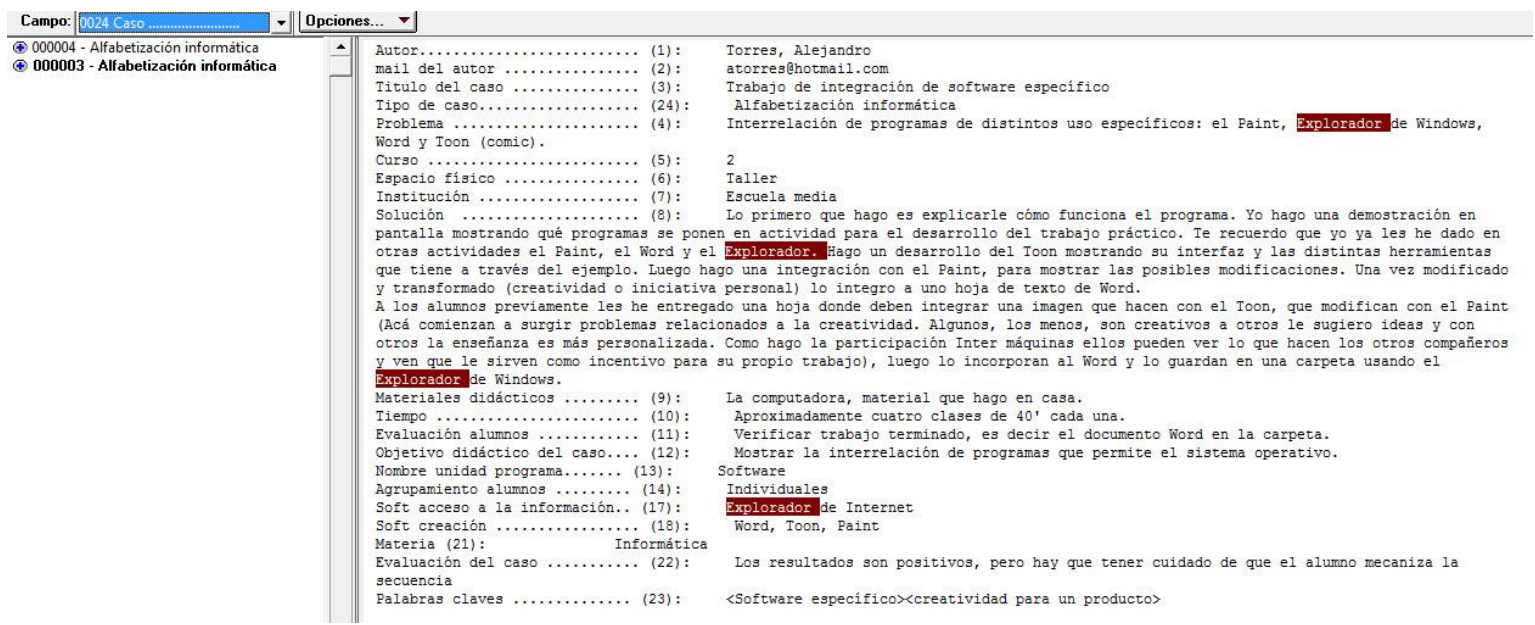

Figura $\mathrm{N}^{\mathrm{o}}$ 27: resultado de ejecutar la expresión de búsqueda, caso 1

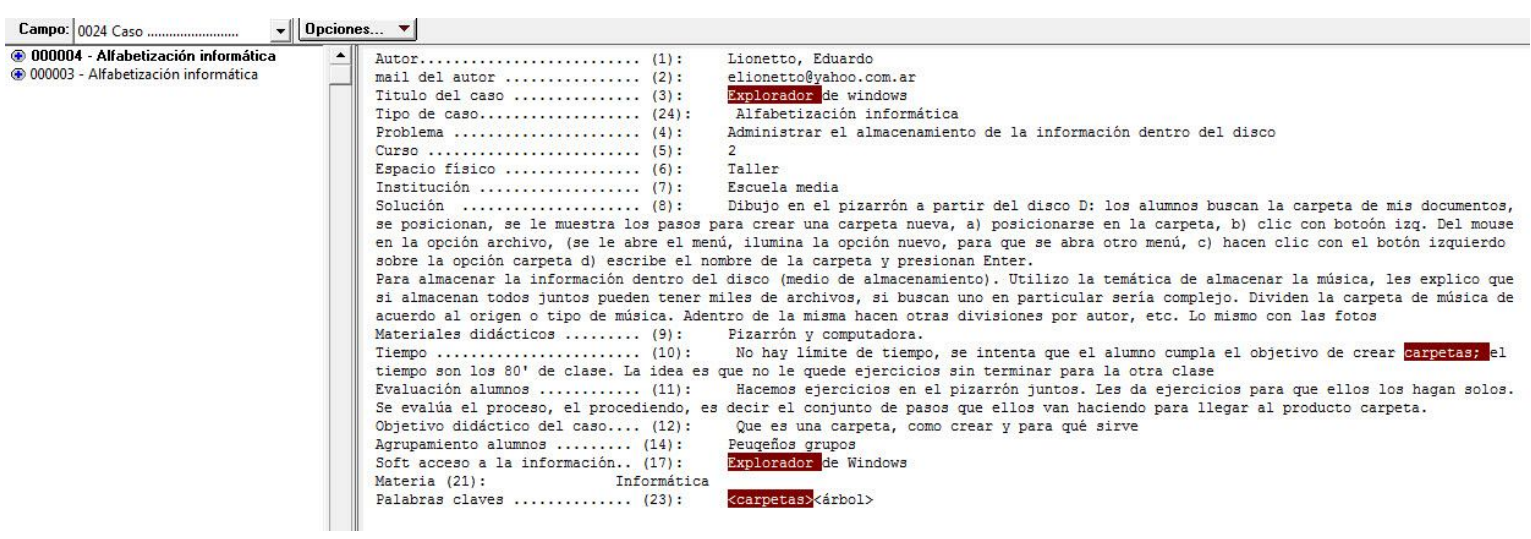

Figura No 28: resultado de ejecutar la expresión de búsqueda, caso 2.

La siguiente etapa del método CBR, la adaptación, la realiza el docente en forma manual; en principio tiene la opción de copiar el resultado o puede usar la analogía o hacer un maping entre los casos recuperados y el caso nuevo usado como búsqueda para obtener un nuevo caso.

La verificación o evaluación de la solución en el mundo real, tercera etapa del método, la hace el docente en el aula, con sus alumnos y la tecnología disponible.

La última etapa, retención o registro de los casos, a diferencia del ejemplo de la base de casos KITE donde el ingreso de los casos lo hace un técnico, en esta propuesta el ingreso del nuevo caso lo hace el propio docente. El ingreso de los datos se realiza mediante las hojas de entrada de datos. El docente debe llenar el campo "Caso" haciendo uso de la técnica PicK-List para especificar el tipo de caso definido en la ontología. Varios son los campos que utilizan la técnica Pick-List; el usuario pueda elegir términos significativos definidos en la ontología para que formen parte del diccionario de términos. Los términos nuevos que no figuran en la lista Pick-List se pueden escribir. Recordemos que el diccionario de términos se utiliza para hacer las búsquedas de casos. 


\section{PARTE VI: CONCLUSIÓN Y TRABAJOS FUTUROS}

El docente cuando se enfrenta a un contendido a enseñar se enfrenta también a la transposición didáctica de ese contenido. Algo similar ocurre con las herramientas y recursos informáticos; la mayoría de los recursos y herramientas que usan los docentes no están diseñados para su uso en el aula, deben resignificarse desde lo operativo y desde lo cognitivo para adecuarlos a los contenidos y al grupo de alumnos que hace uso de ellos. La reutilización de contenidos y herramientas y recursos se desarrolla en una secuencia de hechos, en una narración que puede ser compartida. De ahí la apuesta del presente desarrollo tecnológico en asumir las narraciones de métodos o estrategias de enseñanza como solución de problemas de enseñanza.

El Razonamiento Basado en Caso es un método de resolución de problemas que requiere del supuesto de que un problema similar requiere respuestas similares. Similitud no significa igualdad. Para hacer posible el cumplimiento del ciclo CBR se necesita una base de casos; con la ontología se trabaja en el dominio de los contenidos de casos de enseñanza con tecnología informática, con el objetivo de encontrar conocimientos que permitan modelar las narraciones y para que sean factibles la recuperación de casos con eficiencia. En el CBR la similitud de casos es una noción prioritaria; implica seleccionar los casos que se pueden adaptar fácilmente a la problemática actual, los casos seleccionados tienen -casila misma solución que el problema actual. La similitud en nuestra base de casos se obtiene dividiendo los casos por tipos de casos usando la taxonomía de la ontología; la intersección de contenidos informáticos -herramientas y recursos- y los contenidos curriculares de las materias de nivel medio.

La metodología CBR tiene algunas ventajas cuando intentamos trabajar con un dominio de conocimiento poco estructurado como son las narraciones de los docentes: reduce el esfuerzo de adquisición de conocimientos porque son ellos los que permanentemente suman casos a la base de casos; requiere menos esfuerzo de mantenimiento; mejora con el tiempo y se adapta a los cambios en el entorno; supone, además, una alta aceptación de los usuarios porque son ellos los que moldean el conocimiento de la base de casos. El docente que utiliza la base de casos potencialmente podría beneficiarse de:

a) no comenzar de cero cuando necesita diseñar una metodología o estrategia de enseñanza con contenidos similares a un ya dado;

b) enriquecer los métodos de enseñanza sumando las experiencias de otros docentes cuando se dispone a enseñar los mismos contenidos o similares;

c) establecer un análisis crítico de los métodos de enseñaza para su posterior rectificación;

d) analizar qué estructura subyace a un cuerpo de conocimiento para determinar los problemas que se debe afrontar al momento de su enseñanza;

e) analizar comparativamente los resultados de los métodos de enseñanza usados en otras disciplinas afines sin recursos informáticos con los resultados obtenidos con la utilización de la informática;

La ontología propuesta permite vislumbrar que los distintos tipos de narraciones están intersecadas por el contenido informático y por el contenido curricular de las materias de nivel medio. Esto implica metodologías o estrategias de enseñanza donde la Informática es su objeto de estudio; metodologías o estrategias de enseñanza donde la Informática se asume como un conjunto de herramientas y recursos embebidos en contenidos no informáticos. A su vez, la ontología permite iluminar el discutido campo de la 
significación de los conceptos informáticos que los docentes imparten a diario en las escuelas. Este campo de significación, además, adquiere relevancia adicional al momento de diseñar una base de casos y de recuperar los casos similares de la base de casos.

La combinación de una ontología, construida sobre un marco teórico que da cuenta del uso de la tecnología informática para la enseñanza en las escuelas de nivel medio, con el método CBR, que define a los métodos o estrategias de enseñanza en el espacio de resolución de problemas, parece ser un buen camino metodológico para el diseño y construcción de una base de casos donde prevalece el contenido en forma de narración y donde los casos están organizados en función de las similitudes obtenidas por la ontología.

Trabajos futuros:

a) Analizar la factibilidad de emigrar la base de casos a una aplicación basada en una arquitectura cliente/servidor para ambientes Web.

b) Diseñar actividades para la formación docente alrededor de la base de casos de enseñanza.

c) Rescatar de la base de casos procesos cognitivos y operativos que permitan abonar una futura didáctica de la tecnología.

Para concluir el autor quiere destacar, en forma sintética, dos cuestiones centrales que enmarcan la tesis desde la perspectiva de la creación del conocimiento. Por un lado se recupera de Levy (2004) la noción que denomina "inteligencia colectiva". La define como "una inteligencia repartida en todas partes, valorizada constantemente, coordinada en tiempo real, que conduce a una movilización efectiva de las competencias... el fundamento y el objetivo de la inteligencia colectiva es el reconocimiento y el enriquecimiento mutuo de las personas, y no el culto de comunidades fetichizadas o hipóstasiadas" (Levi, 2004:19). La inteligencia colectiva está repartida en todas partes y todos saben algo que puede ayudar a acrecentar el conocimiento. Esta noción se basa en la hipótesis de que en el entramado social se abre un nuevo "Espacio antropológico", un espacio caracterizado por "un sistema de proximidad (espacio) propio del mundo humano y que depende de las técnicas de las significaciones, lenguaje, la cultura, las convenciones, las representaciones y las emociones humanas" (Levy, 2004:15). Las tecnologías informáticas en este espacio se presentarían entonces como "la infraestructura técnica del cerebro colectivo o de la hipercorteza de comunidades vivas" con el propósito de "favorecer la construcción de colectivos inteligentes en los que las potencialidades sociales y cognitivas de cada cual podrán desarrollarse y ampliarse mutuamente" (Levy, 2004 y Serra, 1999). Por otro, Bruner (1997:144), considerando el soporte narrativo, escribe que "El proceso de creación de la ciencia es narrativo... la historia de la ciencia se puede recontar dramáticamente como una serie de narraciones casi heroicas sobre resolución de problemas" y "la narración como una forma de pensar, como una estructura para organizar nuestro conocimiento y como un vehículo en el proceso de la educación, particularmente en la educación de la ciencia".

Para finalizar, recorriendo las huellas trazadas por el desarrollo de la tesis, se puede decir que la idea que subyace en todo el camino es el de intentar incrementar la infraestructura tecnológica que posibilite, potencialmente, la construcción de conocimiento colectivo a través de los docentes, que tienen mucho que aportar a la enseñanza, y que ese conocimiento se soporta sobre una estructura narrativa. 


\section{BIBLIOGRAFÍA}

Abad, M. T. (2004) Ontologías. Recuperado el de 10 de diciembre de 2010, de: http://www.slideshare.net/cuacua/3-rc2-ontologias-2

Acevedo Díaz, J. A. (2006). Modelos de relaciones entre ciencia y tecnología: un análisis social e histórico. Revista Eureka sobre enseñanza y divulgación de las ciencias, año/vol. 3, número 002, Cadiz, España, pp.198-218. Recuperado el 20 de diciembre de 2010, de: http://redalyc.uaemex.mx/pdf/920/92030203.pdf

Aprea, G. (2006). "Los maestros en la sociedad del conocimiento", en: José Borello, Verónica Robert, Gabriel Yoguel (editores): La informática en la Argentina. Desafios a la especialización y a la competitividad, pp. 249-261. Prometeo Libros, $1^{\mathrm{a}}$ edición, Buenos Aires.

Babibi, N. (1991). La Informática en la Argentina 1956-1966, Ediciones Letra Buena , $1^{\text {a }}$ edición, Buenos Aires.

Barchini, G. E., Sosa, M. y Herrera, S. (2004). La informática como disciplina científica. Ensayo de mapeo disciplinar. Recuperado el 14 de diciembre de 2010, en: http://laboratorios.fi.uba.ar/lie/Revista/Articulos/010102/A1may2004.pdf

Bartolomé, A. y Aiello, M. (2006). "Nuevas tecnologías y necesidades formativas. Blended Learning y nuevos perfiles en comunicación audiovisual". En: Revista Telos. Cuadernos de comunicación e innovación, $\mathrm{N}^{\circ}$ 67, abriljunio de 2006. Recuperado el 10 de agosto de 2011, de: http://sociedadinformacion.fundacion.telefonica.com/telos/articulocuader no.asp@idarticulo=2\&rev=67.htm

Benbenaste, N. (1995). Sujeto $=\frac{\text { política } x \text { tecnología }}{\text { mercado }}, 3^{\text {a }}$ edición, Oficina de Publicaciones del CBC, Buenos Aires.

Bergmann, R. (2000). Introduction to Case-Based Reasoning. Recuperado el 24 de febrero de 2009, en: http://www.rogerschank.com/docs/Bergmann-CBRSurvey.pdf

Bergmann, R., Kolodner, J. y Plaza, E. (2005). Representation in case-based reasoning. Recuperado el 16 de mayo de 2005, en: http://www2.iiia.csic.es/People/enric/papers/Representation_in_CBR.pdf

Boekaerts, M. (2006). Motivar para aprender, Ceneval. Recuperado el 21 de diciembre de 2010,

en: http://www.ibe.unesco.org/fileadmin/user upload/Publications/Education al_Practices/EdPractices_10s.pdf.

Boggino, N. (2004). El constructivismo en el aula, Homo sapiens, $1^{\text {a }}$ edición, Rosario.

Botia, A. B. (1993). ““'Conocimiento didáctico del contenido” y formación del profesorado el programa de L. Shulman". En: Revista Universitaria de Formación del Profesorado, pp. 113-124, No 16, año 1993. Recuperado el 21 de diciembre de 2010, en: http://dialnet.unirioja.es/servlet/articulo?codigo $=286602$

Brito Peixoto, A. S. y Oliveira, R. (1995). "Terminologia do ensino por computador: abordagem socioterminológica”. En: Ciência da Informação - Vol. 24, 
número 3. Recuperado El 14 de diciembre de 2010, en: http://capim.ibict.br/index.php/ciinf/article/view/500/454.

Bruner, J. (1983). Juego, pensamiento y lenguaje. Recuperado el 20 de octubre de 2010, en: http://www.salesianoslitoral.org.ar/files/formacion/pedagogia/documentos /juego_pensamiento_lenguaje.pdf.

Bruner, J. (1995). Actos de significado. Más allá de la revolución cognitiva, Alianza Psicología Minor, $1^{a}$ reimp. Madrid.

Bruner, J. (1997). La educación puerta de la cultura, Visor Dis.,S.A., Madrid, 1997.

Brünner, J. J. (2003). Educación e Internet ¿La próxima revolución?, Fondo de Cultura Económica, Santiago, Chile.

Buch, T. (1999). Sistemas tecnológicos, Aique, Buenos Aires.

Buckingham, B. (2008). Más allá de la tecnología. Aprendizaje infantil en la era de la cultura digital, Manantial, $1^{\mathrm{a}}$ edición, Buenos Aires.

Burghi Cambón M. S. y Bourdieu, M. V. (2009). "Los videojuegos como construcciones de realidad contemporánea" en: Roxana Cabello (coordinadora), Ciberjuegos. Escritos sobre usos y representaciones de los juegos en red, Imago Mundi, $1^{\text {a }}$ edición, pp. 11-31, Buenos Aires.

Busaniche, B. (2007). "Alfabetización digital: las fronteras del aprendizaje y el control de la información”. En: Roxana Cabello y Diego Levis: Medios informáticos en la educación a principios del siglos XXI, Prometeo, $1^{\mathrm{a}}$ edición, Buenos Aires.

Capella, J. V. y Ors, R. (2002). Propuesta metodológica para la impartición de Informática Industrial en la titulación de Ingeniería en Automática y Electrónica en el marco del proyecto EUROPA. Recuperado el 12 de agosto de 2011, en: http://bioinfo.uib.es/ joemiro/aenui/procJenui/Jen2002/Cac505_509.pdf

Carrillo, J. A. (2007). Introducción al Razonamiento Basado en Casos (CBR). Recuperado el 12 de septiembre de 2008, en: www.infor.uva.es/ calonso/IAII/Aprendizaje/.../RBCmemoria.pdf.

Castell, M. (2002). "Epílogo: Informacionalismo y la sociedad red", en Pekka, Himanen, La ética del hacker y el espíritu de la era de la información, Destino, $1^{\mathrm{a}}$ reimpresión, Buenos Aires.

Castells, M. (1999). La revolución de la tecnología de la información. Recuperado el 02 de agosto de 2010 en: http://cdi.mecon.gov.ar/biblio/docelec/MM2161.pdf.

CDS/ISIS for Windows download page. Versión 1.5 Build 3. Software en línea. Revisado el 10 de agosto de 2010, en: http://www.unesco.org/isis/files/winisislicense.html.

Chevallard, Y. (1991). La transposición didáctica. Del saber sabio al saber enseñado, Aique, $1^{\text {a }}$ edición, Buenos Aires.

Ciapuscio, H. P. (1994). El fuego de prometeo. Tecnología y sociedad, , EUDEBA, $1^{\text {a }}$ edición, Buenos Aires.

Cobo Romaní, C. (2007): "Intercreatividad y Web 2.0. La construcción de un cerebro digital planetario" en: Cobo Romaní, C. y Pardo Kuklinski, H. Planeta 
Web 2.0. Inteligencia colectiva o medios fast food. Grup de Recerca d'Interaccions Digitals, Universitat de Vic. Flacso México. Barcelona/ México DF.

Coll, C. (2009). "Aprender y enseñar con las TIC: expectativas, realidad y potencialidades". En: Carneiro, R., Tozcano, J.C. y Díaz, T. Los desafíos de las TIC en el cambio educativo. Fundación Santillana, Madrid. Recuperado el 5 de octubre de 2011 en: http://www.oei.es/publicaciones/detalle_publicacion.php?id=10

Cristina Davini, M. C. (2008). Métodos de enseñanza: didáctica general para maestros y profesores, Santillana, $1^{a}$ edición, Buenos Aires.

Cupani, A. (2006). La peculiaridad del conocimiento tecnológico, Associação Filosófica Scientiæ Studia, , V.3, Sao Paulo. Recuperado el 24 de septiembre del 2007, en: http://www.scientiaestudia.org.br/revista/PDF/04_03_01.pdf.

Denning, P. J. (2005). ¿Es la Ciencia de la Computación Ciencia? Recuperado el 15 de agosto de 2011, en: http://www.cs.gmu.edu/cne/pjd/PUBS/CACMcols/cacmApr05Span.pdf.

Díaz Agudo, B. (2002). Una aproximación ontológica al desarrollo de sistemas de Razonamiento Basado en Casos. Recuperado el 08 de diciembre de 2009, en: http://www.ucm.es/BUCM/tesis/eis/ucm-t26195.pdf.

Elmasri, R. y Navathe, S. (2002). Fundamentos de sistema de base de datos, Parson Eduación, $3^{\text {a }}$ edición, Madrid.

Epelman, M., Fontana, D. y Neffa, J. C. (1990). Efecto de las nuevas tecnologías informatizadas sobre la salud de los trabajadores, Hvmanitas-Credal, $1^{\text {a }}$ edición, Buenos Aires.

Ertmer, P. A., Stepich, D. A. y otros (2009). The Role of Knowledge and Experience in Expert Problem Solving. Recuperado el 13 de abril de 2009, en: http://www.edci.purdue.edu/ertmer/docs/AERA07_Exp_PS.pdf.

Esnaola, G. A. (2006). Claves culturales en la construcción del conocimiento ¿Qué enseñan los videos juegos?, Alfagrama, $1^{\text {a }}$ edición, Buenos Aires.

Felipe, A. E., Gallarreta, S. C. y Merino, G. (2006). Aportes para la utilización de analogías en la enseñanza de las ciencias. Ejemplos en biología del desarrollo. Recuperado el 10 de diciembre de 2010, en: www.rieoei.org/deloslectores/1233Felipe.pdf.

Fenstermacher, G. (1989). Tres aspectos de la filosofía de la investigación sobre la enseñanza. En: Wittrock, M. La investigación en la enseñanza I. Paidós, Madrid.

Fernández, I., Gil, D., Vilches, A., Valdés, P., Cachapuz, A., Praia, J. y Salinas, J. (2003). "El olvido de la tecnología como refuerzo de las visiones deformadas de la ciencia”. En: Revista Electrónica de Enseñanza de las Ciencias; vol. 2, $\mathrm{N}^{\mathrm{o}}$ Especial.

Fernández, M., Gómez-Pérez, A. y Natalia Juristo, N. (1997). METHONTOLOGY: From Ontological Art Towards Ontological Engineering. Recuperado el 23 de febrero de 2010, en: http://www.aaai.org/Papers/Symposia/Spring/1997/SS-97-06/SS97-06005.pdf. 
Freiría, J. (1996). Psicología contemporánea, Oficina de Publicaciones del C.B.C., $3^{\mathrm{a}}$ edición, Buenos Aires.

Gallego Arrufat, M.J. (1998). Investigación en el uso de la informática en la enseñanza, Pixel-Bit: Revista de medios y educación, $\mathrm{N}^{\mathrm{o}} 11$. Recuperado el 15 de octubre de 2011, en: http://www.sav.us.es/pixelbit/pixelbit/articulos/n11/n11art/art111.htm\#

García Peñalvo, F. J. (2004). Web Semántica y Ontologías, Departamento de Informática y Automática. Facultad de Ciencias, Universidad de Salamanca. Recuperado el 02 de marzo de 2010, en: http://zarza.usal.es/ fgarcia/doctorado/iuce/WSemantica.pdf.

Giuliano, G. (2007). Interrogar la Tecnología: algunos fundamentos para un análisis crítico, Nueva librería, $1^{a}$ edición, Buenos Aires.

Grigoris Antoniou, G. (2008). A Semantic Web Primer, The MIT Press, $2^{\text {a }}$ edición, Cambridge, Massachussets, London, England.

Gros Salvat, B. (2000). El ordenador invisible, Gedisa, $1^{\text {a }}$ edición, Barcelona.

Gros Salvat, B. (2000). La dimensión socioeducativa de los videojuegos, Revista electrónica de tecnología educativa, $\mathrm{N}^{\circ} 12$. Recuperado el 8 de septiembre de 2010, en: http://edutec.rediris.es/Revelec2/Revelec12/PDF/gros.pdf

Gruber, T. (2007). "Ontology". Recuperado El 06 de junio de 2011, en: http://tomgruber.org/writing/ontology-definition-2007.htm.

Hamesse, J. (1998). "El modelo escolástico de la lectura". En: Guglielmo Cavallo y Roger Chartier: Historia de la lectura en el mundo occidental, Taurus, $1^{\text {a }}$ edición, Madrid.

Herschbach, D. R. (2007). La tecnología como conocimiento: implicancias para la educación. Recuperado el 12 de noviembre de 2007, en: http://coleccion.educ.ar/coleccion/CD15/contenidos/recursos/lectura/pdf/t ecn como conoc.pdf.

Jonassen, D. H. y Hernandez-Serrano, J. (2002). Case-Based Reasoning and Instructional Design: Using Stories to Support Problem Solving. Recuperado el 15 de abril de 2012, en: http://jesserbishop.wiki.westga.edu/file/view/casebased+instructional+design.pdf

Kolodner, J. L. (B) Instructional Design: Case-Based Reasoning. Recuperado el 16 de mayo 2009,

en: http://www.cc.gatech.edu/projects/lbd/pdfs/instdesign.pdf .

Kolodner, J. L., Cox, M. T. y Gonzalez-Calero, P.A. (A) "Case-based reasoning-inspired approaches to education". Recuperado el 23 de febrero de 2009, en: http://mcox.org/Papers/Ed-in-CBR-final.pdf

Kolodner, J. L., Simpson, R. L., y Katia Sycara-Cyranski, K. (1985). A process model of cased-based reasoning in problem solving. Recuperado el 23 de febrero de 2009, en: http://dli.iiit.ac.in/ijcai/IJCAI-85-VOL1/PDF/053.pdf .

Kriscautzky Laxague, M. (2011). Programa h@bitat puma: Alfabetización digital y formación de profesores en la UNAM. Recuperado el 8 de agosto de 2011, en: http://www.virtualeduca.info/ponencias2011/167/Kriscautzkyhabitatpuma-formaciondocenteUNAM.docx. 
Lacuesta, R. y Catalán, C. (2004) Aprendizaje Basado en Problemas: Una experiencia interdisciplinar en Ingeniería Técnica en Informática de Gestión. Recuperado el 12 de agosto de 2011, en: http://www.dccia.ua.es/jenui2004/actas/ponencias/ponencia35.pdf.

Leliwa, S. (2008). Enseñar educación tecnológica en los escenarios actuales, Comunicarte, $1^{\mathrm{a}}$ edición. Córdoba.

Levis, L. (2007). "Enseñar y aprender con informática/Enseñar y aprender informática. Medios informáticos en la escuela". En: Cabello, R. y Levis, D. Medios informáticos en la educación a principios del siglos XXI, Prometeo, $1^{\mathrm{a}}$ edición, Buenos Aires.

Lévy, P. (2004). Inteligencia colectiva, BIREME. OPS. OMS. Recuperado el 16 de abril de 2011, en: http://inteligenciacolectiva.bvsalud.org.

Liu, Y. (1999). "Dean Ginther: "Cognitive Styles and Distance Education”, en: Online Journal of Distance Learning Administration, Fall1999 State University of West Georgia, Distance Education; Volume II, Number III, Recuperado el 28 de junio de 2011, en: http://www.westga.edu/ distance/liu23.html.

Lopez, R. V. (2003). "El vocabulario metafórico de Internet y su traducción al español". En: Postiguillo, S., Ortells, E., Prado, J. R., Bolaños, A. y Alcina, A. (editores): Internet, in linguistics, translation and literary studies, Castelló de Plana: Publicacions de la Universitat Jaime, I.D.L.

Lozano, L. y Javier Fernández, J. (2008). Razonamiento Basado en Casos: "Una Visión General”. Recuperado el 03 de diciembre de 2008, en: http://www.infor.uva.es/ calonso/IAI/TrabajoAlumnos/Razonamiento\%2 Obasado\%20en\%20casos.pdf.

Mandón, M. J. y Marpegán, C. M. (1999). “Armando el mecano. Aportes teóricos y metodológicos para una didáctica de la Educación Tecnológica”. En: III Congreso Internacional de (Tele) Informática Educativa y II Foro Regional de Tecnología. Universidad Tecnológica Nacional, Santa Fe.

Manzanos, N. (1999). “Por qué ISIS?”. En: Centro de información CAC-CNEA: Manual para instructores de Winisis. Recuperado el 03 de noviembre de 2009, en: www.caicyt.gov.ar/productos/manuales-especializados1/manualwinisis 131.pdf

Martín, María de los Ángeles (2004). Sistema de catalogación de métricas e indicadores con potencia de Web semántica. Recuperado el 11 de abril de 2010, en: http://gidis.ing.unlpam.edu.ar/home/downloads/Tesis-Martin.pdf.

Méndiz, A., Pindado J., Ruiz, J. y Pulido, J. Mª (2001). Videojuegos y educación: revisión crítica de la investigación realizada. Recuperado el 20 de octubre de 20120 en: http://ares.cnice.mec.es/informes/02/documentos/iv04_0301a.htm

Moore, J. L., Means, T. y Bosung Kim, B. (2007). Applying Case-Based Reasoning within a Technology Integration Learning Environment. Recuperado el 11 de febrero de 2010 en: http://tile.missouri.edu/others/CBRandTILE.pdf

Muraro, S. (2005). Una introducción a la informática en el aula, Fondo de Cultura Económica de Argentina, $1^{a}$ edición, Buenos Aires. 
Noguera, I. M. (1992). Un estudio sobre la aplicación del razonamiento basado en casos a la construcción de programas. Recuperado el 09 de diciembre de 2008, en: http://eprints.ucm.es/tesis/19911996/X/1/X1004601.pdf (Revisado 0912-2008).

Novak, J. D. (1982). Teoría y práctica de la educación, Alianza Editorial, $1^{a}$ edición, Madrid.

Papert, S. (1984). Desafío a la mente. Computadoras y educación, Galápagos, $3^{a}$ edición, Buenos, Aires.

Papert, S. (1997). La familia conectada, Emecé, $1^{\text {a }}$ edición, Buenos Aires.

Pardo Kuklinski, H. (2007). "Nociones básicas alrededor de la Web 2.0.”. En: Cobo Romaní, C. y Pardo Kuklinski, H. Planeta Web 2.0. Inteligencia colectiva o medios fast food. Grup de Recerca d'Interaccions Digitals, Universitat de Vic. Flacso México. Barcelona / México DF.

Peinado Gil, F. (2008). Un armazón para el desarrollo de aplicaciones de narración automática basado en componentes ontológicos reutilizables. Recuperado el 22 de marzo de 2010, en: http://www.scribd.com/doc/9178791/Tesisontologia.

Peinado, F., Gervás, P., y Díaz-Agudo, B. (2004). A Description Logic Ontology for Fairy Tale Generation. Recuperado el 18 de febrero de 2010, en: http://www.fdi.ucm.es/profesor/fpeinado/publications/2004-peinadodescription.pdf.

Pentiraro E. (1985). El ordenador en el aula. Anaya Multimedia, Madrid.

Ramos, E. y Nuñez, H. (2007A). ONTOLOGÍAS: componentes, metodologías, lenguajes, herramientas y aplicaciones. Recuperado el 23 de febrero de 2010, en: http://www.ciens.ucv.ve/escueladecomputacion/documentos/archivo/51.

Ramos, E., Pereira, Y. y Núñez, H. (2007B) Aplicación de visualización de una ontología para el dominio del análisis del semen humano. Recuperado el 23 de febrero de 2010, en: http://www.eafit.edu.co/NR/rdonlyres/072CAD307808-49AD-8DB1-6F0D60BBDE27/0/OntologiaALS.pdf.

Raskin, J. (2001). Diseño de sistemas interactivos. La importancia de nuestra relación con las computadoras, Pearson Educación, $1^{a}$ edición, México.

Resnick, M. (2008). Sembrando las semillas para una sociedad más creativa. Recuperado el 12 de febrero de 2011, en: http://www.eduteka.org/modulos/9/284/914/1.

Salomón, G., Perkins, D. N. y Globerson, T. (1992). Coparticipando en el conocimiento: la ampliación de la inteligencia humana con las tecnologías inteligentes. Recuperado el 21 de mayo de 2011, en: https://sparta.ing.puc.c1/ImpactoSocialTI/files/7/70/Salomon1992.pdf.

Scolari, C. (2004). Hacer clic, Gedisa, $1^{\text {a }}$ edición, Barcelona.

Serra, A. (1999). Tres claves para entender el fenómeno Internet. La factoría [en línea], febrero-mayo de 1999, $\mathrm{N}^{\circ}$ 8, Recuperado el 24 de abril de 2010, en www.revistalafactoria.eu

Serrano Santoyo, A. y Martinez Martines E. (2003). La brecha digital: mitos y realidades, Departamento Editorial Universitaria de Baja California. 
Silenzi, M. I. (2007). El problema de marco Considerado desde una perspectiva cognitiva. Recuperado el 24 de abril de 2010, en:

http://www.jornadashumha.com.ar/PDF/2007/EL\%20problema\%20de\%2 0marco\%20considerado\%20desde\%20una\%20perspectiva\%20cognitiva \%20-\%20Maria\%20Ines\%20Silenzi.pdf.

Silvera, C. (2005). La alfabetización digital: una herramienta para alcanzar el desarrollo y la equidad en los países de América latina y el Caribe. Recuperado el 22 de octubre de 2010, en: http://scielo.sld.cu/pdf/aci/v13n1/aci04105.pdf.

Socorro, R. et al (2008). Las ontologías en la representación del conocimiento. Recuperado el 16 de febrero de 2011, en: http://nopiedra.files.wordpress.com/2008/05/rep-con-ontologias.pdf.

Squires, D. y McDougall, A. (2001). Como elegir y utilizar el software educativo, Ediciones Morata, $2^{a}$ edición, Madrid.

Thagard, P. (2008). La mente. Introducción a las ciencias cognitivas, Katz Editores, $1^{\mathrm{a}}$ edición, Madrid.

Tomaél, M. I. et al (2001). "Evaluación de fuentes de información en Internet: Criterios de calidad", en: Ciencias de la Información, Vol. 32, No. 2. Recuperado el 10 de octubre de 2010, en: http://www.cinfo.cu/Userfiles/file/Cinfo/cinfo2001/v32n2a2001/evaluaci on.pdf.

Vosniadou, S. (2006). Cómo aprenden los niños, Ceneval. Recuperado el 21 de diciembre de 2010 ,

en: http://www.ibe.unesco.org/fileadmin/user upload/Publications/Education al_Practices/EdPractices_7s.pdf.

Wassermann, S. (2006). El estudio de casos como método de enseñanza, Amorrortu, $1^{\mathrm{a}}$ edición, $1^{\text {a }}$ reimp., Buenos Aires.

Watson, I. (1999). Case-based reasoning is a methodology not a technology. Recuperado el 24 de octubre de 2008, en: http://www.sciencedirect.com/science? ob=ArticleURL\& udi=B6V0P$3 \mathrm{X} 7 \mathrm{NCCH}-$

F\& user $=1673534 \&$ rdoc $=1 \& \mathrm{fmt}=\&$ orig $=$ search $\&$ sort $=\mathrm{d} \&$ view $=\mathrm{c} \&$ _version $=1 \&$ \& urlVersion $=0 \& \_$userid $=1673534 \& \mathrm{md} 5=1 \mathrm{~b} 1 \mathrm{acfe} 7179 \mathrm{f} 6 \mathrm{~d} 51$ $2604659295828 \mathrm{be} 4$.

Watson, I. y Marir, F. (2000). Case-Based Reasoning: A Review. Recuperado el 08 de abril de 2010, en: http://www.ai-cbr.org/classroom/cbr-review.html.

Winisis (2003)

Manual de Referencia (Versión 1.5). División de la Sociedad de la Información Sector de Comunicación e Información, UNESCO. 

Anexo A: Glosario de términos:

\begin{tabular}{|c|c|c|c|c|}
\hline Nombre & Sinónimo & Acrónimo & Descripción & Tipo \\
\hline contenido_material_educativo & & & $\begin{array}{l}\text { Relación binaria que establece nexo } \\
\text { entre un caso informática como } \\
\text { material educativo y contenido } \\
\text { informático. }\end{array}$ & Relación \\
\hline .contenido_recurso_didáctico & & & $\begin{array}{l}\text { Relación binaria que establece nexo } \\
\text { entre un caso informática como } \\
\text { recurso didáctico y contenido } \\
\text { informático. }\end{array}$ & Relación \\
\hline alfabetización_informática & & & $\begin{array}{l}\text { Relación binaria que establece nexo } \\
\text { entre un caso alfabetización } \\
\text { informática y contenido informático. }\end{array}$ & Relación \\
\hline .contenido_videojuego & & & $\begin{array}{l}\text { Relación binaria que establece nexo } \\
\text { entre un caso videojuego y } \\
\text { contenido informático. }\end{array}$ & Relación \\
\hline Access de Microsoft & & & $\begin{array}{l}\text { Software administrador de bases de } \\
\text { datos. }\end{array}$ & Instancia \\
\hline Agrupamiento de alumnos & & & $\begin{array}{l}\text { Organización de los grupos de } \\
\text { alumnos }\end{array}$ & Atributo \\
\hline Alfabetización informática & & & $\begin{array}{l}\text { Las narraciones que contiene como } \\
\text { objeto de estudio a la computadora } \\
\text { (objeto físico). Los temas de estas } \\
\text { narraciones pueden contener la } \\
\text { organización física y lógica de la } \\
\text { computadora; incluye el análisis de } \\
\text { los componentes y de los materiales } \\
\text { implicados; sus resultados en el } \\
\text { nivel morfológico y de perfomance. } \\
\text { Las narraciones contienen como } \\
\text { objeto de estudio a los programas } \\
\text { (objeto simbólico). Los temas de } \\
\text { estas narraciones pueden contener } \\
\text { los distintos tipos de software } \\
\text { implicados en el funcionamiento de } \\
\text { la computadora; el nivel de } \\
\text { jerarquía y relación con el usuario; } \\
\text { los distintos enfoques y técnicas } \\
\text { implicada en su estudio y } \\
\text { aplicación; el proceso de } \\
\text { construcción de programas. Incluye, } \\
\text { además, el análisis referencial, esto } \\
\text { es: antecedentes del origen e } \\
\text { historia de la informática en el } \\
\text { mundo y en la Argentina. }\end{array}$ & Concepto \\
\hline Analogía & & & $\begin{array}{l}\text { "En términos generales, una } \\
\text { analogía puede definirse como la } \\
\text { comparación entre dos dominios, } \\
\text { uno más familiar (denominado } \\
\text { "fuente"o "análogo") y otro menos } \\
\text { conocido (denominado "concepto", } \\
\text { "blanco" o "target" ), que } \\
\text { comparten información de tipo } \\
\text { relacional. Así Ruhl (2003) señala } \\
\text { que "una analogía es una } \\
\text { comparación de una cosa familiar } \\
\text { con otra no familiar con el objetivo } \\
\text { de interpretar o aclarar una } \\
\text { característica compartida" }\end{array}$ & Instancia \\
\hline Aula & & & $\begin{array}{l}\text { Espacio físico donde se reúnen } \\
\text { docentes, alumnos y tecnología con } \\
\text { la finalidad de enseñar y aprender. }\end{array}$ & Instancia \\
\hline Aula frontal & & & $\begin{array}{l}\text { Agrupamiento de los alumnos donde } \\
\text { las computadoras están frente del }\end{array}$ & Instancia \\
\hline
\end{tabular}




\begin{tabular}{|c|c|c|c|}
\hline & & pizarrón. & \\
\hline Autor & Narrador & Autor de uno o más casos & Atributo \\
\hline Base de datos & & $\begin{array}{l}\text { Una base de datos es una colección } \\
\text { de datos relacionados [Elmasri, } \\
\text { 2002]. }\end{array}$ & Instancia \\
\hline $\mathrm{C}++$ & & Lenguaje de programación & Instancia \\
\hline Cache & & $\begin{array}{l}\text { Es un conjunto de datos duplicados } \\
\text { de otros originales. }\end{array}$ & Instancia \\
\hline Cadena de caracteres & & Tipo de organización de los datos. & Instancia \\
\hline Carpeta & & $\begin{array}{l}\text { Espacio lógico en un dispositivo de } \\
\text { almacenamiento. }\end{array}$ & Instancia \\
\hline Caso & & $\begin{array}{l}\text { El conjunto de propiedades que } \\
\text { forman el caso }\end{array}$ & Concepto \\
\hline Columnas & & $\begin{array}{l}\text { Formato que se da a los documentos } \\
\text { desde un procesador de texto. }\end{array}$ & Instancia \\
\hline Compiladores & & $\begin{array}{l}\text { Los compiladores son programas o } \\
\text { herramientas encargadas de } \\
\text { compilar. Un compilador toma un } \\
\text { texto (código fuente) escrito en un } \\
\text { lenguaje de alto nivel y lo traduce a } \\
\text { un lenguaje comprensible por las } \\
\text { computadoras (código objeto) }{ }^{46} \text {. }\end{array}$ & Instancia \\
\hline $\begin{array}{lll}\begin{array}{l}\text { Contenido informático } \\
\text { caso }\end{array} & & \\
\end{array}$ & Tema & $\begin{array}{l}\text { Conjunto de temas que deben } \\
\text { apropiarse los alumnos a través del } \\
\text { caso. }\end{array}$ & Concepto \\
\hline Contenido_video_juego & & 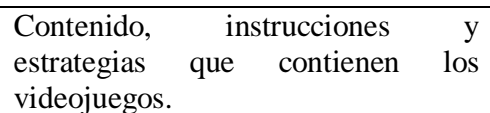 & Relación \\
\hline Curso & & $1^{o}, 2^{o}, 3^{o}, 4^{o}, 5^{o}$ y $6^{o}$ & Atributo \\
\hline Datos & & $\begin{array}{l}\text { Estructura de los datos y } \\
\text { representación del almacenamiento } \\
\text { de los datos. }\end{array}$ & Instancia \\
\hline Definición de caso & Narración & $\begin{array}{l}\text { "Un caso es un fragmento } \\
\text { contextualizado de conocimiento que } \\
\text { representa una } \\
\text { experiencia y que enseña una } \\
\text { lección importante para conseguir } \\
\text { los objetivos } \\
\text { del razonador" }\end{array}$ & Concepto \\
\hline Disco rígido & Hard disk & $\begin{array}{l}\text { Periférico de almacenamiento } \\
\text { permanente reacceso a sus datos en } \\
\text { forma aleatoria. }\end{array}$ & Instancia \\
\hline DVD & & $\begin{array}{l}\text { Periférico de almacenamiento } \\
\text { permanente de acceso a sus datos } \\
\text { en forma aleatoria. }\end{array}$ & Instancia \\
\hline E-mail del autor & & $\begin{array}{l}\text { Dirección electrónica del autor del } \\
\text { caso }\end{array}$ & Atributo \\
\hline Escuela secundaria & $\begin{array}{l}\text { Escuela } \\
\text { Media }\end{array}$ & Institución escolar & Instancia \\
\hline $\begin{array}{l}\text { Espacio_de_la_práctica_alfa } \\
\text { betización_informática }\end{array}$ & & $\begin{array}{l}\text { Relación binaria que establece nexo } \\
\text { entre un caso alfabetización } \\
\text { informática y un espacio de la } \\
\text { práctica (materia de nivel medio). }\end{array}$ & Relación \\
\hline $\begin{array}{l}\text { Espacio_de_la_práctica_mate } \\
\text { rial_educativo }\end{array}$ & & $\begin{array}{l}\text { Relación binaria que establece nexo } \\
\text { entre un caso informática como } \\
\text { material educativo y un espacio de } \\
\text { la práctica (materia de nivel } \\
\text { medio). }\end{array}$ & Relación \\
\hline $\begin{array}{l}\text { Espacio_de_la_práctica_recu } \\
\text { rso_didáctico }\end{array}$ & & $\begin{array}{l}\text { Relación binaria que establece nexo } \\
\text { entre un caso informática como } \\
\text { recurso didáctico y un espacio de la } \\
\text { práctica (materia de nivel medio). }\end{array}$ & Relación \\
\hline
\end{tabular}

\footnotetext{
${ }^{46}$ Diccionario informático: http://www.alegsa.com.ar/Dic/compilador.php (Revisado 06/03/2010)
} 


\begin{tabular}{|c|c|c|}
\hline $\begin{array}{l}\text { Espacio_de_la_práctica_vide } \\
\text { ojuegos }\end{array}$ & $\begin{array}{l}\text { Relación binaria que establece nexo } \\
\text { entre un caso videojuego y un } \\
\text { espacio de la práctica (materia de } \\
\text { nivel medio). }\end{array}$ & Relación \\
\hline Espacio_físico & Aula, taller de informática, otro. & Atributo \\
\hline Estructura de los datos & $\begin{array}{l}\text { Arrays, Distributed data structures, } \\
\text { graphs and networks, Lists, stacks, } \\
\text { and queues, Records, Tables, Trees }\end{array}$ & Instancia \\
\hline Evaluación_del_caso & $\begin{array}{l}\text { Evaluación relacionado al } \\
\text { cumplimiento de las expectativas } \\
\text { que se tiene del caso }\end{array}$ & Atributo \\
\hline Excel de Microsoft & $\begin{array}{l}\text { Programa administrador de } \\
\text { planillas de cálculo. }\end{array}$ & Instancia \\
\hline Explorador de Windows & $\begin{array}{l}\text { Programa incorporado en el SO } \\
\text { para administrar los dispositivos de } \\
\text { almacenamiento. }\end{array}$ & Instancia \\
\hline Firmware & $\begin{array}{l}\text { Consiste del software incorporado a } \\
\text { los circuitos electrónicos durante su } \\
\text { fabricación }\end{array}$ & Instancia \\
\hline Foros & $\begin{array}{l}\text { Agrupamiento de los alumnos en } \\
\text { forma virtual. }\end{array}$ & Instancia \\
\hline Grupo en U & $\begin{array}{l}\text { Agrupamiento de alumnos en forma } \\
\text { de U y el pizarrón en el centro. }\end{array}$ & Instancia \\
\hline Hardware & $\begin{array}{llll}\begin{array}{l}\text { Componentes } \\
\text { computadora }\end{array} & \text { físicos } & \text { de } & \text { la } \\
\end{array}$ & Concepto \\
\hline Hipertexto & $\begin{array}{l}\text { Estructura de los datos. A partir de } \\
\text { la definición original de Ted Nelson } \\
\text { han surgido otras propuestas como } \\
\text { el documento digital, que se puede } \\
\text { leer de forma no secuencial o } \\
\text { multisecuencial. Un hipertexto } \\
\text { consta de los siguientes elementos: } \\
\text { nodos o secciones, enlaces o } \\
\text { hipervínculos y anclajes. Los nodos } \\
\text { son las partes del hipertexto que } \\
\text { contienen información accesible } \\
\text { para el usuario. Los enlaces son las } \\
\text { uniones o vínculos que se establecen } \\
\text { entre nodos y facilitan la lectura } \\
\text { secuencial o no secuencial por los } \\
\text { nodos del documento. Los anclajes } \\
\text { son los puntos de activación de los } \\
\text { enlaces } 47 \text {. }\end{array}$ & Instancia \\
\hline Impresora & $\begin{array}{l}\text { Objeto tecnológico que tiene como } \\
\text { función imprimir en soporte papel u } \\
\text { otro similar el contenido de un } \\
\text { documento elegido por el usuario. }\end{array}$ & Instancia \\
\hline Informática & $\begin{array}{l}\text { La rama de la Tecnología que trata } \\
\text { la información y el conocimiento y } \\
\text { los maneja como objetos } \\
\text { tecnológicos y tiene como soporte } \\
\text { fundamental la computadora. }\end{array}$ & Concepto \\
\hline $\begin{array}{lll}\text { Informática } & \text { como } & \text { recurso } \\
\text { didáctico } & & \end{array}$ & $\begin{array}{l}\text { Estas narraciones suponen que los } \\
\text { docentes harán uso de técnicas y } \\
\text { herramientas informáticas para } \\
\text { resolver problemas de las diferentes } \\
\text { disciplinas y elaborar diferentes } \\
\text { productos que surjan de las } \\
\text { actividades propias del aula; entre }\end{array}$ & Instancia \\
\hline
\end{tabular}

\footnotetext{
${ }^{47}$ Wikipedia: http://es.wikipedia.org/wiki/Hipertexto . Revisado el 06 de marzo de 2010.
} 


\begin{tabular}{|c|c|c|c|}
\hline & & $\begin{array}{l}\text { las herramientas incluye el uso de } \\
\text { procesadores de texto, editor de } \\
\text { representaciones, administrador de } \\
\text { bases de datos, editores de páginas } \\
\text { Web, planillas de cálculo, lenguaje } \\
\text { de programación, browser, } \\
\text { programas de comunicación, etc. }\end{array}$ & \\
\hline $\begin{array}{l}\text { Informática como soporte de } \\
\text { materiales }\end{array}$ & & $\begin{array}{l}\text { El contenido de estas narraciones } \\
\text { usan los productos informáticos } \\
\text { como mediador del conocimiento. } \\
\text { Aquí el docente, como responsable } \\
\text { de la selección de contenidos y de } \\
\text { adecuarlos a la estrategia didáctica, } \\
\text { elige distintos materiales digitales } \\
\text { para conseguir sus objetivos } \\
\text { curriculares. Entre los materiales } \\
\text { educativos informáticos } \\
\text { encontramos: tutoriales, } \\
\text { constructores de resapas } \\
\text { conceptuales, editores de gráficos, } \\
\text { de ejercitación práctica, libros } \\
\text { electrónicos, renciclopedias } \\
\text { temáticas, revistas electrónicas, } \\
\text { páginas Web, juegos lógicos, de } \\
\text { aventura, de simulación, etc. }\end{array}$ & Instancia \\
\hline Institución & $\begin{array}{l}\text { Escuela } \\
\text { media } \quad \text { o } \\
\text { colegio } \\
\text { técnico }\end{array}$ & $\begin{array}{l}\text { Espacio físico formal que puede ser } \\
\text { escuela media o escuela técnica. }\end{array}$ & Atributo \\
\hline $\begin{array}{l}\text { Instrumento_de_evaluación } \\
\text { para_los_alumnos }\end{array}$ & & $\begin{array}{l}\text { Se entiende la evaluación como un } \\
\text { continuo proceso de reflexión acerca } \\
\text { de los procesos realizados en la } \\
\text { construcción de aprendizajes } \\
\text { significativos. Por ello evaluar } \\
\text { implica una permanente actitud de } \\
\text { investigación, por parte de docentes } \\
\text { y alumnos, que intente descubrir y } \\
\text { valorar todos los procesos, aun los } \\
\text { no visible nítidamente [Sanjurjo, } \\
2003 \text { ]. }\end{array}$ & Atributo \\
\hline Internet & & $\begin{array}{l}\text { Red de redes de alcance mundial } \\
\text { para compartir servicios y recursos. }\end{array}$ & Concepto \\
\hline Interprete & & $\begin{array}{l}\text { Programa que trabaja directamente } \\
\text { con el programa fuente en memoria. } \\
\text { El intérprete traduce las } \\
\text { instrucciones del programa fuente } \\
\text { una por una y las ejecuta } \\
\text { inmediatamente. No suele ser } \\
\text { habitual emplear los intérpretes } \\
\text { para traducir y ejecutar los } \\
\text { programas fuente, ya que son lentos, } \\
\text { pero presentan ciertas ventajas en } \\
\text { campos determinados. }\end{array}$ & Instancia \\
\hline $\begin{array}{l}\text { Inversa_ } \\
\text { Espacio_de_la_práctica_alfa } \\
\text { betización_informática }\end{array}$ & & $\begin{array}{l}\text { Relación binaria que establece nexo } \\
\text { entre el espacio de la práctica } \\
\text { (materia de nivel medio) y un caso } \\
\text { alfabetización informática. }\end{array}$ & Relación \\
\hline $\begin{array}{l}\text { Inversa_contenido_alfabetiza } \\
\text { ción_informática }\end{array}$ & & $\begin{array}{l}\text { Relación binaria que establece nexo } \\
\text { entre un contenido informático y un } \\
\text { caso de alfabetización Informática. }\end{array}$ & Relación \\
\hline $\begin{array}{l}\text { Inversa_contenido_material_ } \\
\text { educativo }\end{array}$ & & $\begin{array}{l}\text { Relación binaria que establece nexo } \\
\text { entre un contenido informático y un } \\
\text { caso de la Informática como } \\
\text { material educativo. }\end{array}$ & Relación \\
\hline Inversa_contenido_recurso_d & & Relación binaria que establece nexo & Relación \\
\hline
\end{tabular}




\begin{tabular}{|c|c|c|c|}
\hline idáctico & & $\begin{array}{l}\text { entre un contenido informático y un } \\
\text { caso de la Informática como recurso } \\
\text { didáctico. }\end{array}$ & \\
\hline $\begin{array}{l}\text { Inversa_contenido_videojueg } \\
o\end{array}$ & & $\begin{array}{l}\text { Relación binaria que establece nexo } \\
\text { entre un contenido informático y un } \\
\text { caso de los videojuegos. }\end{array}$ & Relación \\
\hline $\begin{array}{l}\text { Inversa_Espacio_de } \\
\text { la_práctica_videojuegos }\end{array}$ & & $\begin{array}{l}\text { Relación binaria que establece nexo } \\
\text { entre el espacio de la práctica } \\
\text { (materia de nivel medio) y un caso } \\
\text { de videojuego. }\end{array}$ & Relación \\
\hline $\begin{array}{l}\text { Inversa_espacio_de_la_practi } \\
\text { ca_material_educativo }\end{array}$ & & $\begin{array}{l}\text { Relación binaria que establece nexo } \\
\text { entre el espacio de la práctica } \\
\text { (materia de nivel medio) y un caso } \\
\text { de la Informática como material } \\
\text { educativo. }\end{array}$ & Relación \\
\hline $\begin{array}{l}\text { Inversa_Espacio_de_la_práct } \\
\text { ica_recurso_didáctico }\end{array}$ & & $\begin{array}{l}\text { Relación binaria que establece nexo } \\
\text { entre el espacio de la práctica } \\
\text { (materia de nivel medio) y un caso } \\
\text { de la Informática como recurso } \\
\text { didáctico. }\end{array}$ & Relación \\
\hline Laboratorio & $\begin{array}{l}\text { Aula } \\
\text { informática }\end{array}$ & Laboratorio de informática & Instancia \\
\hline Lenguaje de programación & & $\begin{array}{l}\text { Un lenguaje de programación es un } \\
\text { idioma artificial diseñado para } \\
\text { expresar computaciones que pueden } \\
\text { ser llevadas a cabo por máquinas } \\
\text { como las computadoras. Pueden } \\
\text { usarse para crear programas que } \\
\text { controlen el comportamiento físico y } \\
\text { lógico de una máquina, para } \\
\text { expresar algoritmos con precisión,o } \\
\text { como modo de comunicación } \\
\text { humana. } 48 \text { a }\end{array}$ & Concepto \\
\hline Lista & & $\begin{array}{l}\text { Estructura de los datos. La } \\
\text { característica informática de esta } \\
\text { organización es que impone un } \\
\text { recorrido secuencial de sus } \\
\text { elementos, y que es posible operarla, } \\
\text { construyendo otras listas a partir de } \\
\text { condiciones impuestas a sus } \\
\text { elementos. Constituyen un conjunto } \\
\text { ordenado de objetos del mismo tipo: } \\
\text { números, fichas u otras listas. }\end{array}$ & Instancia \\
\hline Materiales_didácticos & & $\begin{array}{l}\text { Computadoras, cañón } \\
\text { cámaras, otros.. }\end{array}$ digital, & Atributo \\
\hline Mail & $\begin{array}{l}\text { Correo } \\
\text { electrónico }\end{array}$ & $\begin{array}{l}\text { Dirección de correo electrónico del } \\
\text { autor del caso. }\end{array}$ & Atributo \\
\hline Memorias & $\begin{array}{l}\text { Almacenami } \\
\text { ento }\end{array}$ & $\begin{array}{l}\text { En informática, la memoria se } \\
\text { refiere a parte de los componentes } \\
\text { que forman parte de } \\
\text { una computadora, Las memorias de } \\
\text { computadora proporcionan unas de } \\
\text { las principales funciones de la } \\
\text { computación moderna, la retención o } \\
\text { almacenamiento de información. }\end{array}$ & Atributo \\
\hline Memorias auxiliares & & La memoria externa hace referencia & Instancia \\
\hline
\end{tabular}

${ }^{48}$ Wikipedia: http://es.wikipedia.org/wiki/Lenguaje_de_programaci\%C3\%B3n . Revisado el 06 de marzo de 2010.

${ }^{49}$ Susana Muraro: Una introducción a la informática en el aula, $1^{a}$ ed. Fondo de Cultura Económica, Buenos Aires, 2005. 


\begin{tabular}{|c|c|c|c|}
\hline & & $\begin{array}{l}\text { a todos los dispositivos y medios de } \\
\text { almacenamiento que no son parte de } \\
\text { la memoria interna de la } \\
\text { computadora (RAM y ROM). Son } \\
\text { parte de la memoria externa los } \\
\text { disquetes, los discos ópticos, los } \\
\text { discos duros, las unidades de cinta, } \\
\text { los ZIP, etc. La memoria externa no } \\
\text { es fundamental para el } \\
\text { funcionamiento de } \\
\text { computadora. }\end{array}$ & \\
\hline Microprocesador & & $\begin{array}{l}\text { El procesador es un circuito } \\
\text { integrado constituido por millones } \\
\text { de componentes electrónicos } \\
\text { integrados. Constituye la unidad } \\
\text { central de procesamiento }(\mathrm{CPU}) \text { de } \\
\text { un PC catalogado } \\
\text { microcomputador }\end{array}$ & Instancia \\
\hline Microsoft Encarta & & $\begin{array}{l}\text { Encarta es una aplicación y servicio } \\
\text { online de Microsoft que funciona } \\
\text { como una enciclopedia multimedia. }\end{array}$ & Instancia \\
\hline Microsoft Windows & & Sistema operativo. & Instancia \\
\hline Monitor & & Periférico de comunicación. & Instancia \\
\hline Mouse & Ratón & Periférico de comunicación & Instancia \\
\hline Narración & & Desarrollo de la narración del caso & Atributo \\
\hline Niños/as & & $\begin{array}{l}\text { Sujetos que concurren formalmente } \\
\text { a las instituciones escolares de nivel } \\
\text { medio. }\end{array}$ & Instancia \\
\hline No ofimáticas & & $\begin{array}{l}\text { Opuesto a la ofimática, son } \\
\text { programas que en su diseño no tiene } \\
\text { como propósito mejorar las tareas } \\
\text { administrativas. Ejemplos de } \\
\text { programas no ofimáticas son } \\
\text { aquellos que permiten graficar } \\
\text { funciones matemáticas complejas. }\end{array}$ & Concepto \\
\hline $\begin{array}{l}\text { Nombre de la unidad del } \\
\text { programa }\end{array}$ & & $\begin{array}{l}\text { Aquí se hace referencia al nombre } \\
\text { de la unidad del programa de la } \\
\text { materia que hace uso didáctico de la } \\
\text { informática o de material educativo. }\end{array}$ & Atributo \\
\hline Nombre de los programas & & $\begin{array}{l}\text { Aquí se hace referencia al nombre } \\
\text { del software involucrados en el caso. }\end{array}$ & Atributo \\
\hline $\begin{array}{l}\text { Objetivo didáctico del } \\
\text { caso }\end{array}$ & & $\begin{array}{l}\begin{array}{l}\text { Objetivos deben alcanzar los } \\
\text { alumnos con el caso }\end{array} \\
\end{array}$ & Atributo \\
\hline Ofimática & & $\begin{array}{l}\text { Es el conjunto de técnicas, } \\
\text { aplicaciones y herramientas } \\
\text { informáticas que se utilizan con el } \\
\text { propósito de optimizar, automatizar } \\
\text { y mejorar los procedimientos o } \\
\text { tareas relacionados a los procesos } \\
\text { administrativos. }\end{array}$ & Concepto \\
\hline Organización de los datos & & $\begin{array}{l}\text { Es una forma de organizar y } \\
\text { representar un conjunto de datos } \\
\text { elementales con el objetivo de } \\
\text { facilitar su manipulación. Un dato } \\
\text { elemental es la mínima información } \\
\text { que se tiene en un sistema. }\end{array}$ & Concepto \\
\hline Saint & & $\begin{array}{l}\text { Programa graficador de } \\
\text { específico }\end{array}$ uso & Instancia \\
\hline Pequeños grupos & & $\begin{array}{l}\text { Agrupamiento de los alumnos en } \\
\text { grupos de n alumnos. }\end{array}$ & Instancia \\
\hline Periféricos & & $\begin{array}{l}\text { Un periférico es un dispositivo } \\
\text { electrónico físico que se conecta o } \\
\text { acopla a una computadora, pero no } \\
\text { forma parte del núcleo básico }(C P U,\end{array}$ & Concepto \\
\hline
\end{tabular}




\begin{tabular}{|c|c|c|c|}
\hline & & $\begin{array}{l}\text { memoria, placa madre, alimentación } \\
\text { eléctrica) de la misma. Los } \\
\text { periféricos sirven para comunicar la } \\
\text { computadora con el exterior (ratón, } \\
\text { monitor, teclado, etc.) o como } \\
\text { almacenamiento de información } \\
\text { (disco duro, unidad de disco óptico, } \\
\text { etc.). }\end{array}$ & \\
\hline Problema & & $\begin{array}{l}\text { Narración de la descripción del } \\
\text { problema didáctico que el autor del } \\
\text { caso intenta resolver dentro del caso } \\
\text { en forma sintética. }\end{array}$ & Atributo \\
\hline Procesador de texto & & $\begin{array}{l}\text { Es una aplicación informática } \\
\text { destinada a la creación o } \\
\text { modificación de documentos escritos } \\
\text { por medio de un ordenador. } \\
\text { Representa una alternativa moderna } \\
\text { a la antigua máquina de escribir, } \\
\text { mucho más potente y versátil que } \\
\text { ésta. }\end{array}$ & Instancia \\
\hline Programas de aplicación & $\begin{array}{l}\text { Aplicaciones } \\
\text { informáticas }\end{array}$ & $\begin{array}{l}\text { En informática, una aplicación es un } \\
\text { tipo de programa informático } \\
\text { diseñado para facilitar al usuario la } \\
\text { realización de un determinado tipo } \\
\text { de trabajo. }\end{array}$ & Instancia \\
\hline RAM & $\begin{array}{l}\text { Memoria de } \\
\text { trabajo }\end{array}$ & Memoria de acceso aleatorio & Instancia \\
\hline Redes jerárquicas & & Estructura de los datos & Instancia \\
\hline Registro & & Es un conjunto de campos. & Instancia \\
\hline $\begin{array}{l}\text { Representación del } \\
\text { almacenamiento de los datos }\end{array}$ & & $\begin{array}{l}\text { Composite structures, Contiguous } \\
\text { representations, Hash-table } \\
\text { representations, Linked } \\
\text { representations, Object } \\
\text { representation, Primitive data items }\end{array}$ & Concepto \\
\hline ROM & $\begin{array}{l}\text { Memoria de } \\
\text { almacenami } \\
\text { ento } \\
\text { permanente }\end{array}$ & Memoria de solo lectura & Instancia \\
\hline Sistema operativo & $\begin{array}{l}\text { Software de } \\
\text { sistemas }\end{array}$ & $\begin{array}{l}\text { Un programa del sistema operativo } \\
\text { controla el proceso a bajo nivel de } \\
\text { un computador y se sitúa entre el } \\
\text { programa de aplicación y el } \\
\text { hardware del computador. El } \\
\text { sistema operativo planifica y } \\
\text { controla la utilización de los } \\
\text { recursos hardware del sistema. } \\
\text { Estos recursos hardware pueden } \\
\text { incluir memoria, unidad de disco, } \\
\text { impresoray terminales. }\end{array}$ & Concepto \\
\hline Software & $\begin{array}{l}\text { Soporte } \\
\text { lógico }\end{array}$ & $\begin{array}{l}\text { Consta de algoritmos y sus } \\
\text { representaciones en la computadora, } \\
\text { es decir, los programas, junto con su } \\
\text { documentación. }\end{array}$ & Concepto \\
\hline Solución & & $\begin{array}{l}\text { Narración de la descripción de la } \\
\text { solución del problema didáctico } \\
\text { aportada por el autor dentro del } \\
\text { caso. }\end{array}$ & Instancia \\
\hline Soporte digital & & $\begin{array}{l}\text { Son programas que soportan los } \\
\text { contenidos digital y que están } \\
\text { intimamente relacionados a una } \\
\text { disciplina como las bibliotecas } \\
\text { digitales olos programas tutoriales }\end{array}$ & Instancia \\
\hline Subtema & & $\begin{array}{l}\text { Es el subtema del tema del contenido } \\
\text { informático del caso, conforme con }\end{array}$ & Atributo \\
\hline
\end{tabular}




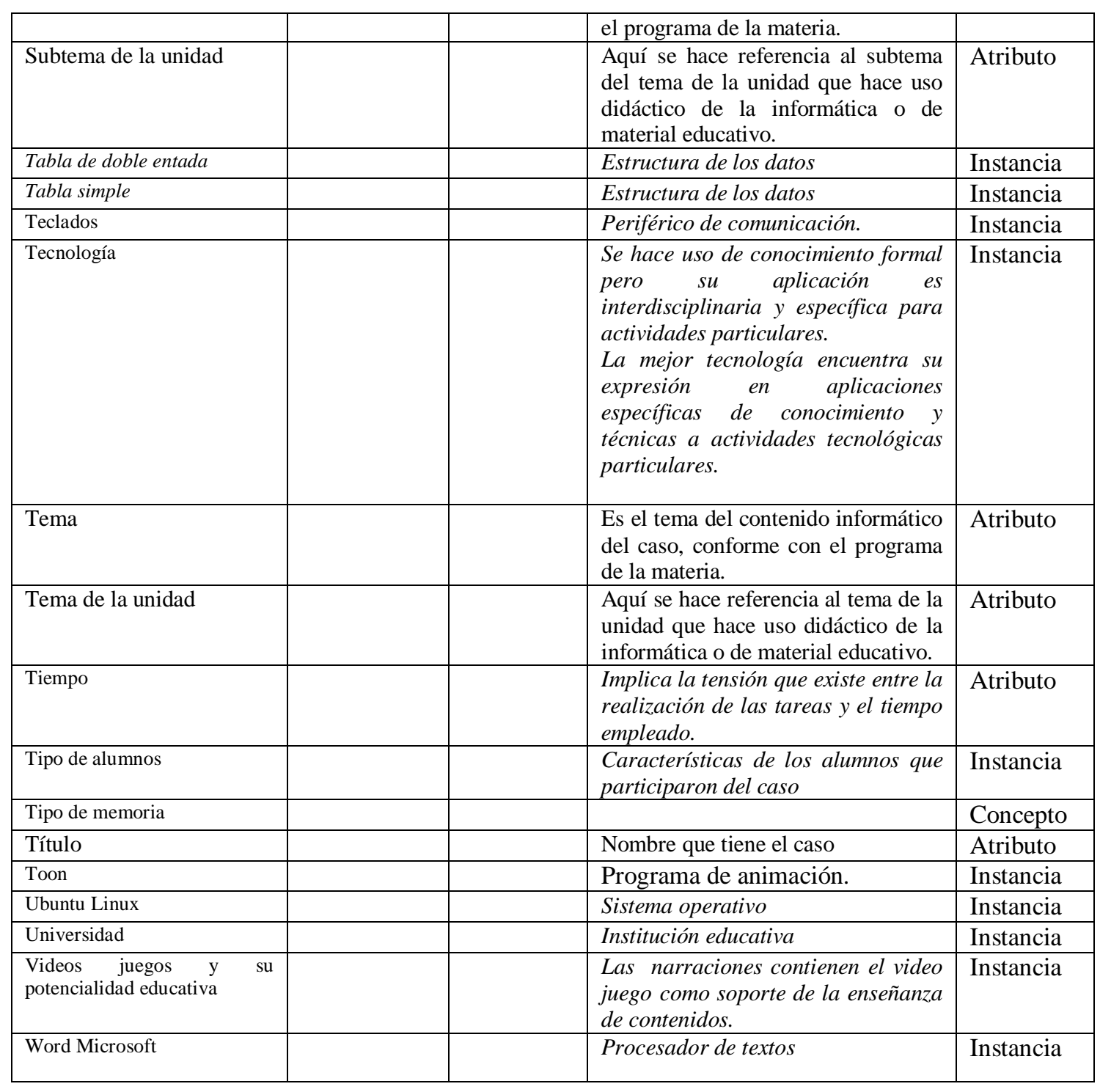




\section{Anexo B: Implementación de la ontología con Protégé}

En esta sección se describe y se presenta el modelo conceptual generado con Metonthology implementado con la herramienta Protégé. Esta herramienta es un software de código abierto codificado en Java y fue desarrollado en la Universidad de Stanford. La característica principal de Protégé son las facilidades que proporciona para la definición y modificación de conceptos, propiedades, relaciones, axiomas y restricciones (Ramos, 2007A). En la figuras 29 se puede observar el área ocupada por la taxonomía de conceptos en la parte izquierda de la pantalla y el área de los atributos para esas clases, en la parte derecha de la pantalla; en particular se puede ver la clase "Alfabetización informática" con sus propiedades object y sus propiedades datatype. En la figura 30 se puede observar las clases de la ontología (corresponde al punto 4.3.2.2 Taxonomía de conceptos en Metonthology). En la figura 31 se muestra dos objetos (individuals), dos casos de enseñanza del dominio de contenidos informáticos con sus propiedades y valores. En la figura 32 se puede observar los atributos de la clase casos de enseñanza. En al figura 33 se puede observar los axiomas (corresponde al punto 4.3.2.8. Axiomas de la ontología en Metonthology). En la figura 34 la ficha Jambalaya representa las clases con nodos y las propiedades en forma de arco.

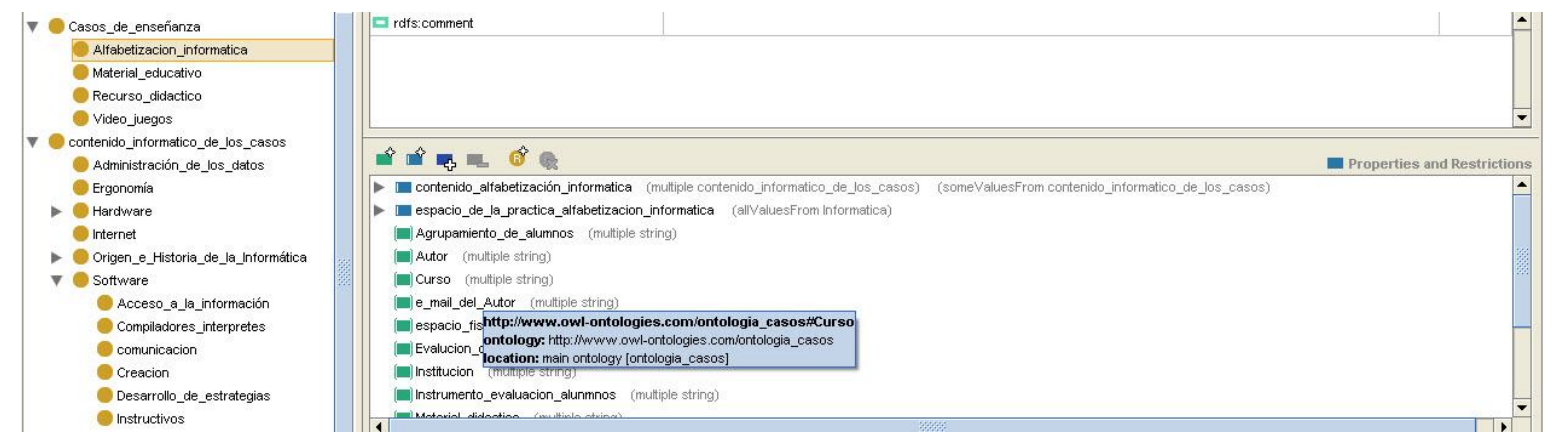

Figura No 29: recorte de las propiedades y objetos de la clase "Alfabetización informática". 


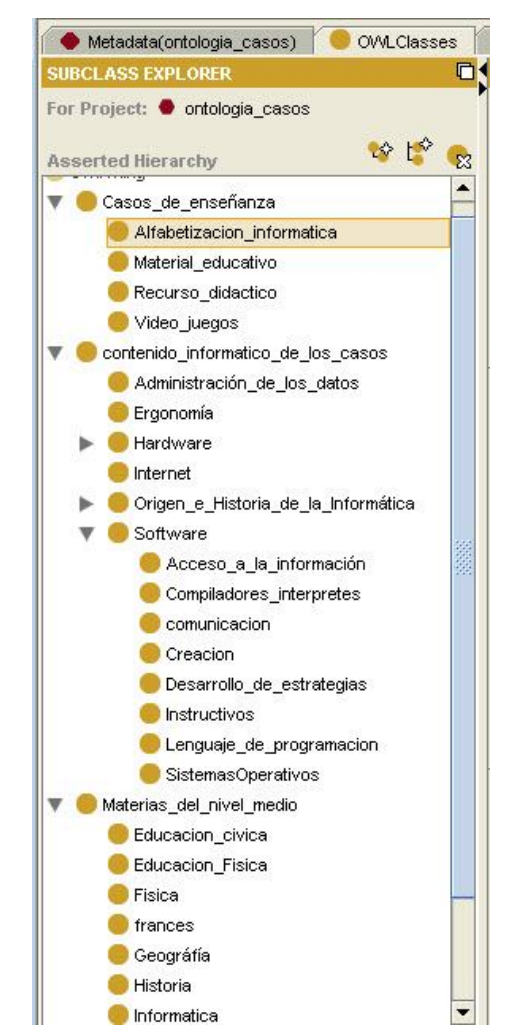

Figura $N^{o}$ 30: las clases de la ontología de casos de enseñanza

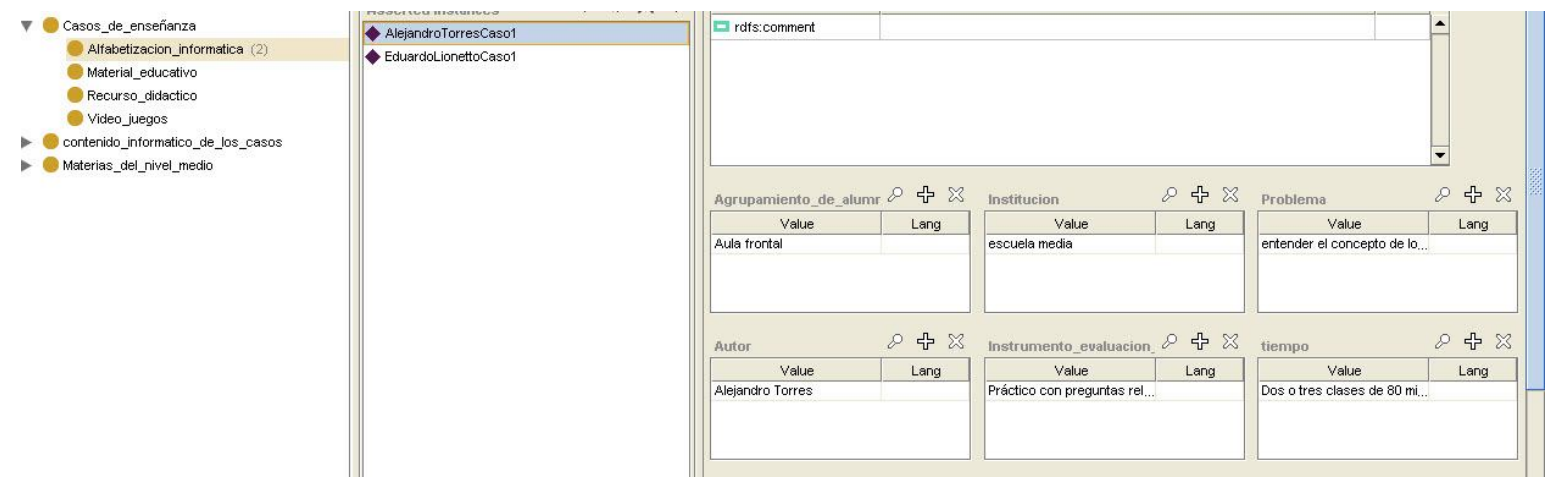

Figura $\mathrm{N}^{\mathrm{o}}$ 31: recorte de dos objetos (individuals) con sus propiedades y valores.

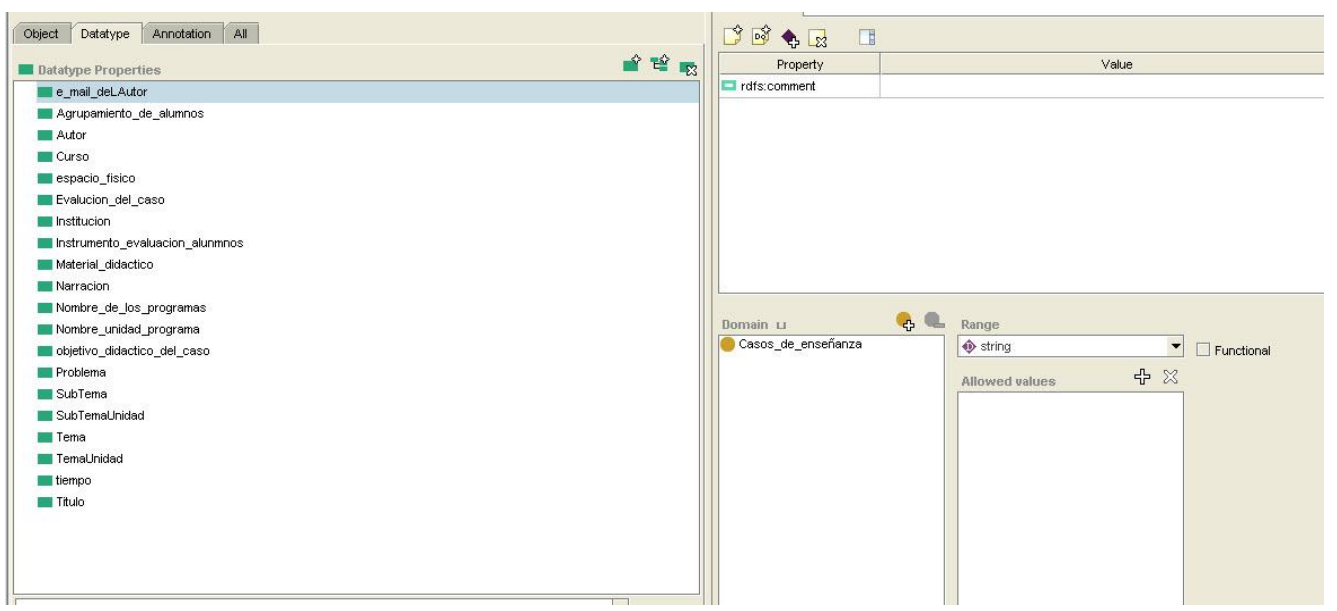

Figura $N^{o} 32$ : los atributos de la ontología de los casos de enseñanza 


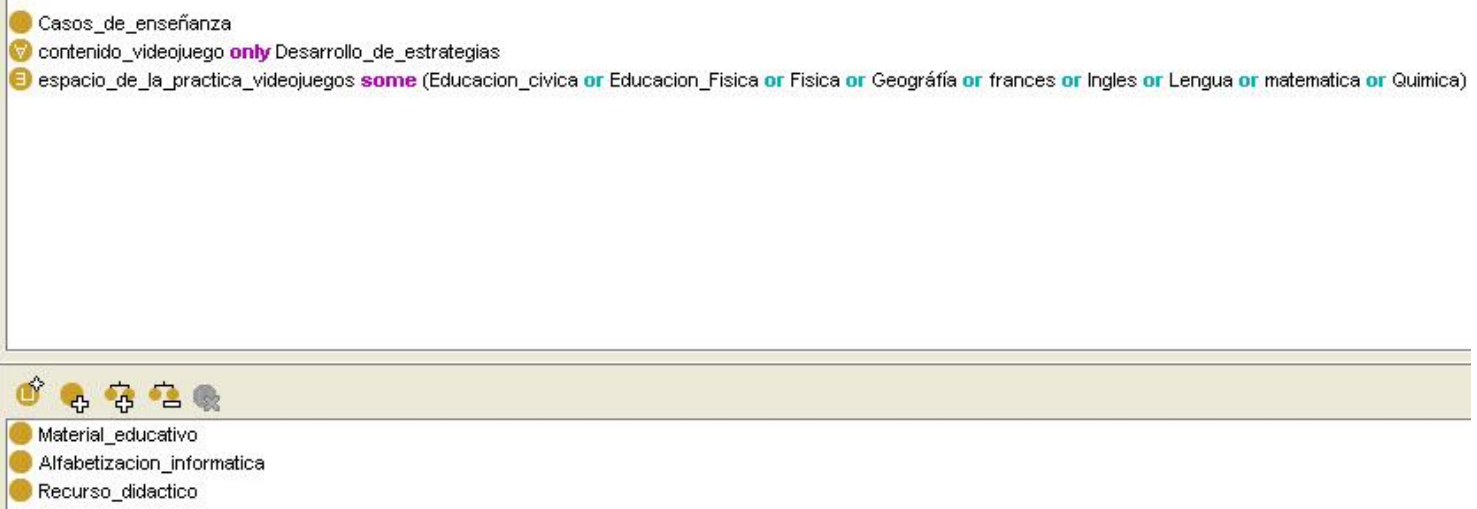

Figura $\mathrm{N}^{\circ}$ 33: los axiomas de la ontología casos de enseñanza 


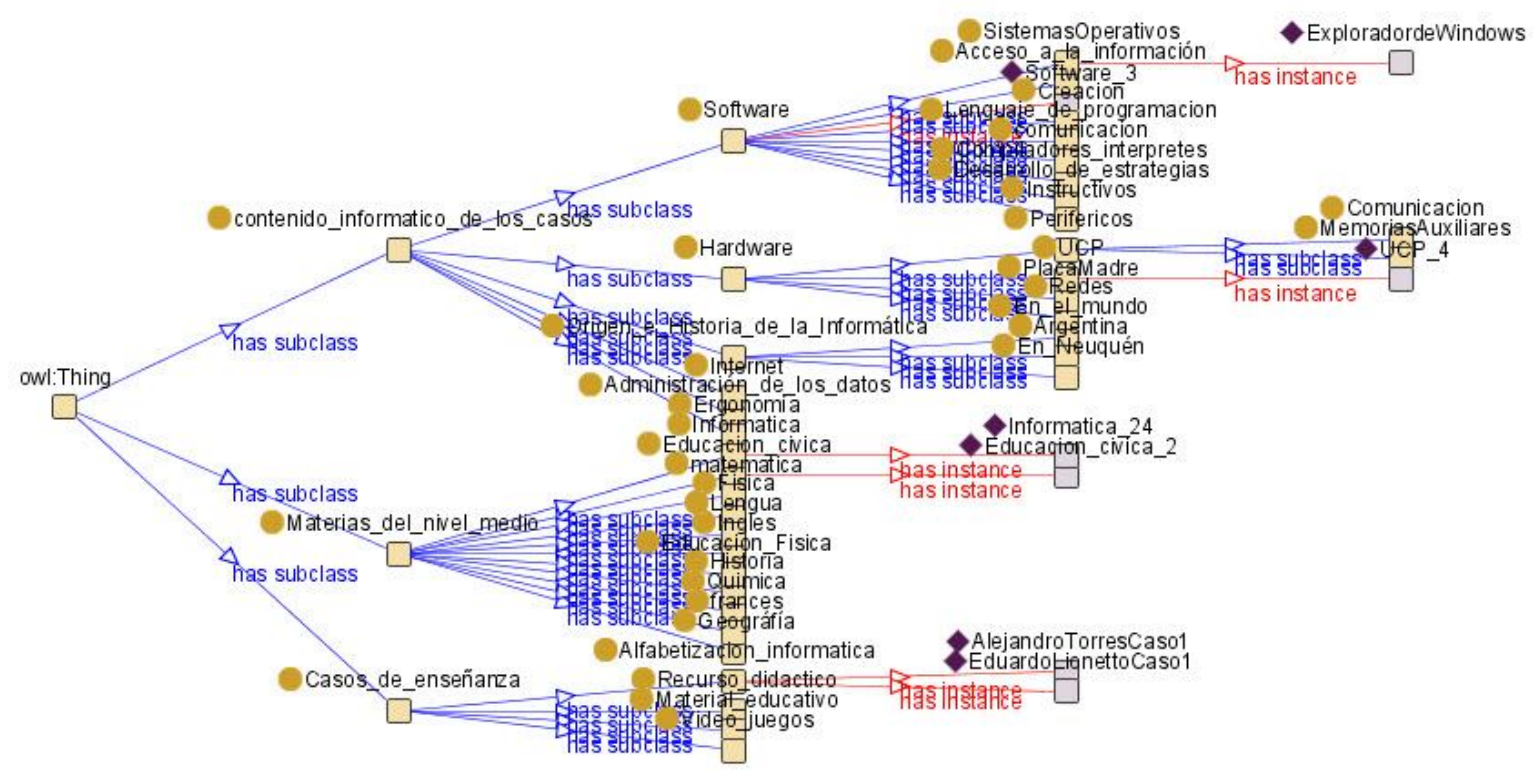

Figura $N^{\circ} 34$ : ficha Jambalaya con nodos y propiedades de dos casos de enseñanza 


\section{Anexo C: impresión de casos de enseñanza desde la base de casos}

Autor (1): Lionetto Eduardo

mail del autor

Titulo del caso (2): elionetto@yahoo.com.ar

propuesto por T. <Buch>

Tipo de caso.

Problema

utilizando un método sencillo pero significativo para los alumnos

Curso (5): 1

Espacio físico (6): Taller

Institución (7): Escuela media

Solución caso (Narración) ..... (8): El método consiste en hacer una introducción acerca del origen del teclado. Por ejemplo se explica que el teclado tiene sus orígenes en el año 1866, que el editor $<$ Christopher Latham Sholes>, con la ayuda de sus colegas Carlos Glidden y Samuel Soules, inventó la primera máquina de escribir y la patentó dos años después. Sholes construyó una maquina que podía imprimir todo el <alfabeto〉, con varios tipos que golpeaban el papel, enrollado sobre un cilindro y con una cinta para la tinta. Tenía un teclado similar al de un piano, pedales y muchos alambres, uno para cada palanca de cada letra.

Las letras estaban ordenadas alfabéticamente en dos filas.

El problema que tenía la máquina de escribir de Sholes es que las teclas se trababan fácilmente. Para resolver este problema, otro socio, James Desmore sugirió a Sholes separar las letras usadas comúnmente juntas en el idoma inglés. Para modificar la organización de las teclas Sholes utilizó un estudio de frecuencia de pares de letras en el idioma inglés preparado por el educador Amos Densmore. Es decir puso en lados opuestos a pares de letras que en el idioma inglés aparecen frecuentemente de a pares, por ejemplo: "sh", "ck", "th", "pr". Este fue el origen del teclado que hoy conocemos como QWERTY y que es el periférico más usado para ingresare datos a la computadora. Esta distribución del teclado se puede leer desde dos posiciones: a) los detractores que acusan a Sholes de intentar retardar a los mecanógrafos más veloces; b) Evitar que se "apelotonaran" las varillas y se "trabara" la máquina de escribir. Esta narración nos invita a reflexionar: ¿Por qué una solución mecánica a un problema mecánico sigue condicionado la fabricación de teclado de computadoras cuando ese problema puede evitarse por la utilización de la tecnología digital?

Luego de la introducción se aplican las categorías de Buch. Comienzo con el análisis morfológico, es decir analizamos la forma y distribución de las teclas, el material constitutivo. Se compara con el teclado de la máquina de escribir. Se le pide al alumno que haga un esquema de cada uno de los teclados con la finalidad de ver espacialmente la ubicación de las teclas y analizar si están organizadas por algún tipo de especialidad de teclas. Luego se pide hacer una tabla de doble entrada que especifique el conjunto de teclas diferentes que encuentra en el teclado de la PC y que no están en el teclado de la máquina de escribir.

En esta primera etapa el alumno sólo llena la columna del "Nombre de la tecla". La segunda columna el alumno la llena cuando estemos en la etapa Funcional. En esta etapa también se analiza el tipo de material usando la comparación de los materiales de la máquina de escribir con los materiales actuales del teclado de la PC. Luego continúo con el Análisis estructural. El teclado por si solo no tiene ninguna funcionalidad, sólo adquiere sentido en el sistema que lo contiene que es el sistema formado por la PC y el monitor (eventualmente otros periféricos). Como es obvio aquí se abre el teclado para analizar los distintos componentes del mismo, los materiales usados y como se interrelacionan entre ellos. Se analiza como el teclado se conecta a la PC, se analizan los distintos tipos de conectores y los mensajes que tiene el gabinete de la PC para evitar conexiones fallidas de periféricos. Continuamos con el Análisis funcional. En esta etapa para describir el funcionamiento del teclado se toman en consideración las etapas anteriores. En principio el teclado debe enchufarse en la PC. Se verifican los mensajes (luces) que muestra el teclado al momento de encender la PC.

Se ejecuta un software adecuado para que el alumno pueda verificar el funcionamiento del teclado, por ejemplo un procesador de texto. Se recupera la tabla de la etapa Morfológica y se pide al alumno que complete la columna dos. Es decir qué función cumple cada tecla especial que no 
figura en la tecla de la maquina de escribir. En esta misma etapa se introduce al alumno en las primeras actividades con la PC; se aprovecha esta etapa para que puedan tener habilidad creciente en el uso del teclado, sumado a correcciones que tienen que ver con lo sintáctico y ortográfico. Por último la Finalidad. En esta etapa se pide al alumno que escriba en función de lo realizado en las etapas anteriores que escriba un texto donde se explicita que finalidad cumple el teclado en relación a la PC. Vale una aclaración Aquiles Gay propone un nivel más de análisis que él le llama "Análisis referencial" que tiene que ver con relacionar el objeto tecnológico con cuestiones referentes a los histórico, económico,social y político.

Materiales didácticos (9): Maquina de escribir y computadora.

Tiempo (10): Cuatro clases de 40 min. cada una.

Evaluación alumnos ............. (11): Se corrige la tabla y el esquema del teclado. Luego se evalúa el texto escrito. Se evalúa lo procedimental y actitudinal frente a la computadora.

Objetivo didáctico del caso.... (12): aplicar el método de análisis tecnológico propuesto por Buch en algún objeto tecnológico.

Agrupamiento alumnos ......... (14): Sentados en U

Hardware

(15): Teclado

Soft creación (18): Word

Materia (21): Informática

Evaluación del caso

(22): Se aplicó en alumnos que por primera vez usaban una PC. El método es efectivo en la medida que tiene continuidad en las distintas actividades que propone el método. Además hay que estar atento en la ansiedad de los chicos en que quieren usar inmediatamente la PC, particularmente los que son repitentes.

Palabras claves (23): <Teclado $><$ Maquina de escribir $>$

Autor.......................... (1): Torres, Alejandro

mail del autor (2): atorres@hotmail.com

Titulo del caso (3): Como funciona la <computadora>: relación interna de los componentes.

Tipo de caso (24): Alfabetización informática

Problema (4): Entender el concepto de lo que

hacen las computadoras cuando la usan los usuarios

Curso (5): 1

Espacio físico (6): Taller

Institución (7): Escuela media

Solución caso (Narración) ..... (8): Se explica al principio que la computadora tiene tres memorias: $\langle$ RAM $>$, <ROM $>$ y <cache>. Se explica usando el <pizarrón> el significado de cada uno. Su origen inglés, ubicación física en la computadora y se utiliza una computadora en desuso para diferenciar su arquitectura. Luego se explica lo que es un microprocesador, se estable la relación entre la memorias y el micro, los procesos de entrada/salida de información y luego los periféricos involucrados. Se hace un esquema en pizarrón y muestro la relación entre ellos. Por último se hace una analogía con la cotidianidad del chico. Por ejemplo se hace participar a los alumnos con las siguientes preguntas: Estas durmiendo ¿Qué es lo primero que haces? Los alumnos contestan en función de su experiencia, por ejemplo algunos contestan que "que se levantan y se lavan los dientes", "toman la leche", etc. entonces ahí yo intervengo y los voy guiando. Les digo que no se pueden hacer cosas simultáneas sino que hay una secuencia. O que hay prioridades. Una vez que se establecen las prioridades, allí hago diferencias, si hay prioridades, les pregunto cómo las tienen incorporadas. Entonces hago la diferencia de que el niño tiene cosas ya sabidas (impuestas) análogamente sería la memoria ROM (donde hay actividades que ya están impuestas, memorizadas) y luego viene las actividades que él tiene que desarrollar durante el día, que análogamente es la memoria RAM que supone tiene que recordar nuevas actividades nuevos trabajos: por ejemplo que materia tiene, que profesor. Aquí se hace la diferenciación entre las dos memorias. Una que ya tiene la secuencia predeterminada, impuesta, la ROM, y la otra la que tiene que desarrollar, porque cada día tiene una actividad diferente.

Siguiendo con la analogía una vez que se establecieron las diferencias con las dos memorias explicamos la memoria cache. Acá presento otro problema un escritorio de trabajo en la misma 
aula y las hojas de trabajo las llevo y las traigo a corregir a la secretaría. Entonces interrogo a los alumnos si me conviene trabajar todas juntas y después llevarlas o llevarlas una por una. Ellos responden que es mejor hacer todo y luego llevarlas. Aquí les hago ver que las prioridades de trabajo entre un lugar distante donde yo tengo ir y volver a buscar la información y corregirla o tenerla cerca y corregir cada vez que sea necesario. Esto lo que hace la cache.

Entonces hacemos una revisión donde se enfatiza los pasos anteriores y los relacionamos con el aula de trabajo.

Ahora vemos el tema del micro. ¿Quién organizaría la información? Entonces hay alguien o algo que administra el orden de la información. Y sería nuestro cerebro, y en la máquina nuestro procesador. Sintetizo: Cerebro es el micro Memoria permanente es la ROM Memoria de trabajo o temporal sería la RAM.

Materiales didácticos ......... (9): Una computadora en desuso, pizarrón

Tiempo ........................ (10): Dos o tres clases de 80' cada uno. Depende del grupo.

Evaluación alumnos ............ (11): Práctico con preguntas relacionadas a la temática y que los alumnos deben responder o utilizo el formato múltiple choice.

Objetivo didáctico del caso.... (12): Entender qué sucede cuando se encienda la computadora

Nombre unidad programa....... (13): Unidad ccentral de proceso

Agrupamiento alumnos .......... (14): Individuales

Materia (21): Informática

Evaluación del caso ............ (22): Evalúo que el resultado es bueno porque tengo índice que lo entiende, por la relación qué ellos hacen en el aula. Me da más resultado que otras experiencias. Palabras claves .............. (23): <memorias $><$ acceso a memorias $><$ funcionalidad de las memorias $><$ diferencias de memorias $>$

\author{
Autor.......................... (1): Torres, Alejandro \\ mail del autor ............... (2): atorres@ hotmail.com \\ Titulo del caso ............... (3): Trabajo de integración de software específico \\ Tipo de caso................... (24): Alfabetización informática \\ Problema ...................... (4): Interrelación de programas de distintos uso específicos: el Paint, \\ Explorador de Windows, Word y Toon (comic). \\ Curso ......................... (5): 2 \\ Espacio físico ................. (6): Taller \\ Institución ................... (7): Escuela media \\ Solución caso (Narración) ..... (8): Lo primero que hago es explicarle cómo funciona el programa. \\ Yo hago una demostración en pantalla mostrando qué programas se ponen en actividad para el \\ desarrollo del trabajo práctico. Te recuerdo que yo ya les he dado en otras actividades el Paint, el \\ Word y el Explorador. Hago un desarrollo del Toon mostrando su interfaz y las distintas \\ herramientas que tiene a través del ejemplo. Luego hago una integración con el Paint, para mostrar \\ las posibles modificaciones. Una vez modificado y transformado (creatividad o iniciativa personal) \\ lo integro a uno hoja de texto de Word.
}

A los alumnos previamente les he entregado una hoja donde deben integrar una imagen que hacen con el Toon, que modifican con el Paint (Acá comienzan a surgir problemas relacionados a la creatividad. Algunos, los menos, son creativos a otros le sugiero ideas y con otros la enseñanza es más personalizada. Como hago la participación Inter máquinas ellos pueden ver lo que hacen los otros compañeros y ven que le sirven como incentivo para su propio trabajo), luego lo incorporan al Word y lo guardan en una carpeta usando el Explorador de Windows.

Materiales didácticos ......... (9): La computadora, material que hago en casa.

Tiempo ......................... (10): Aproximadamente cuatro clases de 40' cada una.

Evaluación alumnos ............ (11): Verificar trabajo terminado,

es decir el documento Word en la carpeta.

Objetivo didáctico del caso.... (12): Mostrar la interrelación de programas que permite el sistema operativo.

Nombre unidad programa....... (13): Software

Agrupamiento alumnos ......... (14): Individuales

Soft acceso a la información.. (17): Explorador de Internet 
Soft creación (18): Word, Toon, Paint

Materia (21): Informática

Evaluación del caso

(22): Los resultados son positivos, pero hay que tener cuidado de que el alumno mecaniza la secuencia

Palabras claves (23): <Software específico> <creatividad para un producto>

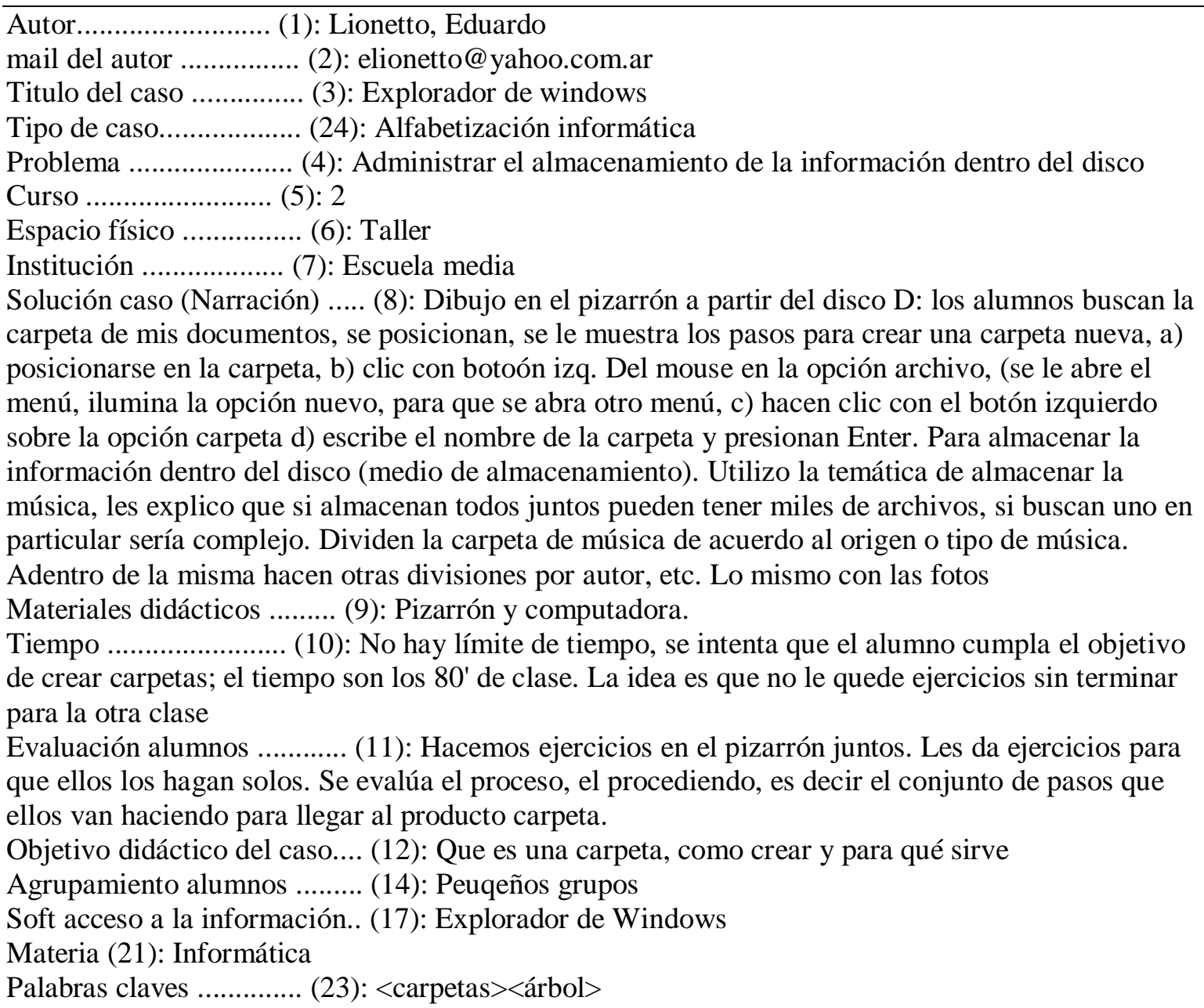

Autor (1): Lionetto, Eduardo

mail del autor (2): alionetto@yahoo.com.ar

Titulo del caso (3): Columnas en Word

Tipo de caso. (24): Alfabetización informática

Problema (4): Modificación de la presentación del formato de los documentos para organizar unas páginas de diario escolar.

Curso (5): 2

Espacio físico (6): Taller

Institución (7): Escuela media

Solución caso (Narración) ..... (8): Generalmente les doy un texto escrito, que tenga ya las columnas (división en columnas) para que ellos tengan y les motive la necesidad de ver cómo se hace. Normalmente voy verificando uno por uno lo que van haciendo. Para que ellos sepan cómo crear las columnas y cómo pasar de una columna a la otra. En otra clase, la siguiente, les explico que hay dos formas de crear las columnas. Escribir todo primero luego seleccionarlo y dividirlo; la otra es dividir primero en columna y después escribirlo. Yo le sugiero que escriban todo en primero y que luego dividan las columnas. Los trabajos son individuales.

Materiales didácticos (9): Pizarrón y computadora.

Tiempo (10): Utilizo aproximadamente 3 clases de $80 \mathrm{~min}$. 
Evaluación alumnos (11): La evaluación se realiza en forma procedimiental. Se avalúa en forma individual. Lo que se evalúa son el tema columna, no hay evaluación colateral. Se pone una nota por la finalización de los ejercicios.

Objetivo didáctico del caso.... (12): Cambiar la presentación de los documentos.

Nombre unidad programa....... (13): Software

Agrupamiento alumnos .......... (14): Individuales

Soft creación (18): Word

Materia (21): Informática

Palabras claves (23): <columnas $><$ procesador de textos $>$

Autor mail del autor Titulo del caso cálculo

Tipo de caso.

Problema utilizando

Curso

Espacio físico

Institución

\section{(1): Caccavari Cristina, I}

(2): cristinacaccavari@yahoo.com.ar

(3): webquest para alumnos de la Escuela técnica - ciclo básico hojas de

(24): Alfabetización informática

(4): La elaboración del presupuesto

Adultos y el Hogar) $\mathrm{N}^{\mathrm{o}} 14$

Solución caso (Narración) ..... (8): Para la elaboración de la presente propuesta se tuvo en cuenta los alumnos de la Escuela Técnica del Ciclo Básico, cuyas edades oscilan entre los 13 y 16 años. El grupo de alumnos conformados por los que recién inician y repitentes, llegan con problemas de comportamiento, actitudes, comunicación interpersonal y baja autoestima. En la mayoría de los casos, carentes de alfabetización tecnológica, que al no disponer de referencias a conocimientos más científicos dificulta la comprensión de lo tecnológico. Vale destacar que las condiciones de infraestructura edilicia y la falta de equipamiento adecuado para llevar a cabo nuestra práctica docente no son las más apropiadas. Pero más allá del contexto en el cual debemos llevar adelante el proceso de enseñanza - aprendizaje, la idea es comprometernos a la realización de proyectos tecnológicos en el aula que se adecuen a diferentes situaciones y aplicable a cualquier contexto social. Asimismo, generar en el aula el espacio adecuado para el fomentar el trabajo colectivo y en equipo, como el procedimiento más adecuado para replicar y aprender cómo se realiza un proceso tecnológico, a la vez que mostraría el carácter social necesario de la actividad tecnológica. Es que decidimos seleccionar el método Webquest como propuesta didáctica para ser utilizada en el aula. Ya que el mismo parte de una mecánica relativamente simple y nos remite a prácticas bien conocidas y asentadas de trabajo en el aula. Al trabajar en grupo nos permite asignar a cada alumno un rol diferente y proponer realizar tareas en conjunto que culmina con un producto con características bien definidas. Los alumnos podrán seguir, un proceso de varios pasos o fases, planificado previamente por el profesor, durante el cual realizarán una amplia gama de actividades como leer, comprender y sintetizar la información seleccionada de Internet o de otras fuentes, organizando la información recopilada, elaborando las hipótesis, valorar y enjuiciar ideas y conceptos, producir textos, dibujos, presentaciones multimedia, objetos físicos, manejar aparatos diversos, entrevistar a sus vecinos, etc. Durante el proceso, se propondrá el uso de diversos recursos, que son accesibles por Internet y cuando sea necesario, una serie de ayudas, transformación y producción de información que les ayudarán a asimilar y acomodar la nueva información y a elaborar el producto final. Los alumnos conocerán de antemano las pautas mediante la cual será evaluado su trabajo, tanto el producto final como el proceso de su elaboración. La WebQuest, es una actividad didáctica que propone una tarea factible y atractiva para los estudiantes. Se concreta siempre en un documento para los alumnos, normalmente accesible través de la web, su estructura está conformada por distintos apartados, como introducción, descripción de la tarea, del proceso para llevarla a cabo y de cómo será evaluada y un conclusión, como así también una guía didáctica, en caso de querer compartirla con otros colegas publicándola a través de Internet. La WebQuest, utiliza diversas estrategias para incrementar la motivación, el interés, la dedicación a la tarea, y por tanto, los resultados de aprendizaje de los estudiantes. Provoca procesos 
cognitivos, ayudan a los estudiantes organizar la información en unidades significativas, analizarla y producir respuestas nuevas. Como grupo, en la elaboración de esta temática, no surgieron dudas en el momento de decidir cuál era el método más adecuado de las tres propuestas presentada por la Cátedra. Luego del análisis de las mismas, coincidimos que el método WebQuest, era el más apropiado y atractivo para el grupo de estudiante a nuestro cargo. Como así también, nos sentimos identificados en el rol de guías, tutores, entrenadores y facilitadores y que nos desafiaba a generar situaciones de aprendizaje que deben representar las complejidades del "mundo real". Lo que sí fue motivo de discusión, entiéndanse buena discusión, la elección del tema a desarrollar. Debía ser a fin a los integrantes del grupo, formar parte del currículum, debía reemplazar a una unidad didáctica o conjunto de actividades. De hacerse uso de la Internet y la web, debíamos aprovechar al máximo sus potencialidades y evitar problemas. La estructura de la WebQuest, debía promover procesos cognitivos de alto nivel. Pero finalmente, consideramos que la selección del tema a desarrollar alcanzaba a cubrir nuestras pretensiones como docentes, que los alumnos al finalizar la WebQuest sean capaces de diseñar y crear una hoja de cálculo para resolver un problema determinado de datos, informes, y otros usos, y que más allá de la información a obtener pudieran comprender y analizar el fenómeno complejo y conflictivo que se le presentaba. Esta Webquest está diseñada para desarrollarse en 2 clases:

- $1^{a}$ Clase: Localización de las empresas, búsqueda de sus catálogos comerciales en Internet, elección de los componentes necesarios para el equipo.

- $2^{\text {a }}$ Clase: Realización de la hoja de cálculo. Se recomienda que la actividad se realice de forma individual en la medida que sea posible, en caso contrario se agruparán los alumnos por parejas. Introducción Una hoja de cálculo es una aplicación informática que permite manipular datos numéricos y alfanuméricos dispuestos en forma de tablas. Habitualmente es posible realizar cálculos complejos con fórmulas y funciones y dibujar distintos tipos de gráficas. Las tablas de las hojas de cálculo comprenden los conceptos de celda, fila y columna, la intersección de una fila y una columna es llamada celda, las filas están etiquetadas por números consecutivos, mientras que las columnas están etiquetadas con letras consecutivas del abecedario. Debido a la versatilidad de las hojas de cálculo modernas, se utilizan a veces para hacer pequeñas bases de datos. Al final de esta WebQuest, vas a ser capaz de diseñar y crear una hoja de cálculo para resolver un problema determinado de datos, informes, y otros usos.

Tarea

Tus padres están pensando en comprar un computadora para la casa y han convocado una reunión familiar para comentar la estrategia de compra. Las conclusiones de la reunión son las siguientes: Tu serás el responsable a indicar las características de los componentes.

Se destinarán $\$ 2.500$ del presupuesto familiar.

Se encargarán los componentes individuales.

La elaboración del presupuesto se realiza consultando los catálogos disponibles en Internet.

Todos los componentes se compraran en el mismo establecimiento.

Proceso

A continuación se presentan los pasos a seguir para completar esta WebQuest.

1.-Averigua los comercios de informática existente en la ciudad y la dirección de las páginas Web donde puedes consultar sus catálogos. Copia estos datos en tu cuaderno de clase.

2.- A continuación ser presenta una lista con todos los componentes que puede llevar tu computadora pero no todos ellos son imprescindibles, tendrás que elegir los más adecuados recordando que en conjunto no debes sobrepasar el límite de $\$ 2.500$.-. Copia en tu cuaderno de clase, el nombre de los componentes que vas a utilizar.

Monitor RatónTeclado

Micrófono AltavocesImpresora

Escaner Caja Disquetera

Tarjeta TV-TDTPlaca BaseTarjeta Gráfica

Tarjeta de sonidoReproductor CD/DVDGrabadora CD/DVD

Tarjeta de redProcesadorDisco Duro

Joystick Memoria RAMWecar 
3.- Con ayuda de la hoja de cálculo tendrás que confeccionar un presupuesto en el que tendrá que figurar los datos que se especifican en la siguiente hoja de cálculo. Una vez terminado, debes grabarlo en un disco y entregarlo al profesor.

Evaluación

La evaluación de tu trabajo se realiza como se indica en la siguiente tabla:

Temas Puntuación

- Presentación del informe. Claridad, orden, limpieza, sin faltas ortográficas. Hasta 20 puntos

- Búsqueda de catálogos comerciales en Internet. Hasta 20 puntos

Elección de los componentes más adecuados para el equipo. Hasta 20 puntos

- La elección se ajusta al presupuesto de \$2.500, -Hasta 20 puntos

- Utilización adecuada de la hoja de cálculo. Hasta 20 puntos

Total 100 puntos

Conclusión

Has aprendido una de las múltiples aplicaciones que tienen las hojas de cálculo, herramienta muy versátil, completa y de mucha utilidad. La función y la ayuda principal que este brinda es, manejar de manera más eficiente la recepción de datos y establecer operaciones numéricas de alta magnitud. Se puede resumir como una herramienta facilitadota de trabajo y fomentadora de habilidades técnicas. Si en un futuro realizas estudios más avanzados descubrirás el resto de aplicaciones con que cuenta.

Materiales didácticos (9): Computadoras personales, pizarrón. Tiempo (10): 2 clases de 40 min.

Evaluación alumnos (11): Ver en la narración la rubrica de evaluación.

Objetivo didáctico del caso.... (12): El objetivo de esta unidad didáctica es mostrar la infinidad de utilidades de las hojas de cálculo y desarrollar una actividad que resulte motivadora para el alumno y refuerce los contenidos referentes a las TICs.

Nombre unidad programa....... (13): Hoja de cálculo

Agrupamiento alumnos .......... (14): Peuqeños grupos

Hardware (15): Teclado Monitores Impresoras

Soft acceso a la información.. (17): Explorador de Internet

Soft creación (18): Excel

Materia (21): Informática

Evaluación del caso ............ (22): La implementación de la Webquest tuvo inconveniente al inicio porque los chicos tuvieron problemas en el acceso a las direcciones de los sitios en la Web. Eso no complicó un poco porque los chicos debían hacer las búsquedas en horario extra clase. Una vez que tuvieron la información se trabajó bien porque la actividad se debía hacer en el taller usando las PC. Desde el punto de vista de la evaluación es bueno usar las rubrica porque los alumnos se enfocan en las actividades que tienen puntaje y eso les permite no perder tiempo. En general es bueno usar la webquest porque se trabaja más ordenado y los chicos saben qué deben hacer.

Palabras claves (23): <webquest $><$ hoja de calculo>

$<$ excel $><$ presupuesto>

http://www.surstore.com.ar/

http://www.compulider.com.ar

http://www.compumaq.com/Home.html

http://www.guiacomahue.com/index.php?ver=guia\&subrubro=188\&pagina=3\&ru=\&

PHPSESSID=f5f77d6d61874c68f734a7c86784ce2f

\section{Autor........................... (1): CACCAVARI, CRISTINA I.}

mail del autor ............... (2): cristinacaccavari@yahoo.com.ar

Titulo del caso ............... (3): Construcción de presentaciones usando mapas conceptuales.

Tipo de caso................... (24): Alfabetización informática

Problema ...................... (4): Narrar un tema usando un conjunto de diapositivas (presentación)

priorizando un estructura con sentido.

Curso …...................... (5): 3

Espacio físico ................. (6): Taller 
Institución (7): Escuela técnica C.E.P.A.HO. (Centro de Educación Práctica de Adultos y el Hogar) $\mathrm{N}^{\mathrm{o}} 14$.

Solución caso (Narración) ..... (8): La primera y la segunda clase la utilizo para desarrollar la trama conceptual ¿Qué significa esto? Usando la computadora y el cañón muestro diversas presentaciones de docentes que uno puede encontrar en cualquier clase, en particular uso una de una clase de química y uno de física; la idea es fijar en los alumnos de qué hablo cuando hablo de una presentación. Luego muestro una presentación en PowerPoint donde enseño los criterios de una buena presentación: idea principal, estrategia de anclaje, tipo de texto, longitud de texto, distractores, fondo, tipo y colores de fuentes. Hablo un poco de la teoría PNL (Programación Neuro Lingüística) para enfatizar la importancia de tener en cuenta los sentidos al momento de abordar la construcción de una presentación. La segunda clase trabajo con una presentación que da cuenta la noción Aprendizaje Significativo y la su relación con la construcción de mapas conceptuales. Digo lo que es un mapa conceptual, los propósitos del mapa conceptual, y los elementos con que está compuesto el mapa conceptual. Luego utilizo el CmapLite para mostrar cómo se construye un mapa conceptual y muestro que cada nodo se puede pensar como una diapositiva de una presentación. La relación entre los nodos es la estructura de la presentación. La clase tres la utilizo para mostrar cómo se construye una presentación tomando como base un mapa conceptual. Para construir la presentación uso el programa PowerPoint. La clase cuatro los alumnos/as la usan para construir su presentación. La consigna para la construcción de la presentación es que busquen un tema de alguna de las materias que tienen para desarrollar la presentación. El trabajo es grupal. La clase cinco es para mostrar las presentaciones producidas por los grupos. Ellos hacen uso de la computadora y del cañón y exponen su presentación a los demás compañeros para que hagan algún aporte tomando en consideración los criterios señalados en la teoría.

Materiales didácticos .......... (9): Computadoras personales, Cañón

digital, pizarrón

Tiempo ...... (10): 5 clases de 40 min. cada uno

Evaluación alumnos ............ (11): El instrumento de avaluación que se utilizó fue una presentación donde se puntualizaban criterios de una buena presentación: idea principal, estrategia de anclaje, tipo de texto, longitud de texto, distractores, fondo, tipo y colores de fuentes. Además se analizaba el tipo de narración y la estructura subyacente de la presentación.

Objetivo didáctico del caso.... (12): Construir presentaciones bajo la estructura de mapa conceptual. Nombre unidad programa....... (13): Construcción de presentaciones

Agrupamiento alumnos .......... (14): Pequeños grupos

Hardware

(15): Teclado, Periféricos, Cañón digital, Computadora personal

Soft creación (18): PowerPoint CmapLite

Materia (21): Informática

Evaluación del caso ........... (22): Lo primero que puedo decir es que los chicos pueden hacer una presentación. Deben asumir los criterios de una buena presentación, esto es: tener en cuenta la necesidad de síntesis en los contenidos de las diapositivas, mejorar el sentido de la narración y evitar la sobre abundancia de colores, tipos de letras llamativas y fondos que no ayudan a la lectura de los textos.

Palabras claves .............. (23): <powerpoint $><$ cmaplite $><$ mapa conceptual $><$ presentación $>$

\author{
Autor........................... (1): Torres, Alejandro \\ mail del autor \\ (2): atorres@ hotmail.com \\ Titulo del caso \\ (3): Búsquedas de información en laWeb \\ Tipo de caso. \\ (24): Alfabetización informática \\ Problema \\ (4): Dado un tema disciplinar qué estrategia de búsqueda es más eficiente \\ para encontrar información sobre dicho tema. \\ Curso \\ (5): 3 \\ Espacio físico \\ (6): Taller \\ Institución \\ (7): Escuela media \\ Solución caso (Narración) ..... (8): El tema de búsqueda de la información yo le doy mucha \\ importancia porque les permite a los alumnos tener una herramienta que les posibilita flexibilizar \\ las fuentes de información. La primera clase comienzo a explicarles la complejidad que implica la
}


búsqueda de información en la Web. La búsqueda de información, desde mi modo de ver, requiere una serie de enfoques que están íntimamente relacionados, todos confluyen a la calidad de la búsqueda. La primera cuestión a considerar en el momento de diseñar una búsqueda es la experticia del usuario en el conocimiento del dominio de la disciplina a la cual pertenecen los términos de búsqueda, esta cuestión no lo abordaremos en el taller. La segunda cuestión es reconocer los distintos modos de accesibilidad que nos presenta la Web. La tercera cuestión, está relacionado al conocimiento que podemos alcanzar del soporte que contiene la información, esto es: qué lectura podemos hacer de la página Web y de los elementos que están en el contexto de los contenidos principales de la página. La última cuestión, tiene que ver con el reconocimiento de algunos criterios de calidad para aplicar a las fuentes de información. Dado esta introducción comienzo a explicarles que tenemos tres alternativas para buscar información en la Web: a través de directorios o índices, utilizando buscadores o utilizando metabuscadores. Les explico las características sobresalientes cada uno de estas posibilidades, y la oportunidad de uso. Les muestro el sitio Web LANIC http://lanic.utexas.edu/subject/countries/indexesp.html que es para mostrar cómo se trabaja con los directorios. Luego les comento que los buscadores utilizan conectores lógicos para reducir o ampliar el número de páginas Web recuperadas. Les doy una breve introducción de cómo funcionan los conectores lógicos AND, OR y NOT. Ejemplifico el uso de los conectores con los buscadores Google y Bing, que son los más populares. Luego les explico como se basca frases exactas, algunos términos especiales, como site, define. Por último les muestro como funcionan los metabuscadores usando el metabuscador http://www.crawler.com/ . La teoría que acabo de explicar intento terminarla en dos clases. Las dos clases siguiente la utilizamos para resolver un práctico que les doy para que experimenten con los buscadores y los directorios. La actividad práctica tiene dos partes, en la primera se pide que realice una tabla comparativa utilizando tres buscadores. La tabla comparativa puede ser construida en un documento tipo procesador de texto Word de Microsoft o puede usar una planilla de cálculo. En la segunda parte se pide que haga un informe de no más de una página A4 de las características organizativas de la información por parte de los directorios y sus posibilidades en las búsquedas eficiente de la información. En la primera parte se pide:

a) Distinción de mayúsculas y minúscula.

b) Conector lógico AND.

c) Conector lógico OR.

d) Excluye términos de búsqueda.- NOT.

e) Usa comodines.

f) Uso de palabras o frases exactas.

g) Distinción de acentos.

h) Términos especiales de búsquedas, por ejemplo define:

i) Incluye términos superfluos.

j) Propone búsquedas avanzadas.

k) El sitio propone búsquedas por índice o directorio.

1) Propone traductor.

m) Características de los filtros en las búsquedas.

n) Ofrece la posibilidad de subir vínculos.

En la segunda parte se da un conjunto de preguntas para organizar el informe:

¿Cuáles son los temas de mayor jerarquía? ¿Los temas están en idioma español? ¿Están divididos en subtemas? ¿Qué profundidad tiene los sub temas? ¿Los sitios Web vinculados a los temas son pertinentes? ¿Existen vínculos rotos? ¿Qué herramientas me brinda para colaborar en la organización de los directorios?¿Qué necesito saber para hacer eficiente las búsquedas en los directorios? ¿Los directorios son más eficientes que los buscadores? ¿Los directorios son eficientes para algún tipo de información y los buscadores para otro? ¿En qué casos uso los directorios y en qué caso uso los buscadores? ¿Qué uso le daría desde una perspectiva didáctica? ¿Hay más información en idioma español que en idioma inglés? ¿Encuentro información relacionada con mi profesión? ¿Por qué uso los buscadores y no uso los directorios? Para la evaluación, en la primera parte, buscadores, se evaluará la mayor cantidad de coincidencias o disidencias obtenidas en la comparación de cada uno de los ítems propuestos. En la segunda parte, directorios, se evalúa:

a. La temática elegida tiene relación con una o más preguntas disparadoras.

b. Establece relación significativa entre la temática de los directorios y de los buscadores. 
c. Tiene una prosa convincente, y es comprensible para los lectores no especializados.

d. Carece de faltas ortográficas y gramaticales.

e. La jerga o los términos técnicos necesarios están brevemente explicados en el mismo artículo, o bien se proporciona un enlace a otro artículo específico.

Materiales didácticos (9): Computadora, acceso a Internet, pizarrón, cañón digital.

Tiempo (10): 4 clases de $40 \mathrm{~min}$.

Evaluación alumnos ............ (11): Un práctico con dos actividades: búsquedas con buscadores y búsquedas en directorios. En el primer caso se pide una tabla comparativo entre buscadores y en el segundo caso un informe que de cuenta de las características de los directorios.

Objetivo didáctico del caso.... (12): Usar estrategias de búsquedas que permitan acceso eficiente a la información.

Nombre unidad programa....... (13): Internet

Agrupamiento alumnos

(14): Peuqueños grupos

Soft acceso a la información.. (17): Firefox

Soft creación (18): Excel, Word

Materia (21): Informática

Evaluación del caso

(22): El primer inconveniente que tuve fue con el acceso a Internet.

Tener muchas computadoras conectadas haciendo búsquedas en la Web es fatal para la baja calidad de velocidad que tenemos en la escuela. Y eso de entorpece mucho la actividad porque los chicos al hacer las búsquedas se quedan esperando la devolución de los buscadores. Creo que en términos generales los chicos entienden la diferencia entre buscar con buscadores y buscar en directorios. Solamente tres grupos terminaron la actividad solicitada, de siete, y son aquellos que en términos generales siempre terminan las actividades solicitadas (los grupos eran de dos o tres alumnos/as). Los grupos rezagados son aquellos que no tienen computadoras en sus casas y mucho menos acceso a Internet. Lo que me queda la incógnita es si en sus actividades de búsqueda ellos aplican lo que vieron conmigo.

Palabras claves .............. (23): $\langle$ Internet $>\langle$ web $>\langle$ buscadores $><$ directorios $><$ metabuscadores $>$ http://dir.yahoo.com/ http://lanic.utexas.edu/subject/countries/indexesp.html http://www.google.com http://www.bign.com

Autor............................ (1): Barrio, Sandra
mail del autor .............. (2) san_barrio@ @otmail.com
Titulo del caso .............. (3): Uso del procesador de texto
Tipo de caso.................. (24): Alfabetización informática
Problema .................... (4): Construir una revista digital utilizando los recursos que presenta el
procesador de textos.
Curso .............................. (5): 2
Espacio físico .............. Taller
Institución .................. (7): Escuela media
Solución caso (Narración) ..... (8): Al comienzo del año le entrego a los chicos una carpeta de
trabajos prácticos, que tienen fechas de entrega, en total son 13 trabajos prácticos. La secuencia de
cada práctico implica el aprendizaje creciente de las posibilidades del procesador de texto. El
procesador que usamos es el <word de Microsoft>. Los chicos en promedio hacen un práctico y
medio por clase. Por ejemplo comienzo a mostrar la descripción de la pantalla de Word en el
pizarrón. Luego toman el primer práctico, y comienzan con el formato de párrafo y de caracteres.
Ellos escriben el texto planificado y lo deben dejar de acuerdo a o que establece en el práctico.
Luego con los prácticos siguientes se le suman más opciones del Word. (Yo trabajo en una red
llamada <Netsoportschool>, bajo <Windows> que me permite visualizar los trabajos de los chicos
desde mi máquina). La corrección la hago sobre los documentos que producen los chicos. Por
supuesto que estoy visitando los chicos en cada máquina cuando ellos construyen su trabajo. Antes
de comenzar cada actividad les explico en el pizarrón las características del práctico en cuestión.
Lo último que vemos, o sea el último práctico, es la barra de dibujo y letra capital. Todo está
planificado para poder construir la revista como actividad final. La revista está planificada para que


trabajen en grupo de dos chicos (en cambio las actividades las hacen en forma individual). Los chicos eligen el contenido de la revista y el formato. La consigna es que la revista debe tener todos lo visto en las actividades previas; la cantidad de hojas de la revista es de 4 y el tamaño es A4 y, por supuesto, debe tener el formato de revistas. Se le trae ejemplos de revistas que pueden diseñar. Yo corrijo la revista en formato digital, antes se imprimían pero por razones obvia, solo vemos el formato digital. Y le damos el formato en pdf si los chicos se lo quieren llevar para mostrar s sus padres.

Materiales didácticos (9): Revistas, pizarrón, cañón digital, PC, netbook

Tiempo (10): Durante todo el año. De Marzo a septiembre, con clases de $80 \mathrm{~min}$.

Evaluación alumnos (11): Se analiza los documentos que corresponden a cada actividad y viendo el aspecto actitudinal del alumno en el taller.

Objetivo didáctico del caso.... (12): Construir una revista digital utilizando las opciones que presenta el procesador de textos.

Nombre unidad programa (13): Introducción al procesador de texto.

Agrupamiento alumnos (14): Individuales cuando hacen las 13 actividades y grupales cuando hacen la actividad final: la revista

Soft acceso a la información.. (17): Hacen uso de los buscadores de la Web (Google, Bing) para bajar imágenes que se usan en la revista.

Soft creación (18): Word

Materia (21): Informática

Evaluación del caso (22): Es positivo porque los chicos se sienten estimulados y al final de clase los chicos tiene los contenidos mínimos para usarlos en otras actividades de la escuela. Palabras claves (23): < procesador de texto $><$ revista $><$ Word $><$ formato del texto $>$

Autor.......................... (1): Barrios, Sandra
mail del autor ............... (2): san_barrio@ hotmail.com
Titulo del caso ............... (3): Noción de software libre.
Tipo de caso.................. (24): Recurso didactico
Problema ................... (4): Mostrar las posibilidades de
uso del software libre en la escuela.
Curso ............................ (5): 5
Espacio físico .............. (6): Taller
Institución ................. (7): Escuela media

Solución caso (Narración) ..... (8): Esta materia es interdisciplinaria trabajo junto con el profesor de contabilidad. Es un micro emprendimiento cuyo es objetivo es elaborar aromatizadores de ambientes para conseguir fondos para la fiesta de $5^{\circ}$ año. Comienzo la clase mostrando dos videos, el primero explica ¿qué es el software libre? y el otro es un reportaje a Richard Stallman. Formamos seis grupos de 5 alumnos. Por cada grupo diseñamos una Wiki. Hacemos un conjunto de preguntas a través de práctico y cada grupo debe responde las preguntas usando una Wiki. La wiki que usamos es la Wikspace. Por ejemplo las preguntas dicen qué es software libre, qué tipo de software conoces, qué significa la libertad en internet, etc. Yo invito a los alumnos a ser parte de la Wiki. Analizo la participación, el tipo de respuesta, el contenido, el recurso que usaron, etc. La idea final es hacer una puesta común de todas las Wiki usando el cañón con la idea de que sepan de qué es software libre y qué es un recurso de la Web 2.

Materiales didácticos ......... (9): Pizarrón, cañón digital, PC, netbook

Tiempo (10): 3 clases de 80 min.

Evaluación alumnos ............. (11): El instrumento de evaluación es la wiki. Se analiza la participación en la Wiki, los recursos usados para dar sustento a las respuestas, pertinencia de la respuesta.

Objetivo didáctico del caso.... (12): Analizar las características del software libre en contraposición del software comercial.

Nombre unidad programa (13): Software libre

Agrupamiento alumnos (14): Grupos de 5 alumnos

Soft acceso a la información.. (17): Explorador de Internet

Soft creación (18): Wikispace 
Materia (21): Organización y procesamiento de la información

Evaluación del caso (22): A los chicos les parece interesante la propuesta de software libre pero la queja es que aun no tiene los recursos que tiene el ambiente Windows.

Palabras claves (23): <wiki ><software libre ><formato del texto>

http://www.youtube.com/watch?v=EZf3Xy2ifaU

http://www.youtube.com/watch?v=2RId43JnJzY

www.wikispaces.com/

Autor........................... (1): Oddo, Carina

mail del autor ............... (2): carinaoddo4@ hotmail.com

Titulo del caso ................ (3): Introducción a la planilla electrónica usando el Excel.

Tipo de caso................... (24): Alfabetización informática

Problema ...................... (4): Tomar conciencia de las utilidades que tiene una planilla para las actividades relacionadas al estudio y al trabajo.

Curso …...................... (5): 3

Espacio físico …............. (6): Taller

Institución ................... (7): Escuela media

Solución caso (Narración) ..... (8): En principio se hace la introducción de los elementos que componen una planilla (libro, hoja, columnas, filas, celdas). Tipos de datos (números, formulas, caracteres alfanuméricos). Luego se da los rangos, el puntero y modo de guardar los datos. En este caso se utiliza el pizarrón y la pantalla de las PC con la presentación del Excel, lo que ven el pizarrón lo ven en la pantalla. Luego usan el Excel ingresando datos, por ejemplo una planilla simple donde ingresan los datos personales, como nombre y apellido, teléfono y dirección, dni, etc. Acá comenzamos a ver el tema de los formatos de celda (cómo agrandar y achicar celdas).

También se ve bordes y sombreados de celdas. Este práctico se dicta el enunciado en algunos casos o se dan las fotocopias. Luego en forma creciente se entregan prácticos con mayor grado de dificultad. Los primeros son enumerados, luego se le agrega el nombre del tema que están viendo, por ejemplo si es función tendrá el nombre de "Práctico de funciones", "Práctico de promedio", etc. Desde la introducción en adelante las actividades mayormente son prácticas y solamente teóricas en el momento de explicar el tema nuevo. En definitivo lo que hago es ir avanzando lentamente sobre los diversos temas que involucran la creación de planillas con Excel.

Materiales didácticos ......... (9): Pizarrón, PC, libros en la biblioteca de Excel.

Tiempo (10): De marzo a septiembre de 40 min. cada clase.

Evaluación alumnos ............. (11): La evaluación es individual en sus computadoras por trabajo práctico.

Objetivo didáctico del caso.... (12): Aprendan a diseñar y construir planillas de cálculo.

Agrupamiento alumnos (14): Individuales

Soft creación (18): Excel

Materia (21): Informática. Taller de informática/Computación

Evaluación del caso (22): Los resultados obtenidos son positivos porque al final del año puedo comprobar por los prácticos realizados que los chicos saben diseñar y construir planillas. Palabras claves .............. (23): $\langle$ Planilla $\rangle\langle$ datos $\rangle\langle$ filas $\rangle\langle$ celdas $\rangle$ $<$ números $><$ formulas $><$ funciones $><$ rangos $><$ herramientas $><$ powerpoint $><$ guardar $><$ copiar $><$ ins ertar $><$ computacion $>$

Autor......................... (1): Oddo, Carina
mail del autor .............. (2): carinaoddo4@ hotmail.com
Titulo del caso ............... (3): Diseño y creación de presentaciones con Powerpoint.
Tipo de caso................. (24): Alfabetización informática
Problema ................... (4): Construir una exposición de una temática escolar que sea práctica,
dinámica, eficiente utilizando herramientas informáticas.
Curso ..................... (5): 3
Espacio físico ............... (6): Taller
Institución .................. (7): Escuela media


Solución caso (Narración) ..... (8): Se presenta la materia explicando las potencialidades del programa y alternativas de uso. Utilizo una presentación que explica qué es una presentación: la definición de presentación, la definición de diapositivas. En la presentación se explica las partes de la pantalla del <PowerPoint>, las barras de herramientas y muestro los tiempos de retardo entre una y otra dispositiva, formatos, inserción de cuadros de textos, edición de objetos y todo lo relacionado a una presentación. Una vez que ven la presentación le doy un trabajo práctico donde se aplican la herramienta vista en la primera parte. Los prácticos se hacen forma creciente. Primero trabajan una diapositiva en blanco donde los chicos pegan distintos objetos: insertan cuadros de textos, imágenes, cambian los fondos, cambian de colores las fuentes, etc. Luego aplican animaciones, retardo de diapositiva, tiempo de duración. Como trabajo final hacen un PowerPoint retomando temas vistos anteriormente de informática o vinculando otras materias: geografía, historia, etc. Aquí ingresan a la Web para bajar información, imágenes, mapas, etc.

Materiales didácticos (9): PC, pizarrón.

Tiempo (10): De noviembre a octubre clases de $40 \mathrm{~min}$.

Evaluación alumnos ............ (11): Mediante trabajos prácticos y un trabajo final integrador.

Objetivo didáctico del caso.... (12): Aprender diseñar y construir presentaciones para aplicarlo en la exposición de temas vinculados a diversas materias.

Agrupamiento alumnos (14): Individuales

Soft creación (18): PowerPoint

Materia (21): Informática. Taller de informática/Computación

Evaluación del caso (22): Es un tema que es muy motivador e interesante para los alumnos por la utilización de las animaciones, colores y porque permite trabajar con temas que ellos eligen. Yo reviso el trabajo final y el modo en que van construyendo la presentación, puedo afirmar que aprenden a construir presentaciones, desde un punto de vista operativo, es decir saben cómo usar el programa. Los contenidos es más problemático.

Palabras claves .............. (23): <presentación $>\langle$ powerpoint $>$

$\langle$ cuadro de texto $\rangle\langle$ herramientas $\rangle\langle$ menú $\rangle\langle$ diseño $\rangle\langle$ creación $\rangle\langle$ objetos $\rangle$

$<$ selección $><$ copiar $><$ pegar $><$ guardar $><$ computacion $>$

www.google.com

www.bing.com 

FIN

- 101 - 